Rankine Lecture 2014

\title{
Interactions in Offshore Foundation Design
}

\author{
G.T. Houlsby ${ }^{1}$ \\ University of Oxford
}

\begin{abstract}
This paper presents some examples of design problems for offshore foundations, drawn from the jack-up industry and the wind turbine industry. The examples are chosen to illustrate some general points about foundation design, geotechnical engineering and its interaction with other disciplines. The first example is drawn from the assessment of the safety of installation of jack-up units (large mobile offshore drilling rigs). It illustrates how more rational approaches can be achieved through a deeper use of probabilistic methods in both the prediction of performance and the assessment of field observations. The second example also comes from jack-up practice, but has wider application too: it addresses the classical problem of the performance of foundations under combined loading, and how this can be understood in a simple theoretical and practical framework based on plasticity theory. The final example comes from the renewables sector, where the rapidly expanding offshore wind industry poses new foundation challenges for geotechnical engineers. Practical and economic foundation solutions are required if the UK is to meet its ambitious plans to exploit larger turbines in deeper waters. Both conventional (monopile) and novel solutions (suction caissons, screw piles) to the foundation problem are discussed. The paper also demonstrates how interactions with other disciplines can enrich geotechnical engineering, illustrated by specific practical examples from the Author's experience.
\end{abstract}

Keywords: cyclic loading, jack-up units, monopiles, offshore wind, plasticity, screw piles, spudcans, suction caissons, yield

\footnotetext{
${ }^{1}$ Department of Engineering Science, University of Oxford, Parks Road, Oxford OX1 3PJ, UK
} 


\section{Introduction}

The subject of this paper is the design of foundations for offshore structures. The structures of interest have in the past been mainly for the offshore oil and gas industry, but increasingly during the last decade the focus has shifted to the offshore renewables sector, especially offshore wind. No attempt is made here to present a detailed or comprehensive review of foundations for offshore structures; instead this paper presents a selection of topics which illustrate certain important themes, some with application throughout geotechnical engineering, not just offshore foundations.

The paper is divided into three sections. The first two use examples from the design and analysis of jack up-units, which are mobile drilling rigs of enormous importance in the oil and gas industry. Part 1 addresses the prediction of the behaviour of a jack-up unit during installation at a particular site - an important consideration because each unit may be moved to different sites several times in a year. In this section a framework is presented in which the predictions, and the comparisons of performance with predictions, are made within a probabilistic framework. This leads to a clear conclusion that there are opportunities to improve geotechnical practice by a more sophisticated application of probability theory than is current.

Part 2 addresses the performance of jack-up units in service, and especially how their safety can be assured during extreme storm conditions. Emphasis is placed on the development of models of soil behaviour based on plasticity theory, effectively generalising the concept of bearing capacity to multi-axial loading. This approach provides a conceptual basis for jack-up behaviour, and is also used to develop detailed numerical models. The models developed also have application to onshore foundations subjected to combined loads.

Part 3 is devoted to the offshore renewables sector, examining the options available for offshore wind turbine foundations as they move to larger installations in deeper water. Both conventional (monopile) and less conventional (suction caisson and screw pile) approaches are discussed.

Although geotechnical engineering forms the core this paper, the opportunity is taken to emphasise links with other disciplines. The "interactions" in the title deliberately has a 
double meaning. First it represents geotechnical problems where the interactions between different forces are important, and each component of the problem cannot be treated in isolation. Second, there are problems where interactions with other disciplines are important for geotechnical engineers, as it is at these interfaces that the most challenging and interesting problems arise.

\section{Part 1: Installation of jack-up units}

A jack-up unit, Figure 1, is a mobile rig mainly used for drilling either exploration or production wells, although also sometimes used for other purposes such as accommodation. The principal concern here is with the very large units used in the oil and gas industry. The large rigs almost always have three lattice-work legs, very occasionally four. Typically the legs are up to $180 \mathrm{~m}$ long, the spacing between them is about $60 \mathrm{~m}$, and large rigs can operate in up to about $120 \mathrm{~m}$ of water. A large jack-up has a mass of around 30,000 tonnes. Much smaller units, of a rather different design, and with four or more legs, are used for inshore work in shallower waters.

The legs can each be moved up and down independently, usually by a rack-and-pinion system, Figure 2, with multiple driving pinions on each leg. On the bottom of the legs are large, roughly circular footings which are called "spudcans". They usually have a shallow conical base, often with a pointed tip, and are of diameter up to about $20 \mathrm{~m}$. The precise reason for this design is unclear, but appears to be based on the concept that the pointed tip provides good location of the rig on initial touchdown of the spudcans with the seabed, with the flatter section then providing a substantial capacity with only a small further penetration. Occasionally other designs are used, for instance incorporating skirts, but these are not discussed here.

The operation of a jack-up follows the sequence:

- The rig is floated to the site on its own hull, with the legs raised, Figure 3(a).

- The legs are lowered to the seabed, and the then jacked into the seabed, Figure 3(b).

- The rig is raised on the legs until it is about $2 \mathrm{~m}$ out of the water, and at that stage the full weight of the rig bears on the three spudcans, Figure 3(c). This is called "light-ship load". 
- Water is then pumped into ballast tanks in the hull, to increase the weight of the rig, and so push the legs further into the seabed, Figure $3(d)$. This process is called "preloading". Typically at full preload the weight of the rig has been increased to twice the light ship weight. For the smaller rigs with four or more legs the process of "diagonal preloading" can be used, in which the jacks are operated in such a way as to load diagonal pairs of legs alternately.

- The preload is then dumped and the rig returns to the light ship weight, Figure 3(e).

- The hull then climbs further up the legs so that a safe air-gap, typically of around $20 \mathrm{~m}$, can be established, Figure $3(\mathrm{f})$. The air gap is necessary so that the rig can survive extreme storm conditions, Figure $3(\mathrm{~g})$, without the wave crest level reaching the hull. Even so the legs may be subjected to large lateral forces from waves and current, and there will also be wind loads on the superstructure.

The installation and preloading process can be understood as a bearing capacity problem indeed it is highly unusual in that it represents a full scale bearing capacity test in which the soil is continually brought to failure as the spudcans penetrate the seabed. Jack-up installation thus provides an almost unique opportunity for checking and calibrating bearing capacity theories at full scale.

Spudcan installation in both coarse and fine-grained soils is important, but the examples pursued here concentrate on installation in soft clay, where the penetrations can be substantial, for example up to $30 \mathrm{~m}$. The penetration process in soft clay occurs as follows, Figure 4. As the spudcan tip first penetrates the soil the load is low, but rapidly increases as the area of the base of the spudcan in contact with the ground increases with penetration. Once the full base of the spudcan is in contact, the rate of increase slows down, and is mainly due to (a) increasing soil strength with depth (as in most soft clays the strength increases markedly with depth), (b) geometric effects which have a smaller but nevertheless important effect. A certain penetration will be reached at light ship load (illustrated as position $A$ to the left of Figure 4), and then as the preload is applied the penetration increases further. When the preload is removed, the spudcan hardly moves at all, although there will be a small upward elastic rebound (position B in Figure 4). 
The vertical load on the spudcan at any penetration is usually calculated according to standard bearing capacity theory, Equation 1:

$$
V=\left(N_{c} s_{u}+\gamma h\right) A
$$

with the first term due to the strength of the soil and a second coming from the overburden pressure once the spudcan is embedded into the soil. An important detail is the definition of the "depth" $h$ of the spudcan. In offshore practice the penetration depth usually refers to the depth of the tip of the spudcan below the seabed. For the purposes of the bearing capacity calculation the depth $h$ is usually taken as the depth of the "shoulder" of the spudcan (the lowest point on the spudcan at which the full bearing area is achieved). Because of the conical base of the spudcan the two values are different, and care is necessary in distinguishing between them. Note that because the entire process is submerged in seawater, the appropriate value for $\gamma$ is the submerged (buoyant) unit weight.

The most important number in Equation 1 is the bearing capacity factor, $N_{c}$. This can be calculated by several means, and one quite accurate method is to use slip line theory of plasticity theory (see e.g. Houlsby and Martin (2003)). This is essentially the same method used to develop the classical Terzaghi bearing capacity factors, but adapted to account for the axi-symmetric problem (see e.g. Szczepinski, 1974, Salençon and Matar, 1982, Houlsby and Wroth, 1982) and a number of other features. A typical lower-bound mesh of characteristic lines is shown in Figure 5. This approach allows one to express the bearing capacity as a function of some key variables:

$$
N_{c}=f\left(\beta, \alpha, \frac{h}{D}, \frac{\rho D}{s_{u 0}}\right)
$$

In Equation 2, $N_{c}$ is considered as a function of:

- The angle of the conical base of the spudcan $\beta$ - for these purposes the rather more complicated actual shape is usually replaced by an equivalent cone.

- The roughness of the base of the spudcan, $0 \leq \alpha \leq 1$. This quantity is difficult to determine, and most spudcans can almost certainly be treated as rough. The maximum adhesion on the spudcan base is defined as $a_{u}=\alpha s_{u}$. 
- The depth of embedment, expressed as fraction of the diameter, $h / D$. Importantly, this is a separate effect from the weight term $\gamma h$ added by the overburden. It arises because a more deeply embedded spudcan involves failure of a larger volume of soil.

- The rate of increase of strength with depth, $\rho$. In most soft clays, where large penetrations occur, the strength increases with depth, often approximately linearly. The rate of increase is expressed in non-dimensional form as $\rho D / s_{u 0}$, following Davies and Booker (1973).

There are two further effects that also need to be taken into account. Firstly, in more complex soil profiles it is inappropriate just to use the strength value at the base of the footing, and instead some averaging procedure over a limited depth of soil needs to be used. A variety of ranges over which this averaging should be taken have been suggested, see for instance Young et al. (1984). However, the geometry of the plastic failure mechanism gives a reasonable clue about how far this should extend both above and below the footing base. For instance, the recommendation of the InSafeJIP study (Osborne et al., 2011) was that averaging should take place over a depth extending from elevation $z=h-0.25 h$ to $z=h+0.25 y_{c}+0.25 D$, where $y_{c}$ is the height of the equivalent cone representing the spudcan.

Secondly, once the spudcan is deeply buried, there is less resistance for the soil to flow back into the hole behind the spudcan, rather than out to the surface. Formally this can be addressed through examination of upper bound failure mechanisms. There is a change of mechanism for deeper penetrations, with the flow-around mechanism governing. Hossain et al. (2005) have suggested an empirical approach for determining the depth at which this transition occurs. Importantly, whether or not the hole behind the spudcan is "backfilled" with soil is correctly determined by a criterion based on this flow-around mechanism, and not on the basis of collapse of an unsupported cylindrical hole, which would indicate unrealistically deep penetration before backfilling occurred.

\section{Deterministic calculations}

The usual approach is to carry out a deterministic calculation for the load-penetration curve. At every depth the geometry of the spudcan is determined, for instance its diameter and the 
cone angle (for partial penetration of the spudcan the diameter in contact with the soil, and therefore the equivalent cone angle, will vary with depth). The strength at the penetration depth is determined from a design profile, and averaged over a range of depths if necessary. The appropriate bearing capacity factor is calculated from Equation (2), and a single value for the load on the spudcan is determined at that depth, using Equation (1), possibly modified to account for flow-around conditions, which result in changes in the buoyancy terms as well as in the bearing capacity factor (Osborne et al., 2011).

This process is repeated at every depth, so that a complete predicted load-penetration curve is obtained, extending well below the expected depth of penetration of the spudcan. In practice this process is taken at least one step further: the design strength profile is invariably obtained as a fit to some fairly scattered data, often from multiple measurement devices, for instance a CPT profile, an extensive number of measurements on samples using perhaps a Pocket Penetrometer, a Torvane and/or a Minivane, and a few isolated UU measurements. It is usual to derive a best fit (or most probable) design profile, and also a lower bound (or worst case), Figure 6. The most probable profile would provide expected penetrations of the spudcans, and the worst case would give the maximum penetration values that could reasonably be expected. It is these maximum values which will determine whether it is safe to proceed with the installation operation. If installation does proceed, then the field behaviour would be compared with the predictions (both expected and worst case).

The key question is how the lower bound to the strength profile can be chosen in a rational manner. If the designer is too cautious, the predicted penetration will be so large that, quite incorrectly, it may be concluded that operation at the site is not possible. It is common, for example, to adopt "characteristic values" for strength. These are specified for instance in Eurocode (BSI, 2004) as $5^{\text {th }}$ percentile values, i.e. only 1 in 20 of the strength measurements is expected to fall below the characteristic value. However, there is no rational basis for expecting that characteristic values with this definition lead to an appropriate "worst case" estimate of the spudcan penetrations, and confusingly, other standards adopt other definitions for characteristic values. This is an important example of a problem where useful progress can be made by adopting a rather more sophisticated approach, in which the statistical variations of the parameters governing the problem are addressed. 


\section{Probabilistic calculations}

A probabilistic calculation proceeds in slightly different way. At the heart of the process is exactly the same calculation as before. However, it is now acknowledged that there is not a uniquely known undrained strength at any depth, but that the design profile comes from a probabilistic distribution of possible strengths, characterised by a mean value and standard deviation at any depth. The fitting of design profiles using rigorous statistical methods, for instance those based on Bayesian probability techniques, is an important topic that it now receiving some attention (e.g. Bienen et al. (2010), Cao and Wang (2013), Houlsby and Houlsby (2013), Wang et al. (2014)), but is not pursued further here.

Secondly it must be acknowledged that the positions of the boundaries between different layers of soil will be uncertain. For instance, the borehole used to determine the layering may not be precisely at the spudcan location. The measurement of depths within the borehole will itself be subject to some error. Again this uncertainty can be represented as a statistical distribution with mean and standard deviation.

Thirdly, even the geometry of the spudcan itself is not absolutely certain. In an ideal world every geometric detail would be known, but in the real world there will be some uncertainty. This uncertainty will of course be much less than that attached to the soil strength, but there is some uncertainty nevertheless.

Finally the bearing capacity theory itself is subject to uncertainty. Although accurate bearing capacity factors for idealised problems can be determined, slightly different approaches with different assumptions lead to different values. There is of course further uncertainty attached to the idealisation of the problem, for instance a spudcan which is actually in the form of an irregular hexagonal pyramid may be idealised as a circular conical footing. The uncertainty in the applicability of the theory can be captured by assuming some statistical distribution for the bearing capacity factor $N_{c}$ and other factors in the calculation.

Many calculations are then carried out in which, rather than always using the mean value, values are chosen randomly from the probability distributions for each of the variables. Such "Monte Carlo" simulations are common throughout engineering. They are feasible in cases where the underlying deterministic calculation is fast, so that very many simulations can be 
completed. This is the case for the simple bearing capacity calculation presented here. The same approach could not, for instance, be made if the underlying deterministic calculation relied on time-consuming finite element analysis.

The Monte Carlo simulation typically involves hundreds of calculations. There are wellestablished techniques for reducing the number of calculations required to establish the statistical variation of the results, but we adopt a naïve approach here, simply drawing values of the parameters appropriately from the statistical distributions. Because each calculation chooses slightly different parameter values from the distributions, they produce a family of predicted load-penetration curves. They all tend to be roughly alike, but each is slightly different. In particular the curves may cross each other as, for instance, different strengths may be chosen for different soil horizons.

The large number of curves may be processed in a variety of ways, but one intuitively simple approach is to take a slice through them at a particular depth, and rank the predicted values of the spudcan loads at this depth in ascending order in the form of a cumulative distribution curve, see Figure 7. From that curve one can determine, for instance, the $5^{\text {th }}, 25^{\text {th }}, 50^{\text {th }}, 75^{\text {th }}$ and $95^{\text {th }}$ percentile values at each depth. All the $5^{\text {th }}$ percentile values at different depths can be joined to form a $5^{\text {th }}$ percentile curve, and the process is repeated for the other percentile values. This procedure was adopted by Houlsby (2010). The meaning of these curves is that, if the statistical parameters correctly define the true uncertainty, one would expect that about $50 \%$ of measurements would fall between the $25^{\text {th }}$ and $75^{\text {th }}$ percentiles, and $90 \%$ of measurements would fall between the $5^{\text {th }}$ and $95^{\text {th }}$. This approach is therefore more rational than the "worst case" line from the deterministic calculation, which had no rigorous definition. Only one in 20 measurements will fall below the $5^{\text {th }}$ percentile, but note that because all the parameters in the analysis are treated statistically, this does not yield exactly the same result as simply using characteristic ( $5^{\text {th }}$ percentile) values of strength in a deterministic analysis.

Figure 8 shows an example of a prediction made on this basis for one case from the InSafeJIP study: this was a joint industry programme addressing the safe installation of jack-up units (Osborne et al., 2011). The actual installation has to remain anonymous for commercial reasons. The continuous lines on Figure 8 show the various percentile predictions, and the 
highlighted points show the actual measurements at the site. The difference in response of the three legs is fairly typical of these observations, indicating probably slight differences in soil conditions beneath the three legs. Where more extreme differences are encountered, unacceptable tilting of the jack-up can occur, although to a certain extent this can be managed by adjusting the distribution of the preload. This site was unusually wellmonitored: not only are the penetrations of all three legs recorded, but these measurements were made throughout the preloading process. Often the data collected are less comprehensive, for instance the penetration may be recorded just at light ship load and at preload.

A geotechnical engineer must make an assessment of the measured penetrations, essentially to reassure themselves that the observations are in accordance with the understanding of the site, so that subsequent operations can proceed with some confidence. In this case one could be reassured that the observations do indeed match the predictions well. The penetrations are all slightly larger than the most probable, but almost all the values are within the $25^{\text {th }}$ to $50^{\text {th }}$ percentile range, and the trend shown by the data is almost the same as shown by the predictions. At this particular site the underlying model of ground behaviour appears to capture the real response in a satisfactory way.

Such confidence depends, however, on knowing that the chosen statistical variation does indeed capture the variability of sites correctly. For instance, if too wide a distribution of results was predicted, then almost every observation would fall within the $25^{\text {th }}$ to $75^{\text {th }}$ percentile range, and the conclusion would always be that the response was as expected, which would be misleading. It is therefore vital that the statistical variations are properly calibrated, and this can only be achieved by collecting the data from a large number of case records. In practice, however, the variation of the predictions is dominated by the variability of the strength, as this is the most uncertain parameter in the calculation. As part of the InSafeJIP programme, the strength within each soil layer was fitted by statistical methods, the "Coefficient of Variation" (CoV) values for the strength parameters were computed, and these were used to guide the values chosen for the predictions. It was not possible to apply this calibration process for the variability of all the parameters, so for some the uncertainty is simply based on a "common sense" approach. 
The overall range of the predictions was checked by the following procedure. There were (by coincidence) precisely 100 measurements of penetration in clays in the InSafeJIP database. Predictions were made for all these measurements and the measured percentile position noted for each case. These percentiles were assembled in rank order ("actual percentiles"). One could, for instance expect about 5 of the 100 measurements to fall below the $5^{\text {th }}$ percentile, 20 to be in the range $5^{\text {th }}$ to $25^{\text {th }}$ etcetera. By plotting the actual percentile position against the measured one, Figure 9 , it is possible to assess the quality of the overall fit. In probability theory this is called a P-P plot, which can either be used to compare the distributions of two observations, or to compare a set of observations against a theory. If all the data points lie on the diagonal line, then the chosen statistical variations match the real variability well, but if the distributions are too broad or too narrow, then the data points would not lie on the diagonal. It can be seen that, with the values recommended in the InSafeJIP procedures (Osborne et al., 2011), the overall fit is quite good, giving confidence that the true variability has been captured with reasonable precision. Some of the detail is not reproduced, but that is only to be expected.

We now address how one interprets the measurements if they fall near the edge of the distribution, which on the face of it means that our chosen soil model for the site may be incorrect. Figure 10(a) shows schematically the case where the measurements are near the edge of the distribution, around the $95^{\text {th }}$ percentile, but the trend is approximately as predicted. An experienced engineer might be fairly comfortable with this situation, as of course about one time in 10 one would expect to see values near the edge of the distribution. Figure 10(b) shows a slightly more complicated case. Each of the individual measurements is within the expected range, but the trend is incorrect. Houlsby (2010) suggested that this scenario could be treated in a heuristic way, setting out a decision table based on where the measurements are, and whether or not they follow the expected trend, Table 1. Whilst this may have some value, it is possible to take the statistical approach further to understand the correlations as well as the individual values. This is illustrated by the case in Figure 11, which shows the predictions and the measured response from another case from the InSafeJIP database. The measurements taken at this site were for each of the three legs, at light-ship load, where we can see that the penetration is somewhat larger than predicted, and at full preload, where it is rather less than predicted. Neither individual 
observation is far away from the prediction, but the observed trend is somewhat different from the predictions. Does this mean that the model for this site is incorrect?

Figure 12 shows the results of 500 simulations using the statistically varying parameters. The predicted penetration at preload is plotted against the penetration at light ship load. The cloud of predicted points forms a roughly elliptical shape, demonstrating that the two values are closely correlated: for instance any individual prediction may use strength from the lower part of the range, and so will predict larger penetrations at both light ship load and at preload. All of the points of course plot above the 1:1 line because the penetration at preload is always larger than at light ship load. Also shown in Figure 12 is the point that would be obtained from a single deterministic calculation that would be obtained from the expert's fit to the strength data - this of course plots near the centre of the distribution of probabilistic simulations.

The large dot on Figure 12 shows the measured data, averaged for the three legs. The distribution curves for the prediction of light ship and preload penetrations are plotted at the top and side of Figure 12. Examining the distribution of predictions for light ship penetration, at the top of the graph, we can see that the penetration is higher than expected. Examining the distribution of predictions at preload, at the right hand side, however, we see that the penetration is smaller than expected.

The elliptical contours show the curves that would enclose $50 \%, 90 \%$ and $98 \%$ of the predictions - they are the two-dimensional equivalent of the percentile lines shown in Figure 8. The measured data point falls almost exactly on the $98 \%$ curve, indicating that we would expect to this sort of rare event only one time in 50 . That is perhaps sufficient to conclude that the model for this site is in fact deficient: in all probability some important feature of the soil behaviour has not been captured.

The ellipses are drawn on the assumption that the process is "Gaussian" - the very simplest form of statistical distribution. The fact that the actual cloud of points does not fit the ellipses very well is evidence that this process is not Gaussian, which complicates the situation further. Although the variability of each input was treated as Gaussian, the penetration calculation is highly nonlinear, which results in the non-Gaussian response. If we 
compare the measurement directly with the predicted points, rather than with the fitted ellipses, this event looks even more unlikely.

The separate probability curves for the two measurements, plotted at the top and side of the graph are called "marginal distributions" as they integrate out, or marginalise, the effect of the other variable. Note that these alone do not give us enough information - for instance if the measurement of penetration at preload had been the same distance the other side of the mean, which in the marginal distribution is equally likely, then the combination of the two measurements would be solidly within the $50 \%$ contour of the combined distribution.

Of course it is important to close the loop and determine why the initial prediction was apparently inconsistent (in all probability) with the later observations, and if possible use the observations to provide a better understanding of the site. We have approached the problem in the following way, adopting an approach that has been termed "probabilistic programming" (Gordon et al., 2014, Wood et al., 2014), which implements Bayesian techniques. In essence the method proceeds as follows. As before, a large number of stochastic simulations of the prediction are made, with values for the various parameters drawn from "prior" distributions implied by the site investigation data. The predicted loads for the relevant penetrations are compared with the observed loads at those penetrations from the actual installation data. From a large number of simulations those that best fit the observations (in a probabilistic manner) can be determined within a probabilistic programming Bayesian framework. The resulting set of "posterior" simulations contain parameters that will, assuming a "correct" simulator provide a better estimate of the values at the site, and improved, updated versions of the entire load-penetration curve based on these posterior simulations. This can be regarded as an example of formalising the so-called "observational method" (Peck, 1969) within a Bayesian probabilistic setting and extended to include black-box simulation.

Figure 13 shows the calculated load-penetration curves using the posterior values of the parameters. Of course the fit to the observed data is much better than in Figure 11, which used the prior parameters. The fit to the data is still, of course, not exact, as the match is 
only made in a probabilistic sense. Note in particular that at depths not coinciding with the measured data points there is greater uncertainty about the prediction.

Figure 14 shows the measured strength data at the site, from four different devices. The black (solid) line shows the design strength profile which was originally fitted by an expert, and was used for the prior estimate of the load-penetration curve. In the lower stratum the line fits approximately in the middle of the range of the rather scattered data (the level of scatter is absolutely typical of this sort of site). The chosen profile within the upper stratum lies approximately as an upper bound to the strengths measured there, and on the face of it looks too high, but it should be borne in mind that when the expert was fitting this line, she also had available other secondary information about this site, which led her to believe that the measured strengths might be underestimates. However, concentrating just on the Minivane measurements (green triangles), the only device that was used in both the upper and lower strata, it can be seen that the chosen design profile does not really capture the sudden increase of strength at the interface between the two layers.

The magenta (dashed) line in Figure 14 is the most probable set of strength parameters as determined by the probabilistic programming approach. It has a slightly lower strength in the upper layer (closer to the Minivane results), and a very slightly higher rate of increase of strength in the lower layer. To an experienced engineer the modified profile appears every bit as plausible as the original one, and maybe it suggests that the expert should simply have taken the strength values in the upper layer at face value.

Adopting the new profile, and once more carrying out a Monte Carlo simulation for the calculated penetration, Figure 15 shows the joint probability plot. The measured data point now fits between the $50 \%$ and $90 \%$ boundaries, and so the measured data may reasonably be considered as consistent with the modified model of the strength profile. In this case we have therefore resolved the issue - a small change to the strength profile, still perfectly consistent with the original data, is sufficient to explain the observations. Figure 15 also shows the deterministic prediction from the expert: whilst this too is reasonably consistent with the observed soil data (as one would expect it to be), it is less consistent with the observations than the calculations using the updated strength profile. 
The engineer can, however, be satisfied that the site has now been properly understood. Perhaps more importantly, the jack-up installation itself has been used as a gigantic site investigation tool, and has provided a modified strength profile in which we can have more confidence. The modified profile can be used in any future calculations about the performance of the jack-up at this site, with greater confidence because the profile combines both the initial site investigation data and the observed footing behaviour in a rational way. This is an example of the so-called observational method, Peck (1969): large scale field observations allow us to improve our understanding of ground conditions, and therefore allow us to improve our predictions of future response, which is the subject of the next section.

\section{Conclusions from Part 1}

Jack-up foundations, because they cause continuous failure of the soil during penetration, provide almost unique data from large scale foundations which can be used to verify bearing capacity theories.

Making the link with other disciplines, a rational comparison of predictions and measured data during installation of a jack-up can best be understood in the context of probability theory. This conclusion carries over to many other branches of soil mechanics. Soils are materials with inherently variable properties, which are of necessity only sampled in an imperfect manner. The rational treatment of soils data and measurements requires a statistical and probabilistic approach. And yet the level of knowledge of statistics and probability theory of most geotechnical engineers is elementary. A deeper understanding of more advanced statistical and probability techniques would be of great value to professionals in geotechnical engineering.

\section{Part 2: Performance of jack-up units and other shallow foundations}

This section addresses the performance of jack-up units under extreme loading conditions. The important interaction at this stage is with structural engineers, who need to be able to analyse the forces in the structure, and for rather flexible structures such as jack-up units the structural forces depend critically on the foundation response. In particular the response of jack-ups depends on the moment-rotation response of the spudcans, a problem referred to 
in the industry simply as "fixity". The key question asked by the structural engineers is whether the spudcans can be treated as "pinned", "fixed", or somewhere in between as far as the moment-rotation response is concerned.

For simplicity, first idealise the rig as a rather stiff hull with flexible legs, simplifying the problem to planar loading and considering the horizontal forces as if they act at the hull level. The hull is idealised as rigid, and the tops of the legs are assumed to be fully restrained from rotation by the leg guides. A more sophisticated analysis would recognise the flexibility of the hull and the fact that that rack-and-pinion leg guides exhibit a complex non-linear response with both rotational and translational tolerances. Figure 16(a) shows the reactions at the footings if the conservative assumption that the legs are pinned to the seabed and free to rotate is made. The reactions are shown for the case where two of the three legs are to the windward side, and one to the leeward side. The horizontal load on the rig decreases the combined vertical reactions on the windward legs by $H L / w$, and increases the vertical reaction on the leeward one by $H L / w$. Alternatively, assuming that the large spudcans on the legs completely restrain the rotation, the reactions are as shown in Figure 16(b). Note that, compared to the pinned case, the changes in vertical reaction due to the horizontal load are exactly halved to $H L / 2 w$.

Based on this simplified analysis of the unit, there are several benefits of "fixity" of the foundation:

- If the rotation is fully restrained, as noted above, the changes of vertical loads on the spudcans are reduced by a factor of two. This effect is particularly important for the leeward footing which is the most heavily loaded.

- The maximum bending moment in each leg is halved from $H L / 3$ to $H L / 6$. However, the moment at the spudcan connection is of course increased (it is close to zero in the pinned case and $H L / 6$ in the fixed case), and this has implications for fatigue design of the leg-spudcan connection.

- The quasi-static lateral displacement of the deck is reduced by a factor of 4 by full fixity from $H L^{3} / 9 E I$ to $H L^{3} / 36 E I$. 
- Treating the rig as a single degree-of-freedom system, the first natural frequency of the rig is doubled, from $\omega_{n}=3 \sqrt{E I / m L^{3}}$ to $\omega_{n}=6 \sqrt{E I / m L^{3}}$ (assuming the mass is concentrated in the hull). Importantly, for almost all sea states and rig dimensions, this takes the resonance further away from the main wave excitation frequencies, see Figure 17, so that dynamic amplification effects are reduced, and therefore the actual displacements are reduced by fixity by more than a factor of 4 .

A more sophisticated structural analysis of the rig, accounting for instance for deck flexibility, a realistic distribution of the loads, shear deflections of the legs, $P-\delta$ effects, and a more realistic mass distribution will alter the above conclusions slightly, but the broad conclusions are the same.

The structural design of the rig therefore depends on how stiff a moment response the spudcan will offer - a classic problem of soil-structure interaction. Ideally a structural engineer would wish the fixity to be represented as an elastic spring, which would represent some degree of fixity between fully pinned and fully fixed. This would have the advantage that linear analysis of the structure could be retained, employing for example modal analysis techniques. Spudcan foundations are therefore often modelled by rotational springs (as shown for the windward leg in Figure 18), with horizontal and vertical motion restrained. Sometimes horizontal and vertical springs are included too (as shown for the leeward leg in Figure 18). However, as is well known to geotechnical engineers, the soil response is more complicated, and cannot just be represented by elastic springs. In the following we pursue how the foundation response can be realistically described in a way that is intelligible and useful to a structural engineer. The method proposed exploits plasticity theory, which provides the language and mathematics by which geotechnical engineers can readily make knowledge of the response of shallow foundations accessible to structural engineers.

In the following we therefore explore the general relationships between the load resultants $(V, M, H)$ on a foundation and the corresponding displacements $(w, \theta, u)$, see Figure 19 . This approach using force resultants rather than detailed analysis of stresses and strains within the soil is exactly analogous, for instance, to the use of tension, bending moment and shear force in a beam, rather than the detailed stress distributions. 


\section{Elastic response}

Although the soil is not elastic, it is useful first to pursue how the elastic response can be represented. Consider first a circular footing on the soil surface. The relationship between the loads and displacements of a footing on an elastic soil can be expressed in the form of a matrix equation. It is convenient to convert this equation to non-dimensional form by dividing the displacements by the footing diameter, and normalising the forces by the diameter and the soil shear modulus:

$$
\left[\begin{array}{c}
V / G D^{2} \\
M / G D^{3} \\
H / G D^{2}
\end{array}\right]=\left[\begin{array}{ccc}
K_{1} & 0 & 0 \\
0 & K_{2} & K_{4} \\
0 & K_{4} & K_{3}
\end{array}\right]\left[\begin{array}{c}
w / D \\
\theta \\
u / D
\end{array}\right]
$$

It is easy to show that four of the nine terms in the matrix must be zero, but there are three diagonal terms and two off-diagonal terms in the matrix. The diagonal terms are easily recognised as representing the vertical, moment and horizontal stiffnesses. The significance of the off-diagonal terms is less obvious, but they indicate that, for instance, if a horizontal load is applied to the footing it does not just translate horizontally, but it may rotate too. Vice versa, if a moment is applied, the foundation will translate horizontally as well as rotate.

In the standard literature the three diagonal terms in Equation (3) are reported. For vertical loading there are two solutions: $K_{1}=\frac{2}{1-v}$ for a smooth footing and $\frac{2 \times \log (3-4 v)}{1-2 v}$ for the rough case (both of these converge to $K_{1}=4$ for the limiting case of an incompressible material). For the rotational case the solution available is $K_{2}=\frac{1}{3(1-v)}$, and strictly this is only applicable for a smooth footing, although it is often applied otherwise. For horizontal loading there are two commonly available solutions, $K_{3}=\frac{4}{2-v}$ and $K_{3}=\frac{16(1-v)}{7-8 v}$ (both of these converge to $K_{3}=\frac{8}{3}$ for the limiting case of an incompressible material, and the numerical differences are small for other cases); they correspond to subtly different boundary conditions on the footing in terms of the vertical displacements. However, in much 
of the literature the coupling term $K_{4}$ has simply been ignored. For instance, no mention of this term is made in the commonly-used API standard for offshore foundations (API, 2010).

However, there is no rational basis for ignoring the off-diagonal term in the matrix, and its physical significance needs to be properly assessed. The result is that many conventional calculations that ignore this interaction are incorrect.

For a spudcan of realistic geometry there are some further important considerations. Firstly, it is vital that the "Load Reference Point" (LRP, the point at which loads are considered to act, and the reference point for displacements) is clearly defined (see Bell, 1991, Dean et al. 1998). Practice varies, and for instance the LRP may be taken at the mudline (Figure 20(a)), or at the level of the widest part of the spudcan (Figure 20(b)) or at the spudcan tip (Figure 20(c)). All have a certain justification and have been used in practice.

The selection of the LRP, however, affects the values of the stiffness factors. If the LRP is moved downwards by some distance $z^{*}=f D$, then some of the stiffness factors do not change, but some do, as noted by Bell (1991).

$$
\left[\begin{array}{c}
V^{*} / G R^{2} \\
M^{*} / G R^{3} \\
H^{*} / G R^{2}
\end{array}\right]=\left[\begin{array}{ccc}
K_{1} & 0 & 0 \\
0 & K_{2}+2 f K_{4}+f^{2} K_{3} & K_{4}+f K_{3} \\
0 & K_{4}+f K_{3} & K_{3}
\end{array}\right]\left[\begin{array}{c}
w^{*} / R \\
\theta^{*} \\
u^{* / R}
\end{array}\right]
$$

This further raises the possibility of defining the LRP such that the off-diagonal term is zero, the "elastic metacentre" such that $K_{4}+f K_{3}=0$, or $z^{*}=-D K_{4} / K_{3}$. Such an approach can be convenient in some applications.

Clearly if the correct stiffness factors are to be used, the geotechnical engineer must use the same LRP (and sign convention) as the structural engineer, otherwise the calculation is meaningless. This seemingly simply matter of communication is not always addressed as it should be.

Studies of appropriate elastic stiffness factors are reported by Bell (1991), Ngo-Tran (1996) and Doherty and Deeks (2003), dealing with a variety of geometries of foundation, including parametric studies of the effects of the angle of the cone of the spudcan and the depth of 
embedment, and provided these are used with care, these provide a sensible modelling of the elastic behaviour. Example values of the stiffness factor (taking the load reference point as in Figure 20(b)) are shown in Table 2 (Ngo-Tran, 1996). Alternatively, with modern finite element analysis it is relatively straightforward to calculate the various stiffness coefficients directly for a given geometry of spudcan.

However, as is widely recognised, soils are not linear elastic except for within a very small range of strains. Figure 21 shows an early test by de Santa Maria (1988) measuring the moment-rotation response of a model spudcan on clay under carefully controlled conditions. The foundation exhibits highly nonlinear behaviour, with an open hysteresis loop on unloading and reloading. Note that the results are presented in terms of dimensionless quantities, an important detail that makes them more readily compared with other results, and applied to field problems.

We return below to the importance of addressing the whole of the non-linear response, but for the time being we idealise the curve as if it was elastic-plastic with a single yield point (idealised as the green line in Figure 21), and investigate the plastic behaviour. However, as the foundation is subjected to vertical loads and horizontal loads as well as moments, it is the combination of these loads that causes yield. It is necessary therefore to determine the shape of a yield surface in $(V, M, H)$ space. This yield surface limits the safe loads that can be applied to the foundation, resulting only in (relatively small) pseudo-elastic deformations.

Consider first just a flat footing with a vertical and horizontal load. It is tempting to think that failure will occur either by sliding, at some ratio of horizontal to vertical load, or by bearing capacity failure at some limiting vertical load. The shaded area in Figure 22(a) would show the range of allowable loads in this case. [Note that it is common practice in this application to plot the vertical load on the horizontal axis, and the horizontal load on the vertical axis.] In fact there is a very strong interaction between the two failure mechanisms, and any application of horizontal load dramatically reduces the vertical capacity. A more realistic yield surface is shown in Figure 21(b). Much research has been devoted to determining the shape of this surface, but with the additional complication that a moment is applied too. 
This is an old problem: Roscoe and Schofield (1957), Figure 23, first suggested interaction surfaces for combinations of vertical load and moment on shallow foundations; the application was to foundations for steel portal frames, but the concept is the same as for offshore foundations. (In their plot the vertical load was in the vertical direction.) Butterfield and Ticof (1979) presented the first three-dimensional yield surface for combined vertical, moment and horizontal loading, based on a series of tests on sand. The surface they found has a characteristic "rugby-ball" shape, with rather pointed ends at high and low loads, Figure 24 .

We describe below experiments designed to determine the shape of the three-dimensional yield surface. Any combination of loads that falls inside the surface will be safe, whilst large plastic deformations will occur once the surface is reached: the surface represents the generalisation of the idea of bearing capacity for a vertical load, to the more complicated case with multiple load components. There is an important distinction between a failure surface, which represents the envelope of all attainable loads, and a yield surface, which encloses just those loads which are accessible by solely elastic deformation at a given penetration. If work hardening of the yield surface occurs, accompanied in this case by additional vertical penetration, then the failure surface differs from the yield surface. In the following we are concerned entirely with the yield surface.

This problem has been investigated using the apparatus shown in Figure 25, designed at Oxford by Martin (1994) and further developed by Byrne (2000). The apparatus uses stepper motors to drive a model foundation in the vertical direction, in the horizontal direction and to rotate it about a horizontal axis to apply moment. In this way any planar movement can be applied, and is measured with a system of LVDTs. The corresponding loads are measured using a "Cambridge" load cell positioned just above the footing. The apparatus is computer controlled, so that any combination of loads and displacement can be applied, including some quite complex load paths. It has been used for many different types of test, for instance tests in which just a vertical load is applied, or tests with some constant ratio between vertical and horizontal displacement, Figure 26. In the following, however, we concentrate on so-called "swipe tests". Tests of this sort were carried out by Tan (1990) in Cambridge, but have since been adopted successfully by a number of groups. In a swipe test the footing is first pushed into the ground to a given vertical load, and then is moved 
sideways, keeping the vertical displacement constant. As the lateral displacement is applied, the horizontal load builds up and the vertical load reduces. It can be shown theoretically that the load path followed in the test follows very closely (but not quite exactly) the shape of the yield surface, see discussion by Martin (1994). A single test therefore provides the shape of a whole section of the surface.

By carrying out different types of swipe tests the shape of the whole yield surface can be explored. For instance, translating the foundation horizontally principally applies horizontal load, whilst rotation results mainly in moment load. Combinations of sliding and rotation are used to explore the whole yield surface.

Figure 27 shows the results from a swipe test (GG03) on sand (Gottardi et al., 1999). The model footing is first loaded vertically to $1600 \mathrm{~N}$, and then translated horizontally. The test path in $(V, H)$ space follows a roughly parabolic track, with the vertical load reducing, and the horizontal load first increasing and then reducing after passing through a peak. The track of the test follows closely the shape of the yield surface, which is approximately parabolic in this plane. Figure 27 also shows another test GG07, in which the footing was unloaded to $200 \mathrm{~N}$ after the initial loading to $1600 \mathrm{~N}$. This test is analogous to a test on an overconsolidated material. It confirms the shape of the yield surface at low loads.

Figure 28 shows the results of an equivalent pair of tests in which the footing is first loaded vertically and then rotated rather than translated horizontally, but again at constant vertical load. During the swipe test the moment increases and then decreases, and just as in the horizontal swipe it defines the shape of the yield surface.

For further analysis it is useful to define dimensionless quantities - normalising the loads with respect to the maximum load $V_{0}$ that has been applied to the footing, $v=V / V_{0}$, $h=H / V_{0}$ and in addition normalising the moments by dividing by the footing diameter $m=M / D V_{0}$. Normalising the loads in this way allows swipe tests with different modes of deformation to be combined onto a single plot by defining a generalised load $q=\sqrt{\frac{m^{2}}{m_{o}^{2}}+\frac{h^{2}}{h_{o}^{2}}-\frac{2 a m h}{m_{o} h_{o}}}$ that represents the combination of horizontal and moment loads. Note that this expression includes three parameters $m_{0}, h_{0}$ and $a$ that are used in the 
fitting of the yield surface dimensions. The shape of the yield surface is then closely fitted by a parabola in the $(v, q)$ plane, Figure 29.

Figure 30 shows a section of the yield surface on a plane at right angles to the vertical load, eliminating the influence of vertical load (assuming the parabolic shape determined from Figure 29 by introducing the definitions $m_{n}=\frac{m}{4 v(1-v)}$ and $\left.h_{n}=\frac{h}{4 v(1-v)}\right)$. This plot shows that the shape of the yield surface for combinations of vertical and horizontal loads is roughly elliptical in this plane. Importantly though, the principal axes of the ellipse are rotated, and not aligned with the horizontal and moment axes. This is a further example of how the loads interact in a way that cannot be separated. The eccentricity of the surface demonstrates that (for instance) a clockwise moment combined with a horizontal force to the right will have a different effect from an anticlockwise moment combined with the same horizontal force. This asymmetry is not recognized by conventional approaches to combined loading of foundations using the effective area and inclination factor approach (Brinch Hansen, 1970; Vesic, 1975).

Combining the results of several swipe tests, a complete 3D yield surface can be determined that represents the combination of loads that can safely be applied to the spudcan foundation. Within the yield surface the displacements are small, but once the surface is reached there are much larger plastic deformations. A reasonable approximation to the surface is given by the expression:

$$
f=\left(\frac{m}{m_{0}}\right)^{2}+\left(\frac{h}{h_{0}}\right)^{2}-2 a\left(\frac{m h}{m_{0} h_{0}}\right)-(4 v(1-v))^{2}=0
$$

which represents a parabolic section in the $V, M$ and $V, H$ planes and an eccentric ellipse in the $M, H$ plane. More sophisticated expressions can be used to achieve a closer fit to the data. The approach allows complete models of foundation behaviour including both the elastic and plastic behaviour for any load or displacement combination. These foundation "macro-models" can then be integrated as part of a numerical analysis of a structure. The mathematical details of some particular models are given, for example, by Martin and Houlsby (2001) and Houlsby and Cassidy (2002). 
In the analysis of dynamically sensitive structures the importance of the interface between geotechnical engineers and their structural engineering colleagues cannot be overemphasised. To model the foundation realistically structural engineers must accept the nonlinearity of soil (however inconvenient it may be) and realise that soil cannot just be represented by linear springs. Geotechnical engineers must be prepared to cast their soil mechanics models in a way that is understandable to structural engineers, compatible with their analyses and not simply reliant on arcane ad hoc procedures. The appropriate language for this communication is plasticity theory.

Figure 31 shows a "bar stool" model of a jack-up rig: a simple two-dimensional structural model in which the legs and hull are replaced by linear elements. At the bottom of the legs various assumptions can be made about the way the foundations interact with the ground. Lateral loads from waves can be applied to nodes on the legs of the rig. The model is used to investigate the behaviour as a large wave passes through the jack-up (Cassidy et al., 2001).

Figure 32(a) shows the wave elevations on the upstream and downstream legs, plotted against time. The wave itself is represented by "Constrained NewWave" theory, which realistically captures the shapes of real waves: "NewWave" (Tromans et al., 1991) represents well the average shape of an extreme wave, but does not capture a realistic pattern of waves occurring beforehand, which may be important for the behaviour of a dynamically sensitive structure. "Constrained NewWave" (Taylor et al., 1995) is an improvement in which the extreme wave is embedded within a realistic background history of wave elevations. The red (thick) curve in Figure 32(a) shows the extreme wave which has been focussed so that it reaches its maximum height of $15 \mathrm{~m}$ as it reaches the upwind legs of the jack-up. The blue (thin) curve shows it reaching the downwind leg about three seconds later, and with a slightly reduced height.

Figure 32(b) shows the horizontal movement of the deck, making three different assumptions about the foundation behaviour. The blue (thin) curve shows the case where the foundations are pinned, with a maximum displacement of about $1.4 \mathrm{~m}$. At the opposite extreme the green (thick) curve shows the result if the foundations are represented by stiff elastic springs: the deck displacements are reduced by a factor of about 3.5 to just over $0.4 \mathrm{~m}$. Recalling the expected factor of 4 if the foundations were fully fixed, it is seen that the 
elastic foundations provide a high degree of fixity. Notice too that the natural period of the rig reduces from about 14 s to about $6 \mathrm{~s}$.

In between, the red (thick) curve in Figure 32(b) shows the response if the full plasticity model is implemented. The response is very much like the elastic one, as for most of the time the foundations do indeed remain elastic. However, as the largest wave passes there is a permanent movement of the deck of about $0.15 \mathrm{~m}$ - a feature that could not be captured by the elastic model.

We now address two important extensions of the above modelling approach. Firstly, so far the loading has been assumed to be planar - in two dimensions. In reality three dimensional analysis is required, and so the behaviour of foundations subjected to more general loading, Figure 33 , needs to be understood. Figure 34 shows a sophisticated testing rig, developed by Byrne and Houlsby (2005), and unique worldwide for this application. It uses six actuators to apply, under computer control, any general combination of loads or displacements to a model foundation, and uses LVDTs and a six-axis load cell to measure the corresponding displacements and loads.

As a result, tests are possible with the full range of loads in three dimensions, Bienen et al. (2006), and these can be used to derive the shape of the yield surface under general loading. A wider range of swipe tests has been used to identify the yield surface, see Figure 35 . Each of these curves can be imagined as slices through the shape of the yield surface, which now must be expressed in a six-dimensional load space. The general expression for the yield surface becomes more complicated as it involves 6 rather than 3 variables, but conceptually it is essentially the same as Equation (5). Importantly, much of the structure of the equation can be deduced from the symmetry of the foundation about a vertical axis, and only the term involving the torsion about a vertical axis is truly new in the more general equation. In Equation (6) below we have also included the more general form of the section in the vertical direction, which is expressed through power functions, first introduced in this context by Nova and Montrasio (1991). 


$$
\begin{array}{r}
f=\left(\frac{H_{2}}{h_{0} V_{0}}\right)^{2}+\left(\frac{H_{3}}{h_{0} V_{0}}\right)^{2}+\left(\frac{M_{2}}{m_{0} D V_{0}}\right)^{2}+\left(\frac{M_{3}}{m_{0} D V_{0}}\right)^{2}-2 a\left(\frac{H_{3} M_{2}-H_{2} M_{3}}{h_{0} V_{0} m_{0} D V_{0}}\right) \\
+\left(\frac{Q}{q_{0} D V_{0}}\right)^{2}-\beta_{12}\left(\frac{V}{V_{0}}\right)^{2 \beta_{1}}\left(1-\frac{V}{V_{0}}\right)^{2 \beta_{2}}=0
\end{array}
$$

The second important extension derives from the well-known fact that soils exhibit nonlinearity at small strain. Figure 21 shows that the idealisation of elasticity, followed by a sudden yield, is an over-simplification of the real footing behaviour. A well-known way of presenting this nonlinearity is the S-shaped curve in a plot of secant stiffness against strain level. Figure 36 shows the results from some large scale footing tests (in this case on $3 \mathrm{~m}$ diameter caisson foundations, Houlsby et al., 2006), showing how the deduced secant shear stiffness for the soil gradually changes with the amplitude of rotation. A more sophisticated model should capture this reduction of stiffness, which is coupled to the gradual development of plastic strain.

This type of nonlinearity can be captured by using a multisurface model - conceptually very similar to the "Brick" model described by Simpson (1992), but expressed in terms of force resultants and displacements rather than stresses and strains. Rather than a single yield surface the model now employs many yield surfaces, illustrated conceptually in Figure 37. Each is a different size, but for simplicity they are assumed all to be of the same shape. Each surface contributes a small amount of plastic strain. As the preloading and unloading is applied, the surfaces are "dragged" behind the loading point, so that at the end of preloading the surfaces are distributed as in Figure 37(a). Later, when a storm loading is applied, the surfaces are again dragged with the load point, and as each surface is encountered the tangent stiffness gradually decreases. At the point of maximum loading the load point on a windward leg, and the associated positions of the surfaces, would be as illustrated in Figure 37(b), showing the reduction of vertical load on the windward leg as the moment is applied. Complete models of this sort are not trivial, but can be expressed in terms of work hardening plasticity theory (Nguyen-Sy, 2005, Nguyen-Sy and Houlsby, 2005).

Figure 38 shows some results testing a simplified version of the multisurface model (Byrne et al., 2002a, Byrne and Houlsby, 2003). Figure 38(a) shows the results of an experiment with gradually increasing amplitude of cycles, and Figure $38(\mathrm{~b})$ the modelling using the multi- 
surface approach. This pattern of loading is particularly challenging to model accurately, but it can be seen that the multisurface model is able to capture the complete non-linear response of the real foundation with remarkable accuracy. With such sophisticated models the behaviour of spudcans can be modelled quite realistically. Figure 39 shows the results when such a model is used to represent the foundations of a jack-up during the application of an isolated extreme wave, this time modelled just by NewWave, Cassidy et al. (2004). Figure 39(a) shows the wave elevation at the upwind and downwind legs of the jack-up. Figure 39(b) shows the corresponding deck displacement: a maximum displacement of about $0.23 \mathrm{~m}$ occurs, and there is very little permanent displacement after the wave has passed. Figure 40 shows the load paths followed by the upwind and downwind legs: the upwind leg shows a decrease in vertical load as the moment increases, and the downwind leg shows a corresponding increase in vertical load. At some points during the wave cycle there are reversals of moments. Note also that, because of the nonlinearities in the problem, the actual load paths are more complicated than the lines that would be predicted by a simplified elastic analysis. If the behaviour of the jack-up is to be captured then (at the very least) it is necessary to use quite sophisticated modelling of both the wave kinematics and of the foundation: both involve important nonlinearities that can only be captured in numerical analysis.

Perhaps most importantly, Figure 41 shows the moment rotation behaviour of one of the footings. The smaller cycles are almost elastic, whilst in the larger cycles plasticity develops. This is extremely important: for low amplitude cycling there is high stiffness, but relatively low damping. As the cycle amplitude increases the stiffness drops, which is disadvantageous as far as the structural response is concerned, but this is offset by the fact that there is energy absorption through plastic deformation, which is beneficial. The overall result is that a realistically modelled foundation contributes significant fixity which plays a vital role in the performance of the jack-up. Note that only properly formulated plasticity models offer the realistic combination of high stiffness at small deformation and energy dissipation at larger deformations: simpler non-linear elasticity models cannot capture this behaviour.

The calibration of such models has principally been carried out using the results of $1 \mathrm{~g}$ laboratory tests, and of course important questions arise regarding the scaling of both strength and stiffness parameters to field scale. Kelly et al. (2006a) discuss how $1 \mathrm{~g}$ 
laboratory test results can be applied to field scale. Centrifuge testing has a role to play in scaling the results, but it is important to recognise that centrifuges only allow the scaling of stress level - the tests are still conducted at very small scale. The Author finds the routine reporting of centrifuge tests as if they were at "prototype" scale somewhat misleading.

There is, unfortunately, a paucity of case records that can be used to verify the predicated behaviour at large scale. Figure 42 , shows the measured deck deflection for one case of a jack-up under extreme wave loading, McCarron and Broussard (1992). It can be seen that the character of the response is very much as described by the numerical model. McCarron and Broussard (1992) had some limited success modelling this case history using a simplified model for the rotational stiffness of the spudcans which employed vertical springs, with a no-tension cut-off, aligned with the leg chords. Whilst this modelled some aspects of the nonlinearity, it was unable to capture realistically the hysteresis in the moment-rotation response and permanent rotation of the spudcans.

\section{Onshore application: historic towers}

There are other applications of these methods. Pisanò et al. (2014) used this approach to aid the understanding the behaviour of leaning historic towers. Methods based on yield surfaces for foundation loading do not necessarily require complex computation, as the example below illustrates.

We investigate the stability of the Tower of Pisa, using a simple calculation that requires no more than a spreadsheet, and using data entirely available from the literature, Marchi (2008), Marchi et al. (2011). The question that is addressed is how risky was the solution that was adopted for saving the Tower, which involved stacking about 1000 tonnes of lead weights on the uphill side of the foundation, thus increasing the vertical load on the foundation. It is initially perhaps counterintuitive to attempt to stabilise a failing foundation by increasing the loading on it, but the yield surface approach shows that in this case such an approach was rational.

The curve on Figure 43 shows a best estimate of the yield surface for a circular foundation in dimensionless form. The initial position for the load point for the Pisa Tower is at A. The moment is due to the eccentric loading because of the inclination of the tower. The ratio of 
vertical load to moment is about correct, but we do not know the value of $V_{O}$, so the value is simply estimated, knowing that the tower is very close to failure, so the load point is just inside the yield surface.

When the lead blocks were added, the vertical load increased, but the net moment decreased, moving the load point to $B$, slightly further away from the yield surface. The extraction of soil from underneath the uphill side was then used to decrease the tilt by about $10 \%$, thus reducing the moment further, whilst keeping the vertical load constant, the load point moved to $\mathrm{C}$. Finally the lead blocks were removed, taking the load point back towards the yield surface at $D$, but a little bit further away than initially.

From this simple analysis we conclude that the application of the lead weights was indeed a sensible option - as of course it proved to be. It demonstrates that the removal of the lead blocks, when the stress point moved back towards the yield surface, was probably more critical than their initial placement.

\section{Conclusions from Part 2}

It is important that we do not overlook interactions when they may be important, even if they are not obvious or are difficult to calculate. To take the trivial example from the elastic behaviour of footings, in most design codes such as API (2010) the interaction between horizontal load and moment is ignored. This is not on the rational basis that the effect is small, it is simply that it has not been properly accounted for - but that does not mean that in reality it will not influence the results.

More generally, it is vital in problems of soil structure interaction that there is an effective means of communication between geotechnical and structural engineers. The structural engineers must accept that soil response cannot be reduced to the presence of simple linear springs, but geotechnical engineers must play their part, expressing soil and foundation behaviour in a way that is intelligible to structural engineers and compatible with their numerical analyses. Work hardening plasticity theory, combined with macro-models for foundation behaviour, provides an appropriate language for expressing geotechnical knowledge in a way that is compatible with numerical analysis. 


\section{Part 3: Foundations for offshore wind turbines}

\section{Motivation}

In this final section the focus moves to another sector - the rapidly expanding offshore wind industry, and specifically the challenge of foundation engineering for offshore wind turbines. We examine some particular ideas for more economical foundations for offshore turbines, noting that it is estimated that $19 \%$ to $22 \%$ of the capital total cost of an offshore installation may be related to the foundation and substructure (Willow and Valpy, 2011). We consider aspects of the design for conventional solutions (monopiles), less conventional solutions (suction caissons), and a novel idea (screw piles). There will be one general conclusion: that geotechnical engineers need to be fully engaged in, and informed about the energy debate. More specifically, we identify cyclic loading as one of the key issues to be addressed for the design of monopiles; for suction caissons there are a number of important design issues and we concentrate on tension capacity; finally screw piles are introduced as a technology that holds excellent promise for turbines in deep water as their combination of good tensile capacity and noise-free installation meets some key offshore design needs.

It is useful first to examine why we should look offshore for clean renewable power, especially around the UK, and especially exploiting wind power. The primary motivation comes from the increasing levels of carbon dioxide in the atmosphere. Figure 44 shows the famous (or infamous) "Keeling Curve" showing the increase of atmospheric $\mathrm{CO}_{2}$ with time, primarily due to our use of fossil fuels. May 2014 was the first month in human history when the concentration exceeded 400 parts-per-million by volume of $\mathrm{CO}_{2}$, and 2015 is almost certain to be the first year in which the annual average exceeds $400 p p m v$. The figures are even more alarming when one differentiates the curve to get the rate of increase of $\mathrm{CO}_{2}$, Figure 45 . There is some scatter, but the trend is clear: 50 years ago the rate of increase was less that one part per million per year, and now it is more than twice that. Our over-use of fossil fuels is affecting the atmosphere at an ever increasing pace. It is well known that rising $\mathrm{CO}_{2}$ levels are a driver of global warming, with all its consequences. We must find an alternative to fossil fuels.

However, there is another quite different reason why we should reduce our dependency on hydrocarbons, and that is that they are a finite resource. Figure 46 shows (on different 
vertical scales) the UK production of oil and natural gas, mainly from our resources in the North Sea. These peaked in 1999 for oil and 2000 for gas, and are now in steady decline as supplies are depleted. This same pattern is repeated worldwide, although there is some debate about whether or not we have yet passed "peak oil". In broad terms though, economically accessible worldwide oil resources would last in the region of 40 years at present rates of consumption, and gas perhaps 60 years or so. Recent developments in fracking may lengthen this by a few years. We need to find alternative sources of energy within the next few decades, and of course the sooner these are developed the greater the benefit (see King et al., 2015).

There are really only two potential solutions to the twin problem of climate change caused by hydrocarbons, and diminishing supplies of those hydrocarbons: nuclear power or renewables (storage and energy efficiency also have important roles to play). Nuclear power will undoubtedly play a vital part, but we concentrate below on renewables. Wind power is one of the most promising of the renewable resources, and offshore wind power has some particular advantages. The primary benefit is that average wind speeds are typically higher offshore than onshore: in Figure 47 the progression from green to yellow shows higher average wind speeds. Almost as important is the fact that the wind is less turbulent offshore, making it more suitable for power generation. There is also the social advantage that many people do not favour wind turbines on aesthetic grounds, but offshore wind attracts less opposition.

The drawback to offshore wind is of course the additional cost, associated principally with (a) foundation costs, (b) transmission distances and (c) costs of operation and maintenance. Foundation costs can be minimised by seeking locations with reasonably high wind speed but shallow water. Figure 48 shows bathymetry around the UK, and there are some obvious target areas of shallow water, perhaps most notably the Dogger Bank. The highlighted (pink) areas on Figure 49 show the regions available for development in Round 3 of the Crown Estates' licensing process. The small darker areas are those that are already developed or under development. The newer developments will be further offshore, and mainly in somewhat deeper water. 
At the end of 2012 the UK had almost 3GW of installed offshore wind power, accounting for almost $60 \%$ of the offshore wind power worldwide, Table 3 . This is in the context that the average electricity demand in the UK is around $45 \mathrm{GW}$. Of course, because the wind does not blow all the time, 3GW of installed wind power delivers about 1GW on average (a "capacity factor" in the region of 30\%). The UK therefore generates around $2 \%$ of its electrical power from offshore wind (and about twice that amount from onshore wind). There are ambitious plans for much larger developments: the UK is one of the world leaders in offshore wind developments.

The design of an offshore wind turbine involves the analysis of numerous load cases involving fatigue, serviceability and ultimate limit states (generating conditions, extreme storm loading, emergency stop etc.). Much of the design is governed by fatigue life, and this in turn is affected by the dynamic response of the structure. For instance offshore turbines are usually designed so that their first natural frequency falls between the rotational frequency $(P)$ and blade-passing frequency $(3 P)$. For the sake of example though, we reduce all these cases to a single set of representative loads on a turbine. Figure 50 shows the order of magnitude of the maximum forces on a typical modern offshore turbine in around $40 \mathrm{~m}$ of water and delivering about $5 \mathrm{MW}$. The force of the blades is of the order of $2 \mathrm{MN}$, and this may act at around $110 \mathrm{~m}$ above the waterline. The lateral forces from waves and current are much larger, about $4 \mathrm{MN}$, but of course they act much lower on the support structure. It is useful to combine the lateral loads into a single force $H=2 \mathrm{MN}$ (from wind $)+4 \mathrm{MN}$ (from wave + current $)=6 \mathrm{MN}$, which results in a moment $M=2 \times(40+110) \mathrm{MNm}+4 \times 40 \mathrm{MNm}=460 \mathrm{MNm}$. The point of action of the net horizontal load is thus about $80 \mathrm{~m}$ above the seabed in this case.

Since the typical weight of the structure and turbine may be of the order of $10 \mathrm{MN}$ (arising from a mass of 1000 tonnes), the horizontal load is about $60 \%$ of the vertical load. The design problem involves very high lateral load with relatively small vertical load. Contrast this with the jack-up structures addressed in Part 2, where the lateral load is rarely more than $10-15 \%$ of the vertical load.

There are broadly two ways that loads can be transmitted to a foundation. Figure 51(a) shows a monopile foundation, which must resist directly the vertical and horizontal loads 
and the overturning moment. Figure $51(\mathrm{~b})$ shows an alternative with multiple foundations: in this case the moment loading on each foundation is much less important, because the overall overturning moment is resisted by "push-pull" action of the downwind and upwind foundations. The magnitude of this effect depends critically on the spacing of the foundations s. Unless they are very widely spaced, the overturning moment would usually be sufficient that the vertical load on the upwind footing becomes tensile, so there is the special problem of design against tensile loading.

In general the larger the turbine and the deeper the water, the more difficult it is to design a monopile or monopod structure. At present most past installations are in relatively shallow water close to shore, and of devices in the 2 to $3 \mathrm{MW}$ range. Almost all have been founded on monopiles. Figure 52 presents the developments in a plot of turbine power (horizontal axis) and water depth (vertical axis). Blue dots represent UK developments on monopiles and red dots those on multiple foundation (jacket) structures. In general for smaller installations in shallow water the monopile is an economical choice. In the future, as larger devices (5MW and more) are installed in deeper water, it is unlikely that large enough monopiles will be feasible, and the foundations are likely to involve multiple footings of some sort.

\section{Monopiles}

In spite of the above observations, the monopile remains the most important foundation choice for offshore wind turbines at present. Whilst there is a huge amount of experience on piled foundations from the oil and gas industry, it is important to realise that monopiles for wind turbines present a radically different design problem. The most striking difference is their size. In offshore oil and gas, piles are typically anything from $30 \mathrm{~m}$ to about $100 \mathrm{~m}$ long (quite often more), and up to about $2 \mathrm{~m}$ diameter. They are long and slender, with length-todiameter ratios of 50 or more. As a result they behave in a relatively flexible way in bending.

In contrast, monopiles are short and fat. Most are around $30 \mathrm{~m}$ long, with diameters up to about $6 \mathrm{~m}$. Even larger diameters are under consideration. The length-to-diameter ratio is only about 5 , and as a result they are very stiff in bending. This stiffness is of course required as they must resist the large overturning moments directly. 
This remarkable difference is the driver behind the Carbon Trust and industry-sponsored "PISA" project, which is investigating how conventional $p-y$ methods can be adapted for short piles with low L/D ratios (Byrne et al., 2015a,b). The project concentrates on monotonic loading and the first few cycles of load, and should lead to new design methods.

However, a very important feature of monopiles is the fact that they are subjected to extremely large numbers $\left(>10^{8}\right)$ of small amplitude cycles, and we address here how the effects of these on wind turbine performance can be understood. Tests have been carried out on models in a very simple rig designed to apply many thousands of cycles, Figure 53 . A stiff pile is embedded in soil, in this case sand, and a combination of cyclic horizontal load and moment is applied by a simple system of weights and pulleys. As a mass rotates, it results in a changing lever arm which in turn results in the cyclic load on the pile. The displacements are monitored by simple dial gauges, a convenient choice that avoids the problems of long term drift of electrical transducers.

The programme of loading was chosen to be representative of working loads on an offshore turbine. Figure 54 shows the estimated position of the failure surface for the pile under combined lateral and moment loading in a dimensionless plot with $\tilde{H}=H / \gamma^{\prime} D L^{2}$, $\tilde{M}=M / \gamma^{\prime} D L^{3}$. The failure surface is almost straight within the relevant range of loads, and measured failure values correspond closely to the theory. For design in the field we can identify the Ultimate Limit State as a point on the yield surface, and then apply a suitable safety factor. We can also identify appropriate points for the Serviceability Limit State, which would occur many times during the life of the structure, and the Fatigue Limit State for which we might be interested in millions of cycles. The relevant range of loading is typically between $30 \%$ and $50 \%$ of the failure values.

The study, LeBlanc et al. (2010a), involved one way loading of various amplitudes, dimensioned by $\varsigma_{b}=M_{\max } / M_{R}$, where $M_{R}$ is a reference (failure) moment, Figure 55 . The effect of the ratio of the minimum to maximum load in the cycle $\varsigma_{c}=M_{\min } / M_{\max }$ was also examined, as under field conditions load cycles may not just be in the form of one way loading. 
Figure 56 shows the results of a typical test. A relatively stiff response is observed during each loading cycle, in which the soil behaves almost elastically. However, each cycle involves a small hysteresis loop, implying a degree of frictional damping. Perhaps more importantly, during each one-way cycle there is a small accumulation of rotation. Although the residual rotation in each cycle is minute, after many cycles a significant "ratcheting" rotation is accumulated - far more than the elastic or plastic rotations in any one cycle. The accumulation though is at a diminishing rate - in the test shown in Figure 56 the first 1500 cycles cause approximately the same deformation as the next 7500 . Although not immediately visible in Figure 56, the secant stiffness changes gradually with cycling, and the amount of hysteretic damping changes too. All of these effects (change of stiffness, change of damping, ratcheting displacement) have implications for the long term design of wind turbine foundations.

The data are presented in terms of quantities defined in Figure 57 . The secant stiffness $k_{N}$ is defined for each cycle. Figure 58 shows how this stiffness varies with the cycle number. The four curves are for different amplitudes of cycling. The smallest amplitude of cycling gives the highest secant stiffness, which is consistent with usual observations. However, over 10000 cycles, the secant stiffness increases in each of the tests shown. This is contrary to the conventional wisdom that cycling always degrades the performance of a soil. The tests shown were on sand of medium density, and in the case of loose to medium dense sands the stiffness increases with cycling, almost certainly due to slight densification of the sand close to the pile. However, for wind turbine design either a decrease or an increase of stiffness can be important, as the resonant frequency of the entire foundation-structure system should be maintained within a certain range, and the dynamic response of the wind turbine is depends partly on the foundation stiffness. LeBlanc et al. (2010a) suggested that the dependence of stiffness on cycle number from these laboratory tests could be quite well fitted (at least within the range of cycle number tested) by the logarithmic expression:

$$
\tilde{k}_{N}=\tilde{k}_{0}+A_{k} \ln (N)
$$

with the initial stiffness in turn a function of the cycle size and form, $\tilde{k}_{N}=K_{b}\left(\varsigma_{b}\right) K_{c}\left(\varsigma_{c}\right)$. Note that the results of these laboratory tests at $1 \mathrm{~g}$ should be applied to field cases with caution. Field monitoring of natural frequency can shed some light on changes in foundation 
stiffness, and Kallehave et al. (2015) detected no significant change of natural frequency with time over a period of 2.5 years for a monopile in dense sand.

The accumulated displacement during many cycles, normalised by dividing by the displacement in the first cycle, is presented in Figure 59. In each case shown the accumulated rotation, after normalising by the rotation in the first cycle, increases roughly as a power law with number of cycles, and can be quite accurately fitted (within the range of cycles tested) by the expression:

$$
\frac{\Delta \theta}{\theta_{\text {static }}}=T_{b} \times T_{c} \times N^{0.31}
$$

First note the observation that the total accumulated deformation increases as a power function with number of cycles. The exponent of about one third seems quite well established from a number of different tests. As a result, the incremental accumulation in any one cycle decreases with cycle number: $\frac{d \Delta \theta}{d N} \alpha N^{0.31-1}=N^{-0.69}$.

The absolute magnitude of the accumulated deformation is expressed through two empirical factors $T_{b}\left(s_{b}\right)$ and $T_{c}\left(s_{c}\right)$, multiplying the power function of the number of cycles. Figure 60(a) shows the dependence $T_{b}\left(\varsigma_{b}\right)$ on the magnitude of the cycle. Unsurprisingly, larger cycles produce more accumulated rotation, and $T_{b}$ is also found to be a function of the relative density.

Figure 60(b) is more interesting, as it shows the dependence on the form of cycling. Symmetric cycling $\left(\varsigma_{c}=-1\right)$ of course produces no accumulated deformation. One way cycling $\left(\varsigma_{c}=0\right)$, however, does cause accumulated rotation. The value $\varsigma_{c}=1$ represents a constant applied load with no cyclic component, and again produces no accumulation. What is most striking though is that the maximum accumulated deformation is caused by cycles some way between one way and two way cycling. In other words, the largest accumulations occur when the pile is first pushed in one direction, then partially pushed backwards, then pushed again in the first direction. Cyclic loading test programmes often concentrate on oneway and two way loading, and may miss this more damaging intermediate condition. 
Cyclic testing is often only carried out for a few tens of cycles, and these data are unusual in extending to over 20000 cycles. Whilst the slopes in Figure 59 are almost constant over three decades of cycle number (approximately 10 to $10^{4}$ ), the field problem involves of the order of $10^{8}$ cycles in the lifetime of the turbine, and there are serious questions about extrapolation of these data to very large numbers of cycles. Furthermore, the real loading involves a complex combination of cycles of different magnitudes and in different directions. LeBlanc et al. (2010b) suggested a methodology for how the effects of these could be combined.

There is much further important work currently underway on the performance of monopiles, which will continue to find wide, and even dominant, use in the offshore wind industry, but we do not pursue this topic further here.

\section{Suction caissons}

We now turn to suction caissons, widely regarded as attractive alternatives to piling for offshore wind turbines. Often informally termed "suction buckets" they are large thin-walled cylindrical structures, sealed by a stiffened plate on the top and open at the base. They are installed into the ground first by penetration under their own weight, and then by pumping water out of the caisson to create a suction that forces the caisson into the ground, Figure 61. In clay the mechanism of penetration is entirely driven by the differential pressure across the lid of the caisson (Houlsby and Byrne, 2005a), but in sand there is an additional beneficial effect that a seepage pattern is set up which reduces the effective stresses inside the caisson, further assisting penetration (Houlsby and Byrne, 2005b).

The caissons themselves may be no less expensive than piles of equivalent capacity, but they have two great advantages. Firstly they do not require expensive equipment for installation - essentially all they require is a pump and control system - and secondly the installation is almost silent. There is a major concern that the vibration from pile driving operations is sufficiently detrimental to marine mammals - dolphins and seals - that strict limits are being placed on the noise from offshore operations, especially driven piling (Bailey et al., 2010).

There are a number of issues around the design of suction caissons for offshore wind turbines, and these were the subject of a major design study undertaken for the DTI, EPSRC 
and a consortium of companies (Byrne et al. (2002b), Houlsby and Byrne (2005a,b), Doherty et al. (2005), Kelly et al. (2006a,b), Villalobos et al. (2009, 2010). The most pressing issues are:

- Assessment of whether the caisson can be installed at a given site. There seems little doubt that they can be installed in relatively homogeneous sand, even very dense sands, and in most clays. However, very stiff or fissured clays may be a problem, as might very coarse grained soils in which it may not be possible to form a satisfactory seal to apply the suction. Isolated larger stones may also cause a problem. Installation in some layered or inhomogeneous soils may also not be possible. However, the range of soils where installation can be achieved is quite wide.

- The tensile capacity of caissons, under both serviceability and ultimate conditions, when they are used in a multiple footing configuration to support a jacket.

- Performance under cyclic loading.

Of the above issues, the one that is most frequently raised by designers is the question of how much tension can be reasonably allowed in design, and so we address just the tensile loading problem here. On average a caisson supporting a wind turbine will be in compression, but it will be subjected to small amplitude cyclic vertical loading during operating conditions, and occasional much larger cycles during extreme conditions. Figure 62 shows the results of a model test of a caisson in saturated sand with packets of gradually increasing load cycles. In this and the following figures, the vertical load is converted to an equivalent stress by dividing by the area of the caisson. Examining the first four packets, each of 10 cycles, not surprisingly the hysteresis in the cycles increases with amplitude, as well as the accumulated deformation in each cycle. In the fifth packet, of 5 cycles, the amplitude is sufficient that tension is just reached at the limit of the cycles: again the hysteresis and accumulated deformation increase.

In the final packet of 5 cycles the amplitude of cycling was only slightly larger, but involved a more significant tension. It can be seen that there is a dramatic change in the nature of the response, with each application of tension involving significant upward movement. On removing the tension and reapplying compression there is equally large downward movement, so that the hysteresis loop takes on a characteristic "banana" shape. Note that 
these cycles result in the important phenomenon that in each cycle there is a large residual downward movement, even though this is triggered by the application of a tensile (upward) load in part of the cycle. The implication is that if a turbine on multiple caissons were to be subjected to very large overturning moments from wind loading, sufficient to cause substantial tension, then the accumulated displacement would cause the turbine to tilt towards the prevailing wind direction - a somewhat paradoxical result. The explanation surely lies in the fact that the average load on each foundation is downwards, and the large cyclic displacements caused by tensile loading result in damage to the soil fabric resulting in an overall weakening of the foundation.

At the end of this test a tensile pullout test was applied, and the tensile stress, even at quite large displacements (approximately 250kPa), was much smaller than the compressive capacity, which was not even approached in the largest cycles, and must be significantly greater than $1300 \mathrm{kPa}$.

The results in Figure 62 were from small scale tests, and the question of course arises whether they are also applicable in the field. It is very costly to carry out cyclic tension tests on full size caissons, but there are data from quite substantial field trials on a $1.5 \mathrm{~m}$ diameter caisson, Houlsby et al. (2006). Figure 63 shows the results of cyclic tests from four different tests at different sizes and with different modes of installation. In each of the four tests three selected hysteresis loops at different amplitudes have been extracted from a longer sequence of cycling. After normalising the results using the procedures in Kelly et al. (2006a), the hysteresis loops from the different tests are remarkably similar. The scaling involves normalising the applied vertical load as $V / \gamma^{\prime} D^{3}$ and displacement as $\frac{w}{D} \times\left(p_{a} / \gamma^{\prime} D\right)^{0.5}$. The second part of the displacement normalisation accounts approximately for the change of soil shear modulus with stress level. The results in Figure 63 give confidence that, provided appropriate normalisation techniques are used, laboratory experimental results can be scaled to predict field conditions.

It is generally accepted though that the ultimate capacity of a suction caisson in tension will be very large. Figure 64 shows the results for tensile loading of a model caisson in sand. First consider curve $A$, which is from a test involving a very slow application of the tensile load. 
The net vertical stress on the caisson is small, and equates approximately to the friction that is developed on the outside and inside of the skirts, as during the slow extraction excess (negative) pore pressures beneath the caisson can dissipate.

Curve B shows the result of an equivalent test in which the same caisson is pulled very fast: the ultimate capacity is much larger, as negative excess pore pressures are developed underneath the caisson. This case is more relevant to the rapid wave loading that a turbine would experience during a storm. The capacity is limited by cavitation of the pore fluid underneath the caisson. In this case the test is carried out at atmospheric pressure, so cavitation occurs at approximately $-100 \mathrm{kPa}$ gauge pressure and, comparing to Curve $A$, the capacity is increased by approximately this amount (in fact rather more, presumably because the negative pore pressures enhance the effective stresses acting on the skirts, and hence enhance the frictional component of the capacity).

Curve $C$ shows the result of a fast test on the same caisson, but carried out at an elevated pressure in a pressure chamber. This is used to simulate the water pressure conditions on the seabed. In this case the pressure is elevated by $200 \mathrm{kPa}$, and so cavitation now occurs after reduction of gauge pressure by a correspondingly larger pressure change. The ultimate capacity is seen to increase by a little more than $200 \mathrm{kPa}$, confirming that the capacity is determined by the onset of cavitation, which depends on the water pressure at the seabed.

The result is that in the field the ultimate tensile capacity will be very high. However, concentrating on just the early stages of all three of the tests, it is seen that they each show an initially very soft response, followed in the rapid loading cases by an increase in load. When scaled up to field dimensions using the procedures described above, the displacements in this initial phase would be unacceptable on serviceability grounds. Note, however, that tensile capacity approximately equal to the frictional resistance is developed during the rapid tests at very small incremental displacement. The conclusion is that, on serviceability grounds, tension on caissons should be limited to the frictional capacity, and no account should be taken of the end bearing which is limited by cavitation, except under truly exceptional load conditions. If deformations are to be limited to acceptable values, significant tension must be avoided. 
It is worth noting that the tensile capacity limited by cavitation is one of the exceptionally rare cases in soil mechanics where the soil behaviour is not determined by effective stresses, but is limited by a total stress value. Such cases only arise when the absolute pressure in the pore fluid affects the overall soil response, which is of course the case when cavitation is relevant.

Screw piles

Screw piles, or helical piles, have not yet been adopted as foundations for offshore wind turbines, but several of their characteristics suggest that they are potentially attractive and economical for this application. A screw pile consists of a shaft to which are fixed large diameter helical plates, Figure 65. They are installed by twisting them into the ground by a hydraulic torque motor. Some additional vertical load ("crowd") can be applied, which assists installation. They are robust and simple, can be installed in many different soil types, and have good tensile capacity. Onshore, screw piles are now routinely used for installations that involve light vertical loads, but also require tensile capacity, most usually due to overturning moments. Examples are the gantries for signs over motorways. Onshore the piles are typically small, with the helical flights up to about $600 \mathrm{~mm}$ diameter.

The loading of an offshore wind turbine results in similar load ratios: relatively low vertical load combined with a tension caused by overturning moment, suggesting the use of screw piles offshore (Byrne and Houlsby, 2015). There are key additional advantages:

- Firstly the installation is potentially almost silent. This is a significant advantage as it is now recognised that the noise from driven piling for large numbers of wind turbines is damaging to marine mammal populations. Driven piles are often now ruled out on environmental grounds;

- Secondly, as the screw pile is installed the torque can be monitored, and the torque can be closely correlated with the load capacity (see below), so that the installation provides a confirmation of the future performance.

However, there are also challenges in moving this technology offshore. Firstly the loads offshore are vastly greater than those encountered onshore, so screw piles need to be scaled up by a factor of 3 or 4 , to the order of $2 \mathrm{~m}$ diameter. Secondly installation equipment 
must be developed that can cope with the required torque, and be operated in the offshore environment. There are also non-geotechnical challenges, but such problems are not insuperable. For instance the shaft/plate connection is vulnerable to fatigue, suggesting that cast construction (successfully used in other offshore applications, Broughton et al., 1997) could be employed.

In developing design methods for much larger piles, it is important to identify the key dimensionless groups that define the pile behaviour. Firstly there are groups that represent the geometry of the pile - for instance the ratio of shaft to helix diameter $D / D_{p}$ (see Figure 65), length to diameter ratio $L / D_{p}$, and the number, spacing ratio $s / D_{p}$ and pitch ratio $p / D_{p}$ of the helix plates. There is no particular reason to depart from well-established onshore practice in choosing these ratios, at least for initial design.

The design in both clay and sand can be simplified by normalising the capacity in an appropriate way. The relevant dimensionless groups are $V / s_{u} D_{p}^{2}$ and $V / \gamma^{\prime} D_{p}^{3}$, suggesting that for clay the capacity increases with the square of the helix diameter, and for geometrically similar piles in sand it increases with the cube of the diameter. However, in sand it is more likely that the length may be chosen independently of diameter, and for this case the capacity varies approximately with the square of the diameter, suggesting that it would be more appropriate to use $V / \gamma^{\prime} L D_{p}^{2}$.

The installation torque can also be expressed in terms of dimensionless groups, and here we see for instance that the torque in clay scales with the cube of the diameter as the relevant group is $T / s_{u} D_{p}^{3}$. For geometrically similar piles in sand the relevant group is $T / \gamma^{\prime} D_{p}^{4}$, but for the reasons discussed above it may be more appropriate to use $T / \gamma^{\prime} L D_{p}^{3}$.

Some key ratios are useful in design. The first is the capacity, multiplied by the plate diameter and divided by the installation torque $V D_{p} / T$. We would expect this number to be roughly constant for piles of similar geometry and in similar soil types (although the ratio may be expected to differ for sands and clays, and to vary with for instance angle of friction or overconsolidation ratio). Note that onshore the current practice is to use the capacity to 
torque ratio $V / T$, but this has the odd dimension of $1 /$ length, and thus depends on the scale of the pile.

The second useful ratio is simply the ratio of tensile capacity $V_{t}$ to compressive capacity $V$.

Perko (2009) gathered data from various sources (onshore practice and model tests), from piles typically only $300 \mathrm{~mm}$ in diameter, and up to $900 \mathrm{~mm}$; the loads were correspondingly small. Data from Perko (2009), together with other sources, are collated in Table 4. Although there are some outliers, the geometric mean of the ratio $V D_{p} / T$ is 8.23 for compressive loading, and for $V_{t} D_{p} / T$ it is 6.66 for tensile loading. The geometric mean value of $V_{t} / V$ is 0.85. (Note that there is a slight inconsistency in these values because gaps in the data sets mean that slightly different data are used to determine the different factors.) There were insufficient data to be able to determine these ratios with greater accuracy for particular soils, although there is some indication that the lower $V D_{p} / T$ and $V_{t} D_{p} / T$ values are associated with coarser grained materials (sands). These figures, however, provide the empirical background against which we can calibrate any design methods for offshore piles.

There are essentially two ways we can calculate the capacity for compressive loading. In the first, Figure 66(a), we assume that each helix acts as an independent plate, and calculate the capacity as a function of plate bearing and shaft friction components. Alternatively, Figure 66(b), we can assume that the soil fails on a cylindrical envelope around all the plates. End bearing is only developed on the bottom plate, but the side friction is over a much larger area. Of course the design capacity will be the lower of these two values, and an efficient design may involve adjusting the plate spacing so that both occur almost simultaneously.

The tensile capacity can be calculated in a very similar way, again treating the plates as independent or as a single unit, Figure 67(a) and (b), although the detailed shape of the breakout surface is uncertain, and is still a subject for research. The problem in clay is reasonably well understood, Merifield (2011), but there remains considerable uncertainty about tensile capacities in sand.

Calculations of the installation torque can similarly be made, at least in clay, assuming either that each plate cuts a path through the soil, or that an entire block of soil rotates with the 
pile. The latter would be unsatisfactory, and for realistic combinations of design parameters it does not occur.

Figure 68 shows the results of a calculation for an offshore screw pile with realistic dimensions for a four-legged jacket structure supporting a large wind turbine at a deep water site in the North Sea (the details are confidential). The soil is clay. The steps in the capacity come as each new helix enters the ground, and in this case the independent capacity of the plates is always a little less than the envelope capacity. Figure 69 shows the dimensionless torque ratio $V_{t} D_{p} / T$ for the same site, giving values a little over 10 - slightly higher than the typical values expected from the empirical database, but well within the variability observed. The calculations also give a ratio of tensile to compressive capacity $V_{t} / V$ in the range from about 0.7 to 0.95 , Figure 70 , which is also consistent with the empirical database. These comparisons provide considerable confidence in the design method.

It would be desirable to compare these predictions with measurements of performance of screw piles in the North Sea, but alas that is yet to happen. However, screw piles could offer an economical and environmentally acceptable solution to the foundation problem for deep water wind turbines. What is needed at this stage is for an installation contractor to develop the necessary equipment. There is a golden opportunity to achieve a step change in the technology employed offshore.

Although not used in recent practice offshore, there is, however, ample historical evidence of their successful use offshore. The earliest known offshore structure supported on screw piles was the Maplin Sands lighthouse. The foundation was designed by an Irish engineer, Alexander Mitchell, remarkable for his achievements not least because he was totally blind from the age of 21 . The lighthouse, see Figure 71, was supported on 9 screw piles, 8 forming an octagon and one in the centre. They were driven into the sand by a man-powered capstan system. Each pile had a single helix of diameter a $1.2 \mathrm{~m}$ (4 feet), and was driven $7 \mathrm{~m}$ (22 feet) below mudline. The lighthouse was operated for over 90 years until 1931, but scouring around the structure had gradually undermined the foundation, and the lighthouse finally collapsed in 1932 . 
Mitchell had a clear motivation for using screw piles. In his paper to the Institution of Civil Engineers in 1842 (reprinted Mitchell, 1848) he made it clear that the tensile capacity of screw piles was one of their attractions. He also correctly identifies depth, helix area and soil type as the key elements affecting the capacity:

"Whether this broad spiral flange, or 'Ground Screw', as it may be termed, be applied to the foot of the pile to support a superincumbent weight, or be employed as a mooring to resist an upward strain, its holding power entirely depends upon the area of its disc, the nature of the ground into which it is inserted, and the depth to which it is forced beneath the surface.

The proper area of the screw should, in every case, be determined by the nature of the ground in which it is to be placed, and which must be ascertained by previous experiment" (Mitchell, 1848)

Note that Mitchell recommends testing to prove the capacity of his innovative design. Over 160 years later, Mitchell's wise advice still holds true.

\section{Conclusions from Part 3}

Offshore wind power can and should be an important contributor to the UK's energy supply in the future. As turbines are installed offshore and in deeper water, and as the turbines themselves become larger ( $5 \mathrm{MW}$ or more), the trend will be away from monopile foundations towards jacket structures on multiple footings.

In order to drive costs down, novel solutions will be required. One such option is the use of suction caissons, which have already been the subject of much study and are now beginning to be deployed in this sector. A more radical solution would be the use of helical piling, already in use over 150 years ago, but not currently deployed offshore. As the performance characteristics of helical piles are well matched to the loading conditions offshore (principally because of their tensile capacity), they could offer an economically viable and environmentally acceptable solution for large turbines on multiple piles. 


\section{Overall Conclusion}

This paper is intended to encourage geotechnical engineers to be outward looking towards other disciplines.

Throughout soil mechanics we deal with a material which is intrinsically variable: as illustrated in Part 1, it is vital that geotechnical engineers embrace more sophisticated statistical and probabilistic techniques to address this variability in a rational way.

In Part 2 the behaviour of a jack-up unit was used to illustrate how rigorous and well defined mathematical techniques such as plasticity theory can be used to define models for soil mechanics problems, especially for foundation. These models allow the behaviour of footings to be framed in a way that is compatible with advanced numerical codes, thus allowing geotechnical expertise to be encoded and communicated to structural engineers and to others. For their part, structural engineers must accept that foundation response cannot adequately be represented by elasticity theory.

Geotechnical engineers have an important role to play in contributing to our future energy supply, one of the most important challenges of the $21^{\text {st }}$ Century. They can contribute to the solutions, and should engage knowledgably with the wider energy debate, drawing on past experience to seek novel solutions to challenges such as those offered by the design of offshore wind turbine foundations, as illustrated in Part 3.

\section{Postscript}

The four elements recognised in classical times were Fire, Air, Water and Earth. The fire represents the oil and gas that has driven so much of offshore engineering; the air represents wind power that we should exploit economically; the water stands for the offshore environment and the earth is the subject of Géotechnique. All the four elements come together in the area of offshore structures, and it is the way they interact that creates the fascination of the topic.

\section{Acknowledgements}

The author is very grateful to the British Geotechnical Association for giving him opportunity to present a Rankine Lecture and this accompanying paper. 
This paper draws on work carried out in collaboration with a many colleagues, too many for all to be named individually here, but importantly including Ross Bell, Assoc/Prof. Britta Bienen, Prof. Roy Butterfield, Prof. Mark Cassidy, Prof. Guido Gottardi, Dr Neil Houlsby, Mike Hoyle, John Huxtable, Dr Richard Kelly, Dr Christian LeBlanc, Prof. Chris Martin, Dr Luan NgoTran, Dr Nguyen-Sy Lam, Julian Osborne, Brooks Paige, Yura Perov, Prof. Mark Randolph, Dr Paulo de Santa Maria, Dr Teh Kar-Lu, Dr Richard Thompson, Tor-Inge Tjelta, Dr Felipe Villalobos, Prof. Frank Wood and Prof. Zhu Bin. I am grateful to Prof. Alan Lutenegger for generously providing information about helical piling.

Finally I am particularly grateful to Prof. Byron Byrne, who led much of the experimental work presented here. I also wish to express my deep sense of gratitude for the wise guidance from my mentor, the late Prof. Peter Wroth.

\section{Notation}
A Area of foundation
D Diameter of circular footing or pile
$D_{p} \quad$ Helix diameter of screw pile
El Bending stiffness of leg of jack-up
$G \quad$ Soil (small strain) shear modulus
$h \quad$ Depth of embedment of footing
$H \quad$ Horizontal load on jack-up unit or foundation
$K_{1} \quad$ Dimensionless vertical stiffness factor
$K_{2}$ Dimensionless rotational stiffness factor
$K_{3} \quad$ Dimensionless horizontal stiffness factor
$K_{4} \quad$ Dimensionless stiffness factor coupling horizontal and rotational response
$L \quad$ (1) Leg length of jack-up, (2) length of pile
$m \quad$ Mass of jack-up
$M \quad$ Moment on footing
$N_{C} \quad$ Bearing capacity factor
$q \quad$ Generalised horizontal/moment load on foundation
Q Torsional load on foundation
$s \quad$ (1) Spacing of piles, (2) spacing of helix plates on screw pile 


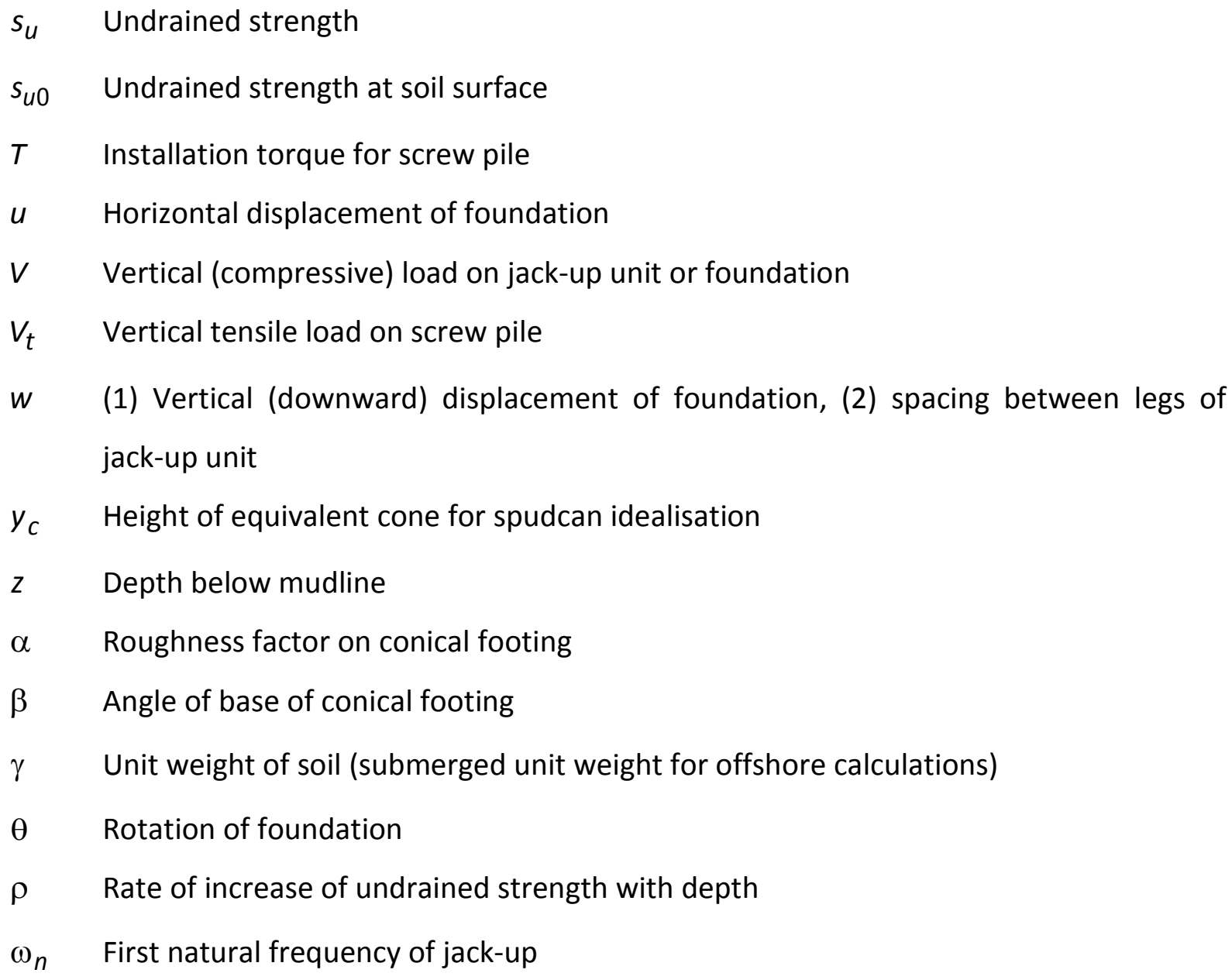

w (1) Vertical (downward) displacement of foundation, (2) spacing between legs of jack-up unit

$y_{c} \quad$ Height of equivalent cone for spudcan idealisation

$z \quad$ Depth below mudline

$\alpha \quad$ Roughness factor on conical footing

$\beta \quad$ Angle of base of conical footing

$\gamma \quad$ Unit weight of soil (submerged unit weight for offshore calculations)

$\theta \quad$ Rotation of foundation

$\rho \quad$ Rate of increase of undrained strength with depth

$\omega_{n} \quad$ First natural frequency of jack-up

\section{References}

API (2010). RP 2A-WSD - Recommended Practice for Planning, Designing and Constructing Fixed Offshore Platforms. Washington: American Petroleum Institute

Bailey, H., Senior, B., Simmons, D., Rusin, J., Picken, G. and Thompson, P.M. (2010). Assessing underwater noise levels during pile-driving at an offshore windfarm and its potential effects on marine mammals, Marine Pollution Bulletin, 60(6), 888-897, doi:10.1016/j.marpolbul.2010.01.003

Bell, R.W. (1991). The analysis of offshore foundations subjected to combined loading. M.Sc. Thesis, University of Oxford

Bienen, B., Byrne, B.W., Houlsby, G.T. and Cassidy, M.J. (2006). Investigating six-degree-offreedom loading of shallow foundations on sand. Géotechnique, 56(6), 367-379 
Bienen, B., Cassidy, M.J., Randolph, M.F. and Teh, K.L. (2010). Characterisation of undrained shear strength using statistical methods. 2nd International Symposium on Frontiers in Offshore Geotechnics, ISFOG 2010, 8-10 November, Perth, Australia, 661-666

Brinch Hansen J. (1970). A revised and extended formula for bearing capacity. Bulletin No. 98, pp 5-11. Copenhagen: Danish Geotechnical Institute

Broughton, P., Hayes, R., Wood, A., and Komaromy, S. (1997). Cast nodes for the Ekofisk 2/4J jacket. Proc. ICE, Structures and Buildings, 122(3) 266-280

BSI (2004). BS EN 1997-1: 2004 Eurocode 7: Geotechnical Design - Part 1: General rules. BSI, London

Butterfield, R. and Ticof, J. (1979). The use of physical models in design. Discussion, Proc. 7th ECSMFE, Brighton, 4, 259-261.

Byrne, B.W. (2000). Investigations of Suction Caissons in Dense Sand, D.Phil. Thesis, University of Oxford

Byrne, B.W. and Houlsby, G.T. (2003). Foundations for offshore wind turbines. Phil. Trans. the Royal Society of London, Series A, 361, 2909-2930

Byrne, B.W. and Houlsby, G.T. (2005). Investigating 6 degree-of-freedom loading on shallow foundations, Proc. Int. Symp. on Frontiers in Offshore Geotechnics, Perth, Australia, 1921 September, Taylor and Francis, 477-482

Byrne, B.W. and Houlsby, G.T. (2015). Helical piles: an innovative foundation design option for offshore wind turbines, Phil. Trans. Roy. Soc., 373, Issue 2035, February

Byrne, B.W., Houlsby, G.T. and Martin, C.M. (2002a) Cyclic loading of shallow offshore foundations on sand, Proc. Int. Conf on Physical Modelling in Geotechnics, St John's, Newfoundland, Canada, 10-12 July, 277-282

Byrne, B.W., Houlsby, G.T., Martin, C.M. and Fish, P. (2002b) Suction Caisson Foundations for Offshore Wind Turbines, Wind Engineering, 26(3), 145-155

Byrne, B.W., McAdam, R., Burd, H.J., Houlsby, G.T., Zdravković, L., Taborda, D.M.G., Potts, D.M., Jardine, R.J., Sideri, M., Schroeder, F.C., Martin, C.M., Gavin, K., Doherty, P., Igoe, D. Muir Wood, A., Kallehave, D. and Skov Gretlund, J. (2015a). New design methods for large diameter piles under lateral loading for offshore wind applications, 


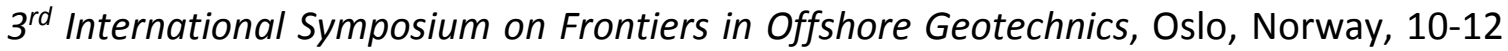
June, CRC Press, 705-710

Byrne, B.W., McAdam, R.A., Burd, H.J., Houlsby, G.T., Martin, C.M., Gavin, K., Doherty, P., Igoe, D., Zdravković, L., Taborda, D.M.G., Potts, D.M., Jardine, R.J., Sideri, M., Schroeder, F.C., Muir Wood, A., Kallehave, D. and Skov Gretlund, J. (2015b). Field testing of large diameter piles under lateral loading for offshore wind applications, $16^{\text {th }}$ European Conference on Soil Mechanics and Geotechnical Engineering, Edinburgh, 13-17 September, ICE Publishing, 3, 1255-1260

Cao, Z. and Wang, Y. (2013). Bayesian approach for probabilistic site characterization using cone penetration tests. Proc. ASCE, J. Geotech. Geoenviron. Eng., 139(2), 267-276.

Cassidy, M.J., Eatock Taylor R. and Houlsby, G.T. (2001) Analysis of jack-up units using a Constrained NewWave methodology, Applied Ocean Research, 23, pp 221-234

Cassidy, M.J., Martin, C.M. and Houlsby, G.T. (2004). Development and application of force resultant models describing jack-up foundation behaviour, Marine Structures, (special issue on Jack-up Platforms: Papers from 9th Int. Conf. on Jack-Up Platform Design, Construction and Operation, September 23-24, City University, London), 17(3-4), 165193

Cerato, A.B. and Victor, R. (2009). Effects of long term dynamic loading and fluctuating water table on helical anchor performance for small wind tower foundations. Proc. ASCE, Jour. of Perf. of Constr. Facilities, 23(4), 251-261

Davies, E.H. and Booker, J.R. (1973). The effect of increasing strength with depth on the bearing capacity of clays. Géotechnique, 23(6), 551-563

Dean, E.T.R., James, R.G., Schofield, A.N. and Tsukamoto, Y. (1998). Drum centrifuge study of three-leg jackup models in clay. Géotechnique, 48(6), 761-786

de Santa Maria, P.E.L. (1988). Behaviour of footings for offshore structures under combined loads. D.Phil. Thesis, University of Oxford

Doherty, J.P. and Deeks, A.J. (2003). Elastic response of circular footings embedded in a non-homogeneous half-space, Géotechnique 53(8), 703-712 
Doherty, J.P., Houlsby, G.T. and Deeks, A.J. (2005) Stiffness of Flexible caisson Foundations Embedded in Nonhomogeneous Elastic Soil, Proc. ASCE, Jour. Geotech. and Geoenvironmental Eng., 131(12), 1498-1508

DTI (2004). Atlas of UK marine renewable energy resources. Technical report no. R.1106, Department of Trade and Industry

Ghaly, A.M., Hanna, A. and Hanna, M. (1991). Installation Torque of Screw Anchors in Dry Sand, Soils and Foundations, 31(2), 77-92

Gordon, A.D., Henzinger, T.A., Nori, A.V. and Rajamani, S.K. (2014) Probabilistic programming, in Proceedings of the on Future of Software Engineering, ACM, 167-181

Gottardi, G., Houlsby, G.T. and Butterfield, R. (1999). The plastic response of circular footings on sand under general planar loading. Géotechnique, 49(4), 453-470

Hossain, M.S. Hu, Y., Randolph, M.F. and White, D.J. (2005). Limiting cavity depth for spudcan foundations penetrating clay. Géotechnique, 55(9), 679-690

Houlsby, G.T. (2010). A probabilistic approach to the prediction of spudcan penetration of jack-up units. 2nd International Symposium on Frontiers in Offshore Geotechnics, ISFOG 2010, 8-10 November, Perth, Australia, 673-678

Houlsby, G.T. and Byrne, B.W. (2005a). Design procedures for installation of suction caissons in clay and other materials, Proc. ICE, Geotechnical Engineering, 158(GE2), April, 75-82. doi:10.1680/geng.158.2.75.61630

Houlsby, G.T. and Byrne, B.W. (2005b). Design procedures for installation of suction caissons in sand, Proc. ICE, Geotechnical Engineering, 158(GE3), 135-144. doi:10.1680/geng.158.3.135.66297

Houlsby, G.T. and Cassidy, M.J. (2002). A plasticity model for the behaviour of footings on sand under combined loading, Géotechnique, 52(2), 117-129. doi:10.1680/geot.52.2.117.40922

Houlsby, G.T., Kelly, R.B., Huxtable, J. and Byrne, B.W. (2006). Field trials of suction caissons in sand for offshore wind turbine foundations. Géotechnique, 56(1), 3-10

Houlsby, G.T and Martin, C.M. (2003). Undrained bearing capacity factors for conical footings on clay. Géotechnique, 53(5), 513-520 
Houlsby, G.T. and Wroth, C.P. (1982). Direct solution of plasticity problems in soils by the method of characteristics. Invited Keynote Paper, Proc. 4th Int. Conf. on Numerical Methods in Geomechanics, 3, Edmonton, June, 1059-1071

Houlsby, N.M.T. and Houlsby, G.T. (2013). Statistical fitting of undrained strength data. Géotechnique, 63(14), 1253-1263

IEA (2013). "IEA Wind: 2012 Annual Report"

Kallehave, D., Thilsted, C.L. and Troya, A. (2016). Observed variations of monopile foundation stiffness, $3^{\text {rd }}$ International Symposium on Frontiers in Offshore Geotechnics, Oslo, Norway, 10-12 June, CRC Press, 717-722

Kelly, R.B., Houlsby, G.T. and Byrne, B.W. (2006a). A comparison of field and laboratory tests of caisson foundations in sand and clay. Géotechnique, 56(9), 617-626

Kelly, R.B., Houlsby, G.T. and Byrne, B.W. (2006b). Transient vertical loading of model suction caissons in a pressure chamber. Géotechnique, 56(10), 665-675

King, D., Browne, J., Layard., R., O’Donnell, G., Rees, M., Stern, N. and Turner, A. (2015). Global Apollo programme to combat climate change, London School of Economics http://www.globalapolloprogram.org/

LeBlanc, C., Houlsby, G.T. and Byrne, B.W. (2010a). Response of stiff piles in sand to longterm cyclic lateral loading. Géotechnique, 60(2), 79-90

LeBlanc, C., Byrne, B.W. and Houlsby, G.T. (2010b). Response of stiff piles to random twoway lateral loading. Géotechnique, 60(9), 715-721

Livneh, B. and El Naggar, M.H. (2008). Axial Testing and Numerical Modelling of Square Shaft Helical Piles under Compressive and Tensile Loading, Canadian Geotechnical Journal, 45, 1142-1155

Marchi, M. (2008). Stability and strength analysis of leaning towers, PhD thesis, Università di Parma, Italy

Marchi, M., Butterfield, R. Gottardi, G. and Lancellotta, R. (2011). Stability and strength analysis of leaning towers, Géotechnique, 61(12), 1069-1080 
Martin, C.M. (1994). Physical and Numerical Modelling of Offshore Foundations under Combined Loads. D.Phil. Thesis, University of Oxford

Martin, C.M. and Houlsby, G.T. (2001). Combined loading of spudcan foundations on clay: numerical modelling, Géotechnique, 51(8), 687-700. doi:10.1680/geot.51.8.687.40470

McCarron, W.O. and Broussard, M.D. (1992). Measured Jack-up Response and SpudcanSeafloor Interaction for an Extreme Storm Event, Proc. $6^{\text {th }}$ Int. Conf. on Behaviour of Offshore Structures, BOSS 92, 349-361

Merifield, R.S. (2011) Ultimate uplift capacity of multiple helical type anchors in clay, Proc. ASCE, Jour. Geotech and Geoenvironmental Eng., 137(7), 704-716

Mitchell, A. (1848). On Submarine Foundations, Proc. ICE, 5-61

Ngo-Tran, C.L. (1996). The analysis of offshore foundations subjected to combined loading. D.Phil. Thesis, University of Oxford

Nguyen-Sy, L. (2005) The Theoretical Modelling of Circular Shallow Foundation for Offshore Wind Turbines, D.Phil. Thesis, University of Oxford

Nguyen-Sy, L. and Houlsby, G.T. (2005) The theoretical modelling of a suction caisson foundation using hyperplasticity theory, Int. Symp. on Frontiers in Offshore Geotechnics, Perth, Australia, 19-21 September, Taylor and Francis, 417-422

Nova, R. and Montrasio, L. (1991). Settlements of shallow foundations on sand. Géotechnique, 41(2), 243-256.

Osborne, J.J., Teh, K.L., Houlsby, G.T., Cassidy, M.J., Bienen, B. and Leung, C.F. (2011). Improved guidelines for the prediction of geotechnical performance of spudcan foundations during installation and removal of jack-up units, Report of InSafeJIP Joint Industry Study (multiple sponsors), RPS Energy

Peck, R.B. (1969). Advantages and limitations of the observational method applied in soil mechanics, Géotechnique, 19(2), 171-187

Perko, H.A. (2009). Helical piles: a practical guide to design and installation, Wiley

Pisanò, F., di Prisco, C.G. and lancellotta, R. (2014). Soil-foundation modelling in laterally loaded historical towers, Géotechnique, 64(1), 1-15

Poulos, H.G. (1988). Marine Geotechnics, London: Unwin Hyman 
Rao, S.N., Prasad, T.V.S.N. and Shetty, M.D. (1991). The Behaviour of Model Screw Piles in Cohesive Soils, Soils and Foundations, 31(2), 35-50

Roscoe, K.H. and Schofield, A.N. (1957). The stability of short pier foundations in sand. Discussion, British Welding Journal, January, 12-19.

Sakr, M. (2009). Performance of Helical Piles in Oil Sand, Canadian Geotechnical Journal, 46, 1046-1061

Sakr, M. (2011). Installation and performance characteristics of high capacity helical piles in cohesionless soils, Deep Foundations Institute Journal, 5(1), 39-57

Salençon, J. and Matar, M (1982). Bearing capacity of axially symmetrical shallow foundations. Jour. de Mécanique Théorique et Appliquée, 1(20), 237-267

Simpson, B. (1992). Retaining structures: displacement and design, Géotechnique, 42(4), 539-576

Szczepinski, W. (1974). Stany graniczne i kinematyka ośrodków sypkich (in Polish), Państwowe Wydawnictwo Nakowe, Warsaw

Tan, F.S.C. (1990). Centrifuge and theoretical modelling of conical footings on sand, Ph.D. thesis, Cambridge University

Taylor, P.H., Jonathan, P. and Harland, L.A. (1995). Time domain simulation of jack-up dynamics with the extremes of a Gaussian process. 14th Int. Conf. on Offshore Mechanic and Arctic Engineering (OMAE), 1-A, 313-319

Tromans, P.S., Anaturk, A.R. and Hagemeijer, P. (1991). A new model for the kinematics of large ocean waves -applications as a design wave. Proc. 1st Int. Offshore and Polar Eng. Conf., Edinburgh, 3, 64-71.

Tsuha, C.H.C., Aoki, N., Rault, G., Thorel, L. and Garnier, J. (2010). Physical modelling of Helical Screw Piles in Sand, Physical Modelling in Geotechnics, 841-846

Vesic, A.S. (1975). Bearing capacity of shallow foundations. In Foundation engineering handbook (eds H.F. Winterkorn and H.Y. Fang), 121-147. New York: Van Nostrand Reinhold

Villalobos, F., Byrne, B.W. and Houlsby, G.T. (2009) An Experimental Study of the Drained Capacity of Suction Caisson Foundations under Monotonic Loading for Offshore Applications, Soils and Foundations, 49(3), 477-488 
Villalobos, F. Byrne, B.W and Houlsby, G.T. (2010) "Model testing of suction caissons in clay subjected to vertical loading, Applied Ocean Research, 32(4), 414-424

Wang, Y., Huang, K. and Cao, Z. (2014). Bayesian identification of soil strata in London Clay, Géotechnique, 64(3), 239-246

Willow, C. and Valpy, B. (2011) Offshore Wind: Forecasts of Future Costs and benefits, Report to renewableUK, BVG Associates

Wood, F., van de Meent, J.W. and Mansinghka, V. (2014) A New Approach to Probabilistic Programming Inference, Proc. 17th Int. Conf. on Artificial Intelligence and Statistics, 1024-1032

Young, A.G., Remmes, B.D. and Meyer, B.J. (1984). Foundation performance of offshore jack-up drilling rigs, Jour. of Geotechnical Eng. ASCE, 110(7), 841-859

(21,169 words; main text 17,579$)$ 


\section{Tables}

Table 1: Decision table based on absolute position and trend of measured data on spudcan penetrations compared to percentile predictions (from Houlsby, 2010)

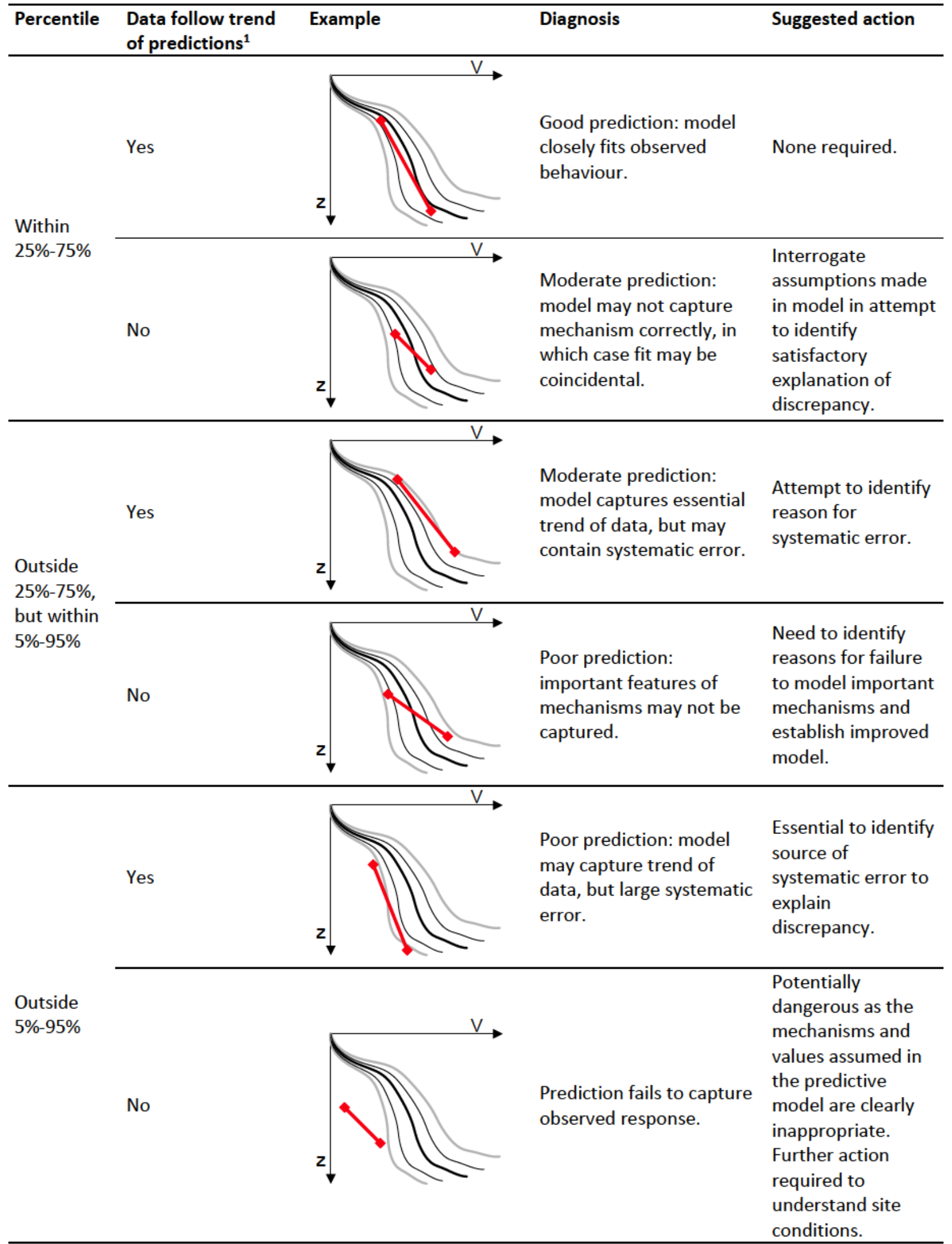

${ }^{1}$ Note: if only one measured point then no assumption about trend of data can be made. 


\begin{tabular}{lcccccccccc}
\hline $\begin{array}{l}\text { Embed- } \\
\text { ment }\end{array}$ & $\begin{array}{c}\text { Cone } \\
\text { angle }\end{array}$ & $K_{1}$ & \multicolumn{3}{c}{$K_{2}$} & \multicolumn{3}{c}{$K_{3}$} \\
\cline { 3 - 10 } & $\beta$ & $v=0.2$ & $v=0.49$ & $v=0.2$ & $v=0.49$ & $v=0.2$ & $v=0.49$ & $v=0.2$ & $v=0.49$ \\
\hline & $180^{\circ}$ & 5.4058 & 8.1971 & 4.6517 & 5.5541 & 3.8161 & 5.5627 & -0.5734 & -0.0148 \\
\hline$z_{D} / R=0.0$ & $150^{\circ}$ & 5.5643 & 8.2998 & 4.9739 & 5.9450 & 4.0661 & 5.7684 & -0.7589 & -0.0737 \\
& $120^{\circ}$ & 5.7790 & 8.3429 & 5.4976 & 6.6326 & 4.6563 & 6.0640 & -1.1966 & -0.4862 \\
\hline$z_{D} / R=0.5$ & $180^{\circ}$ & 5.9509 & 8.8098 & 6.1173 & 7.2258 & 4.5860 & 6.5826 & -0.8425 & -0.4020 \\
& $150^{\circ}$ & 6.0893 & 8.8102 & 6.4086 & 7.5634 & 4.8308 & 6.5728 & -1.0197 & -0.4504 \\
& $120^{\circ}$ & 6.2850 & 8.8438 & 6.8879 & 8.1766 & 5.4227 & 6.8440 & -1.4398 & -0.8166 \\
\hline$z_{D} / R=1$ & $180^{\circ}$ & 6.4950 & 9.2537 & 6.4992 & 7.5899 & 5.0156 & 7.1627 & -0.9360 & -0.5691 \\
& $150^{\circ}$ & 6.6361 & 9.2510 & 6.8183 & 7.9544 & 5.2733 & 7.1301 & -1.1228 & -0.6086 \\
& $120^{\circ}$ & 6.8383 & 9.2830 & 7.3376 & 8.6101 & 5.8902 & 7.3744 & -1.5638 & -0.9762 \\
\hline$z_{D} / R=2$ & $180^{\circ}$ & 7.0817 & 9.9857 & 6.7742 & 7.7012 & 5.1903 & 7.6739 & -0.9786 & -0.7327 \\
& $150^{\circ}$ & 7.2633 & 10.0702 & 7.1262 & 8.1210 & 5.5033 & 7.8269 & -1.1645 & -0.7070 \\
& $120^{\circ}$ & 7.4950 & 9.9811 & 7.6962 & 9.1741 & 6.1621 & 7.8945 & -1.6233 & -1.0750 \\
\hline
\end{tabular}

Table 3: Status of offshore installed wind capacity at end of 2012 (data from IEA, 2013)

Total installed capacity Offshore installed

Country (MW) capacity (MW)

$\begin{array}{lrrr}\text { China } & 91413 & 428 & 6 \% \\ \text { US } & 61110 & 0 & \\ \text { Germany } & 34660 & 903 & 14 \% \\ \text { Spain } & 22959 & 0 & \\ \text { India } & 20150 & 0 & \\ \text { UK } & 10861 & 3653 & 55 \% \\ \text { Italy } & 8554 & 0 & \\ \text { France } & 8254 & 0 & \\ \text { Canada } & 7803 & 0 & \\ \text { Denmark } & 4808 & 1271 & 19 \%\end{array}$

...rest of world

47533 335 $5 \%$

Total

318105

$6590 \quad 100 \%$ 
Table 4: Onshore and model data for helical piles: geometric means of measured dimensionless parameters

\begin{tabular}{|c|c|c|c|c|c|c|}
\hline Source & Test type & Soil & $\begin{array}{c}\text { No. of } \\
\text { tests }\end{array}$ & $V D_{p} / T$ & $V_{t} D_{p} / T$ & $V_{t} / V$ \\
\hline Ghaly et al. (1991) & Laboratory & Sand & 40 & & 4.33 & \\
\hline Rao et al. (1991) & Laboratory & Soft Clay & 17 & & & 0.71 \\
\hline Tsuha et al. (2010) & Centrifuge & Sand & 18 & & 8.09 & \\
\hline Livneh and El Naggar (2008) & Field & Silt & $\begin{array}{c}8 \\
11\end{array}$ & 12.33 & 7.96 & $0.65^{*}$ \\
\hline Sakr (2011) & Field & Sand & $\begin{array}{l}7 \\
4\end{array}$ & 6.61 & 5.50 & $0.83^{*}$ \\
\hline Sakr (2009) & Field & Oil Sand & $\begin{array}{l}2 \\
3\end{array}$ & 9.58 & 5.20 & $0.54^{*}$ \\
\hline Cerato and Victor (2009) & Field & Layered & 8 & & 11.15 & \\
\hline Perko (2009) & Various & Various & $\begin{array}{c}117 \\
86\end{array}$ & 8.09 & 7.41 & $0.92^{*}$ \\
\hline Weighted geometric mean & & & $\begin{array}{l}134 \\
170\end{array}$ & 8.23 & 6.66 & 0.85 \\
\hline
\end{tabular}

*implied 


\section{Figures}

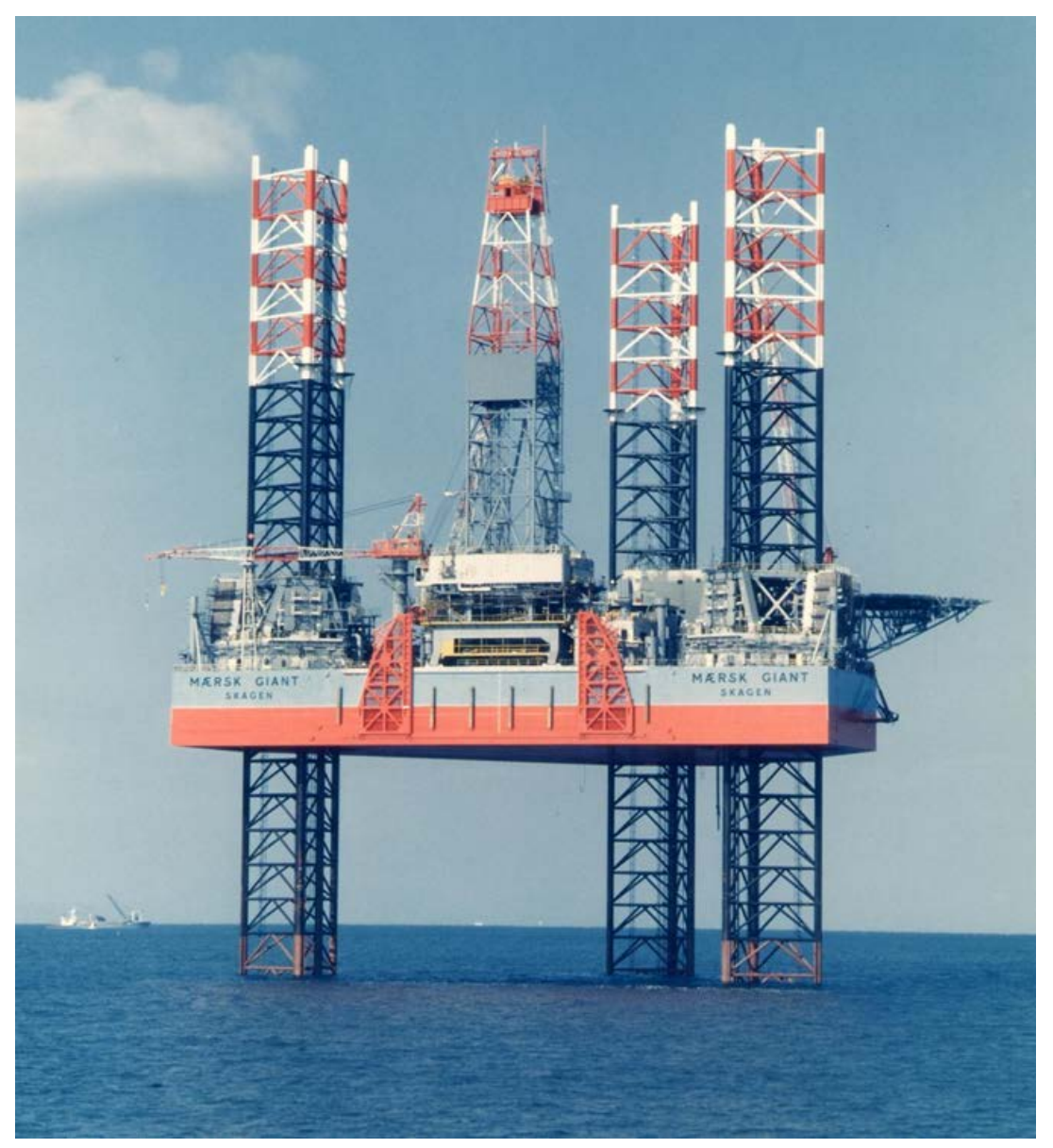

Figure 1: A typical large mobile jack-up unit

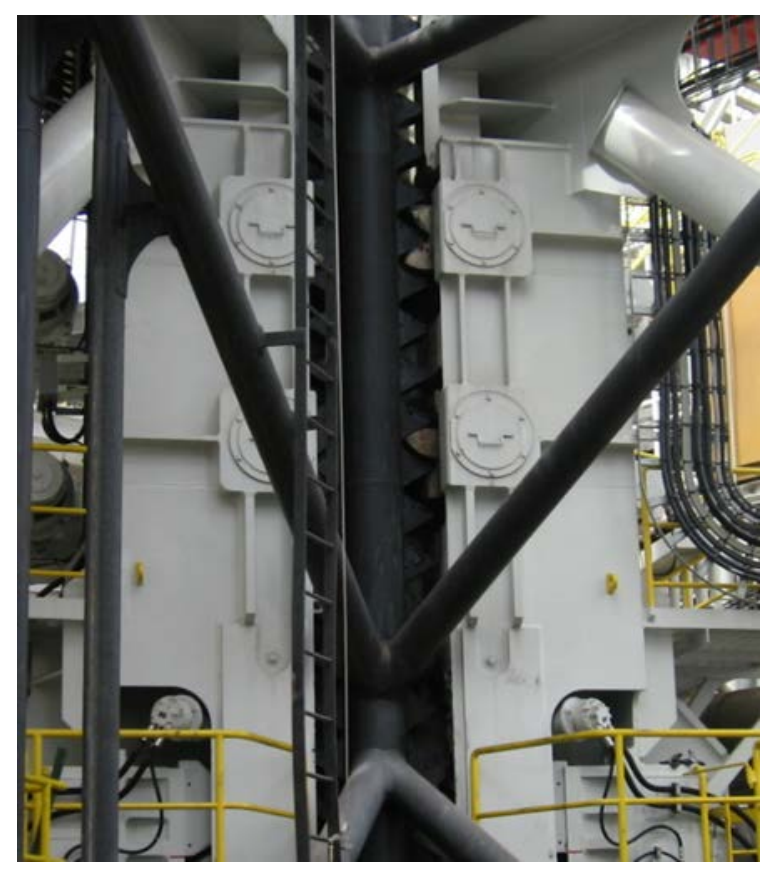

Figure 2: Rack-and-pinion jacking units (photo: Keppel FELS) 

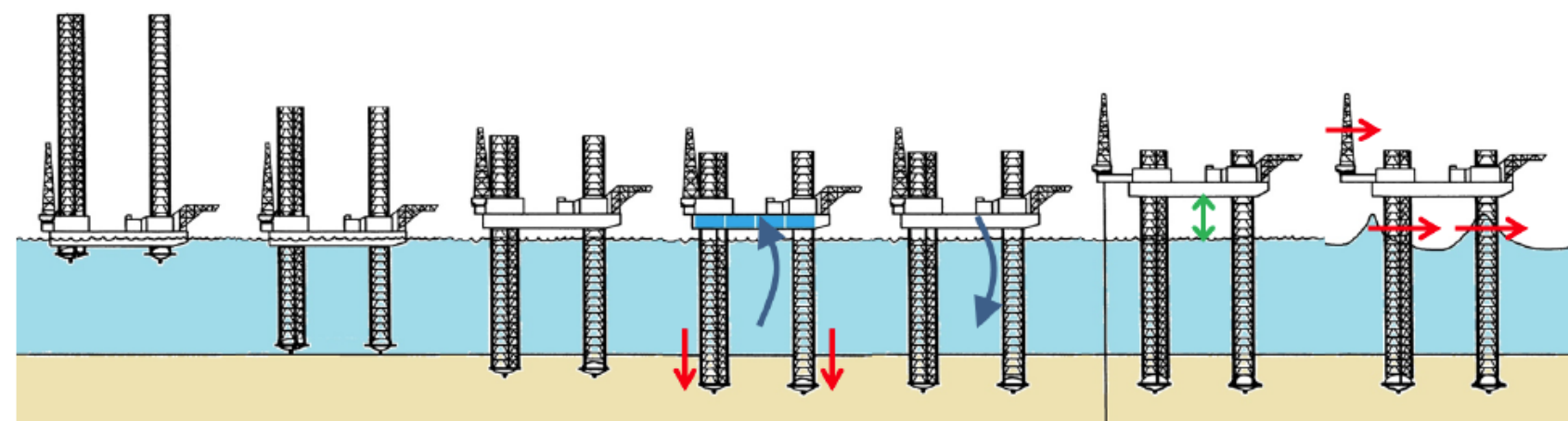

(a)

(b)

(c)

(d)

(e)

(f)

(g)

Figure 3: Stages in the installation and operation of a jack-up unit (a) float to site, (b) lower legs, (c) light ship load, (d) preload), (e) dump preload, (f) climb to air gap and operate, (g) storm. (adapted from Poulos, 1988)

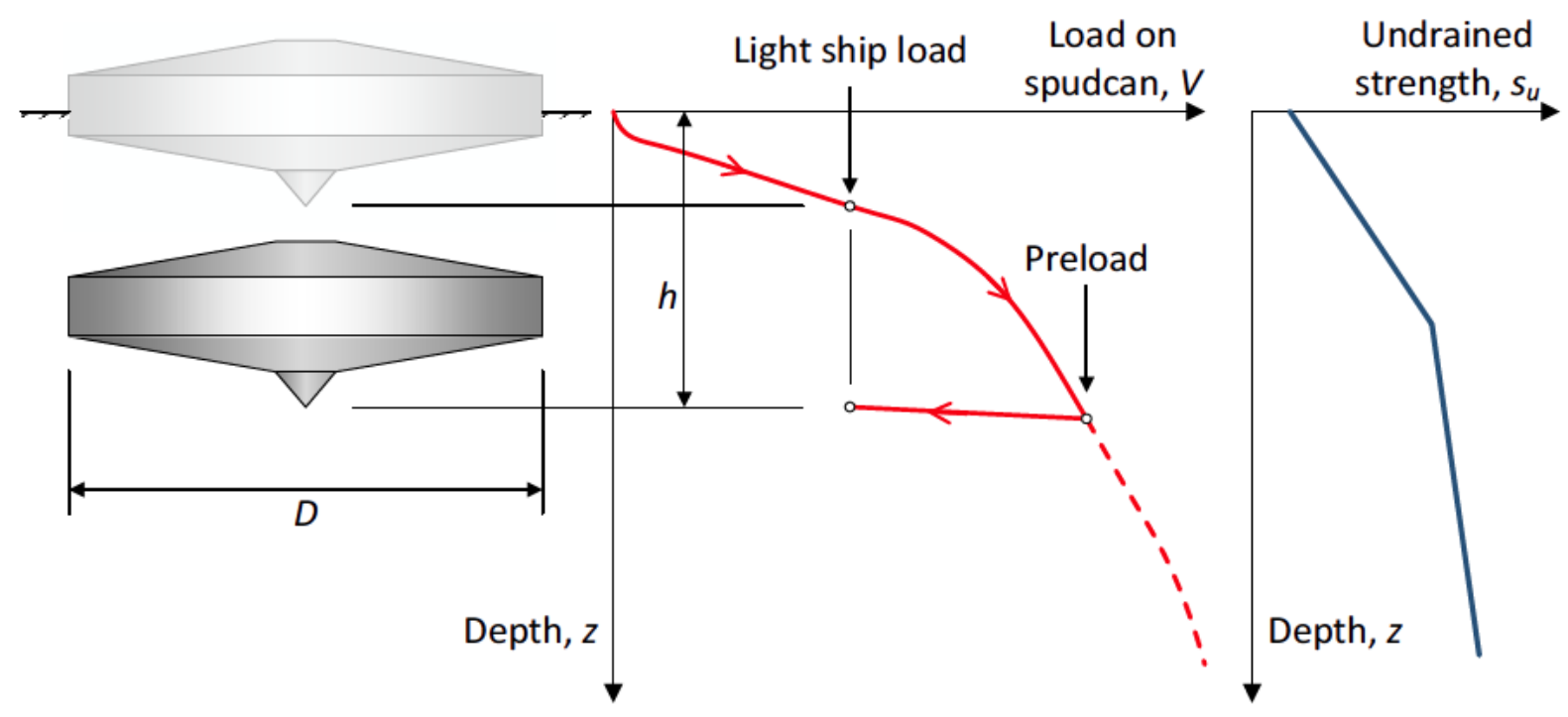

Figure 4: Idealised load-penetration curve for a spudcan footing 


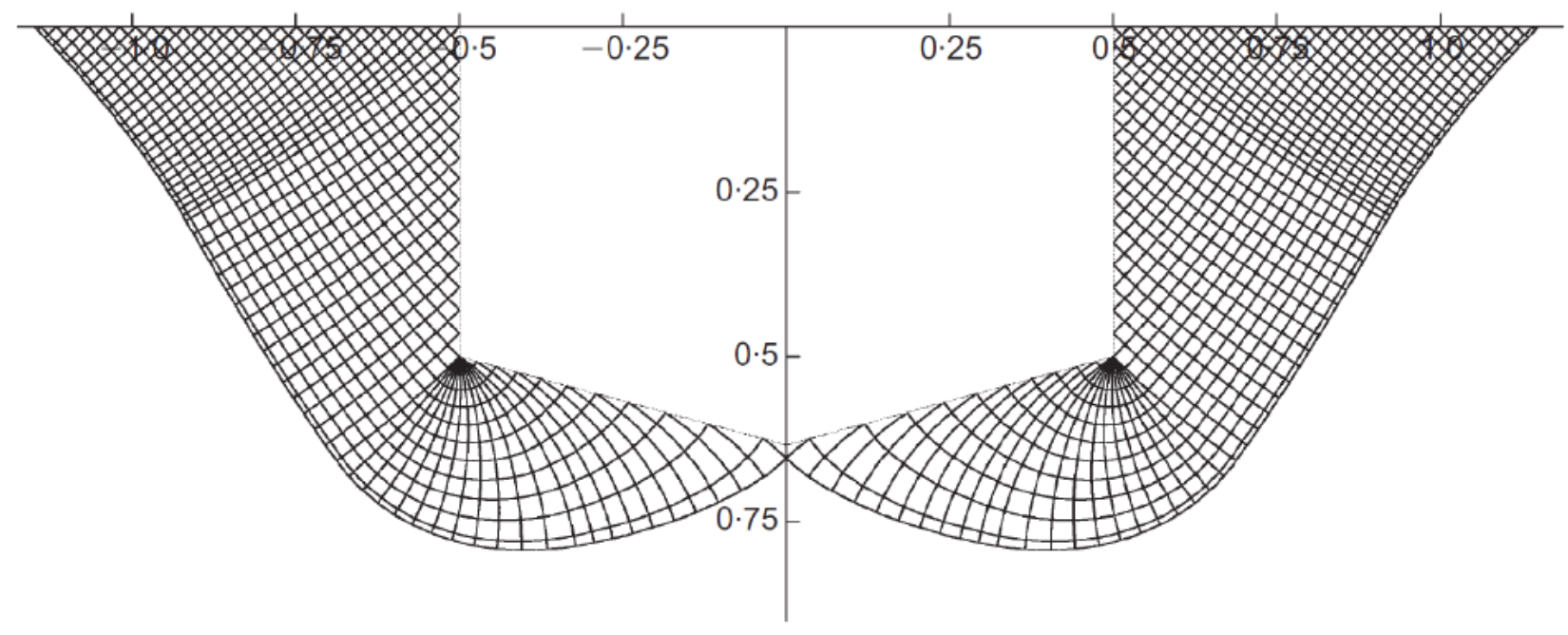

(Figure 2 from Houlsby and Martin, 2003)

Figure 5: Characteristic lines for lower bound solution for an embedded conical footing (from Houlsby and Martin, 2003)
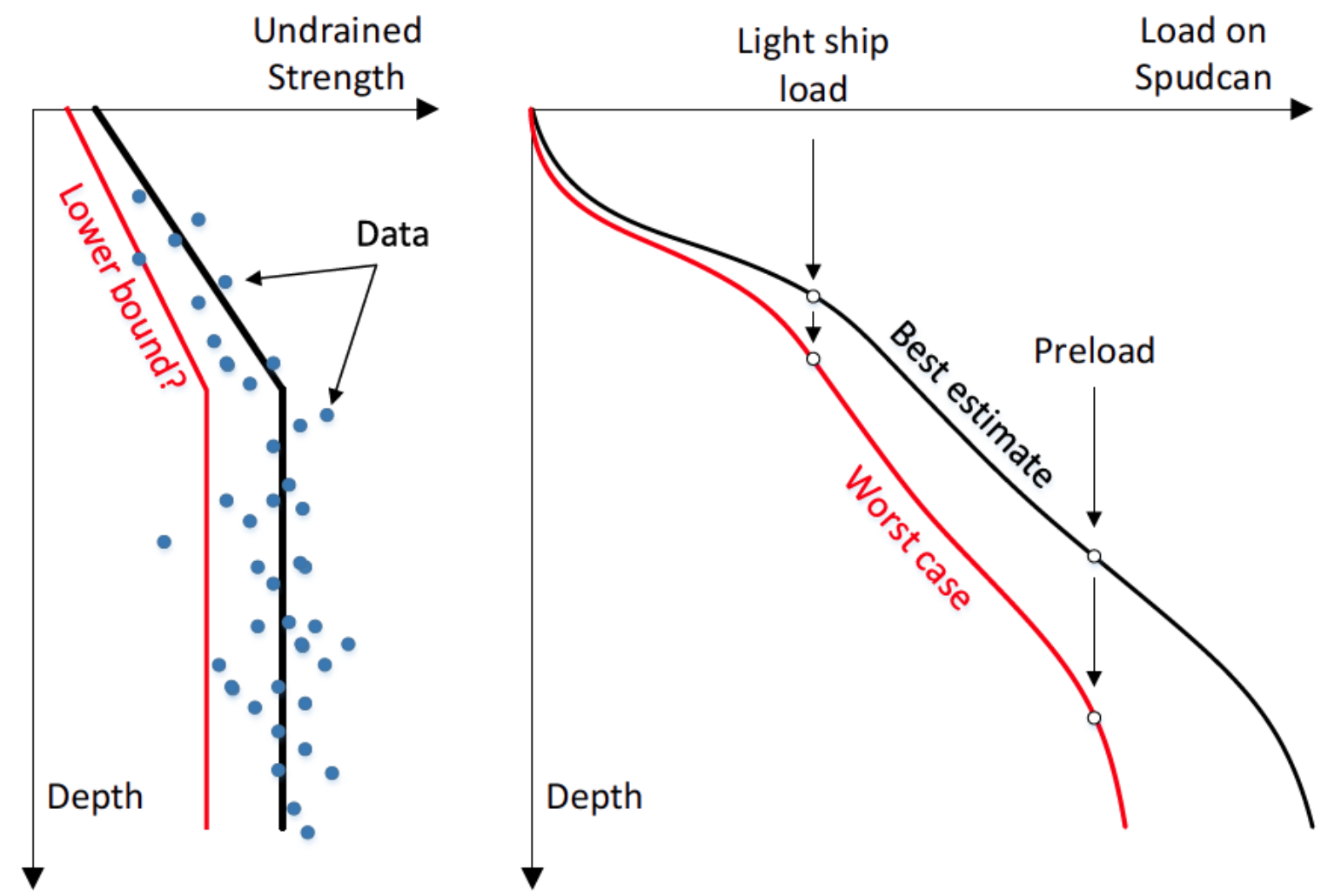

Figure 6: Most probable and worst case penetration curves for a spudcan 


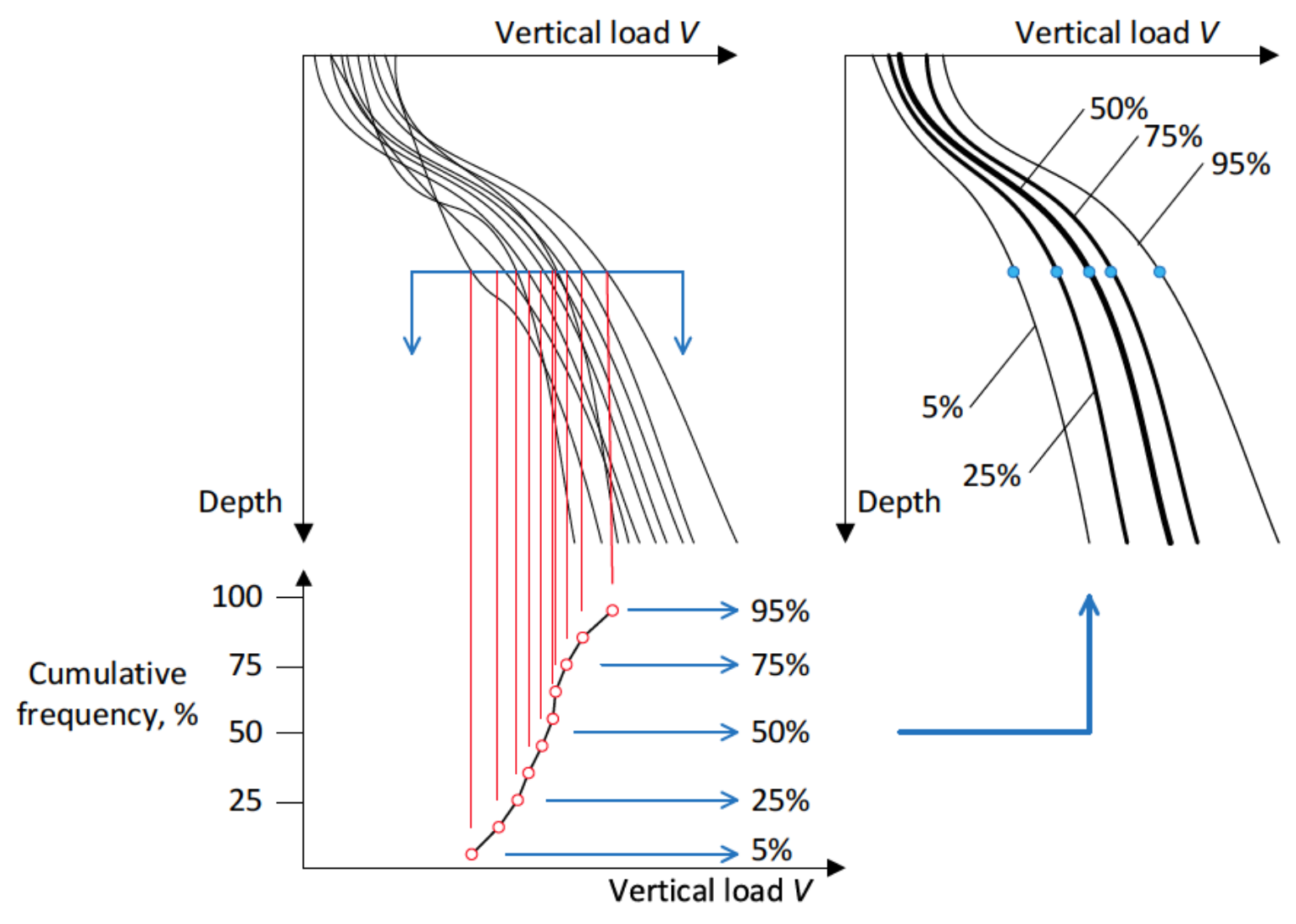

Figure 7: Monte Carlo simulations and their interpretation 


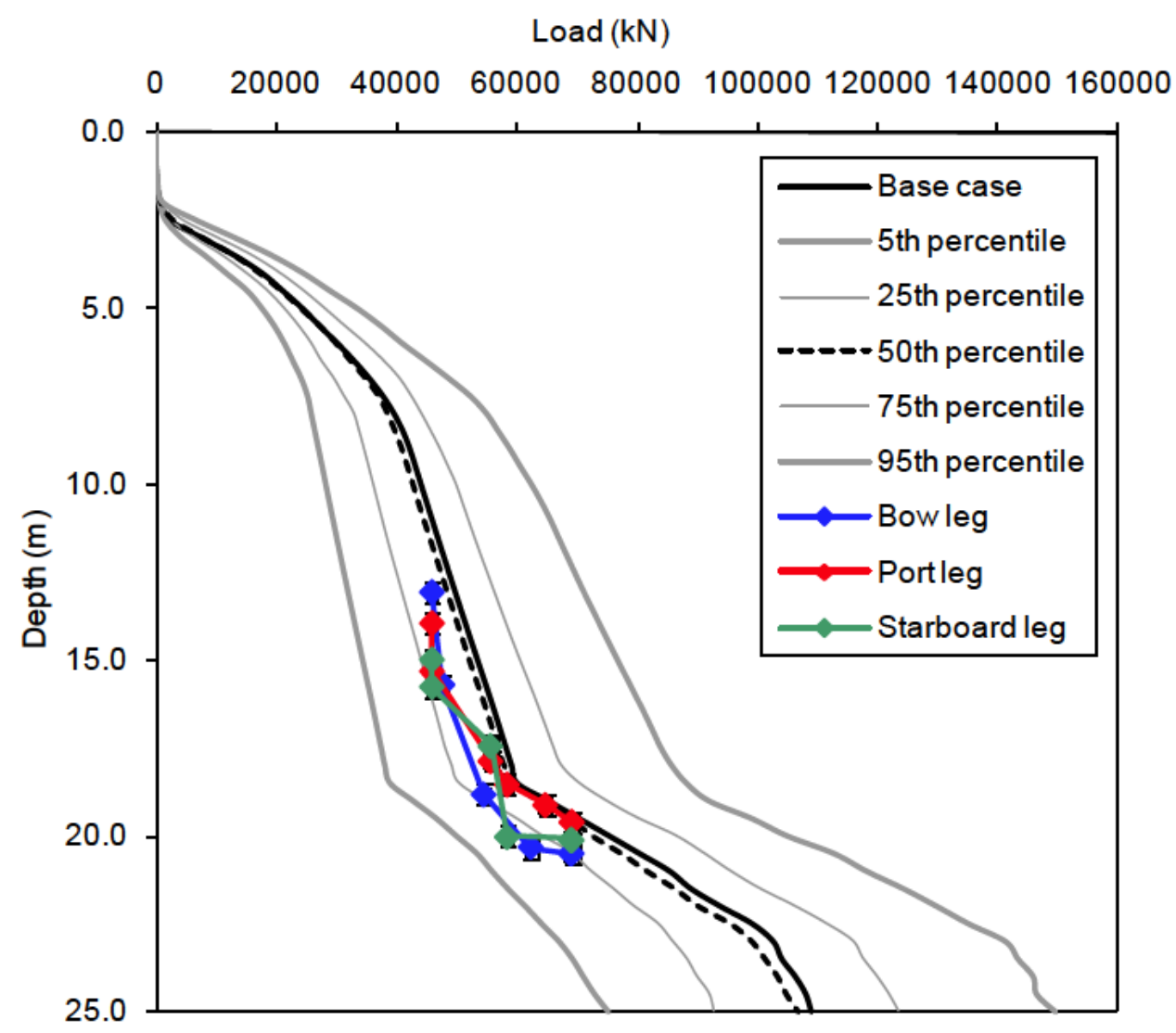

Figure 8: Case record A from the InSafeJIP database 


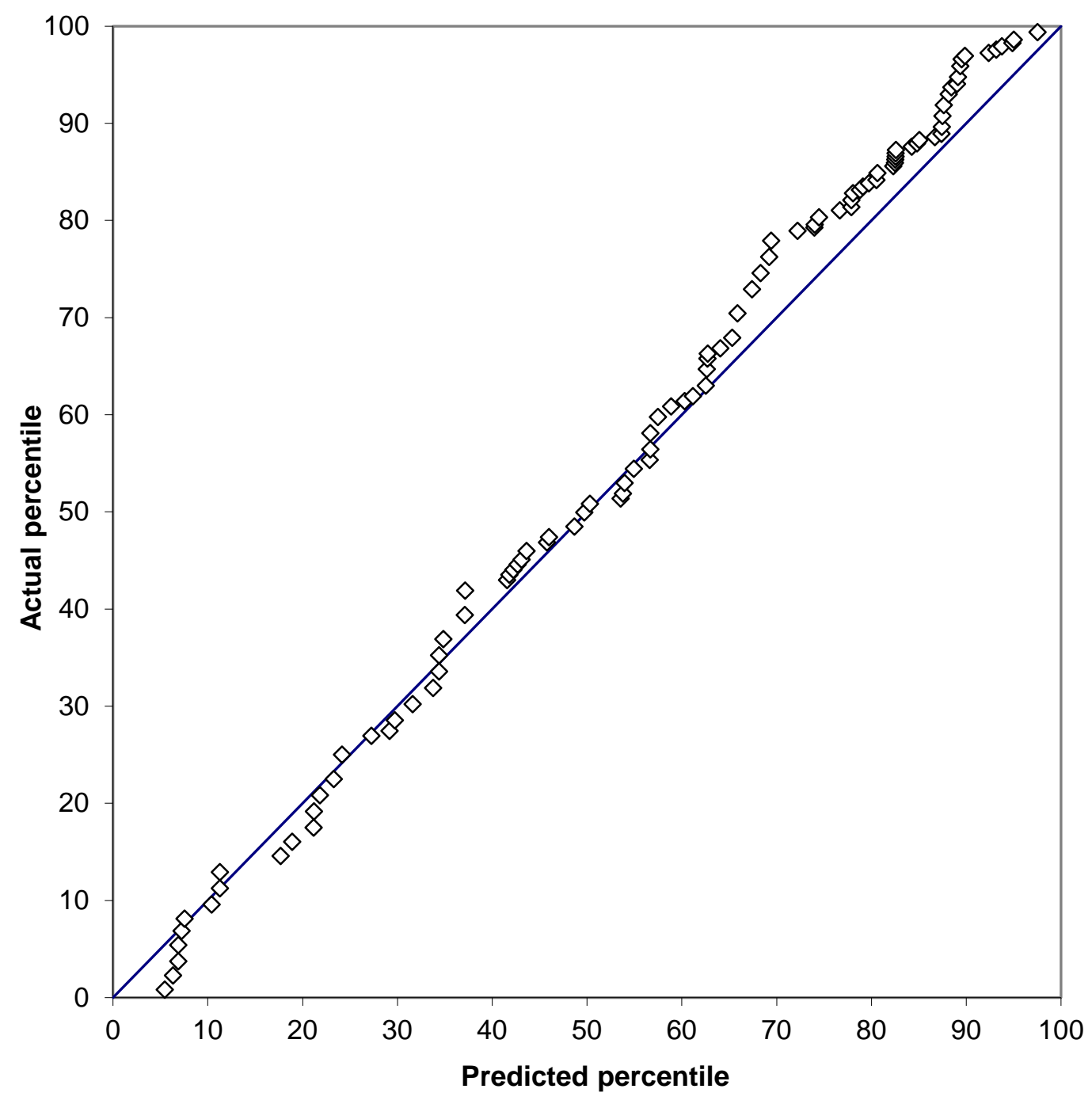

Figure 9: Actual and predicted percentile positions of calculated spudcan loads 


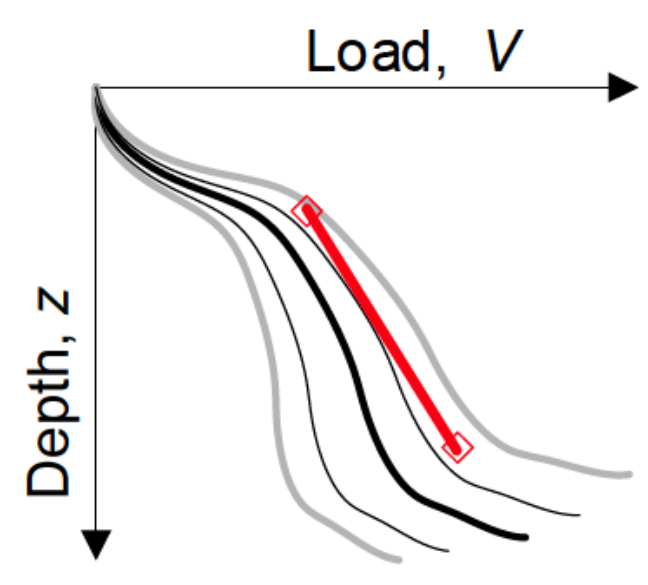

(a)

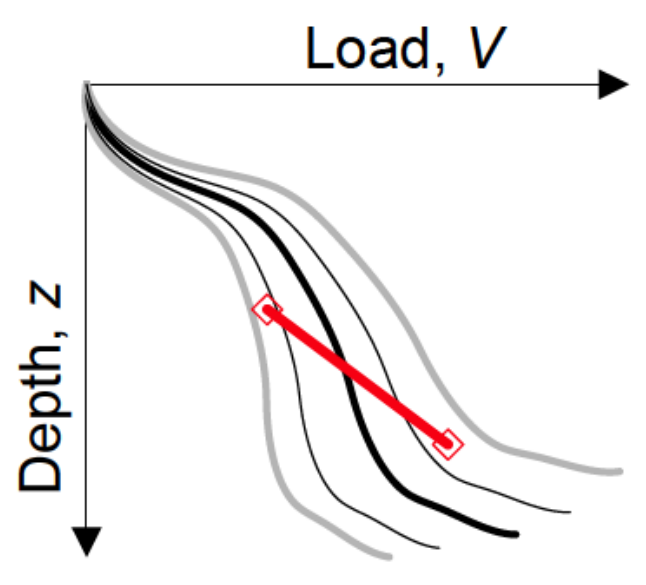

(b)

Figure 10: Schematic diagrams for observations near limits of distribution with (a) trend correct and (b) trend incorrect (adapted from Houlsby, 2010)

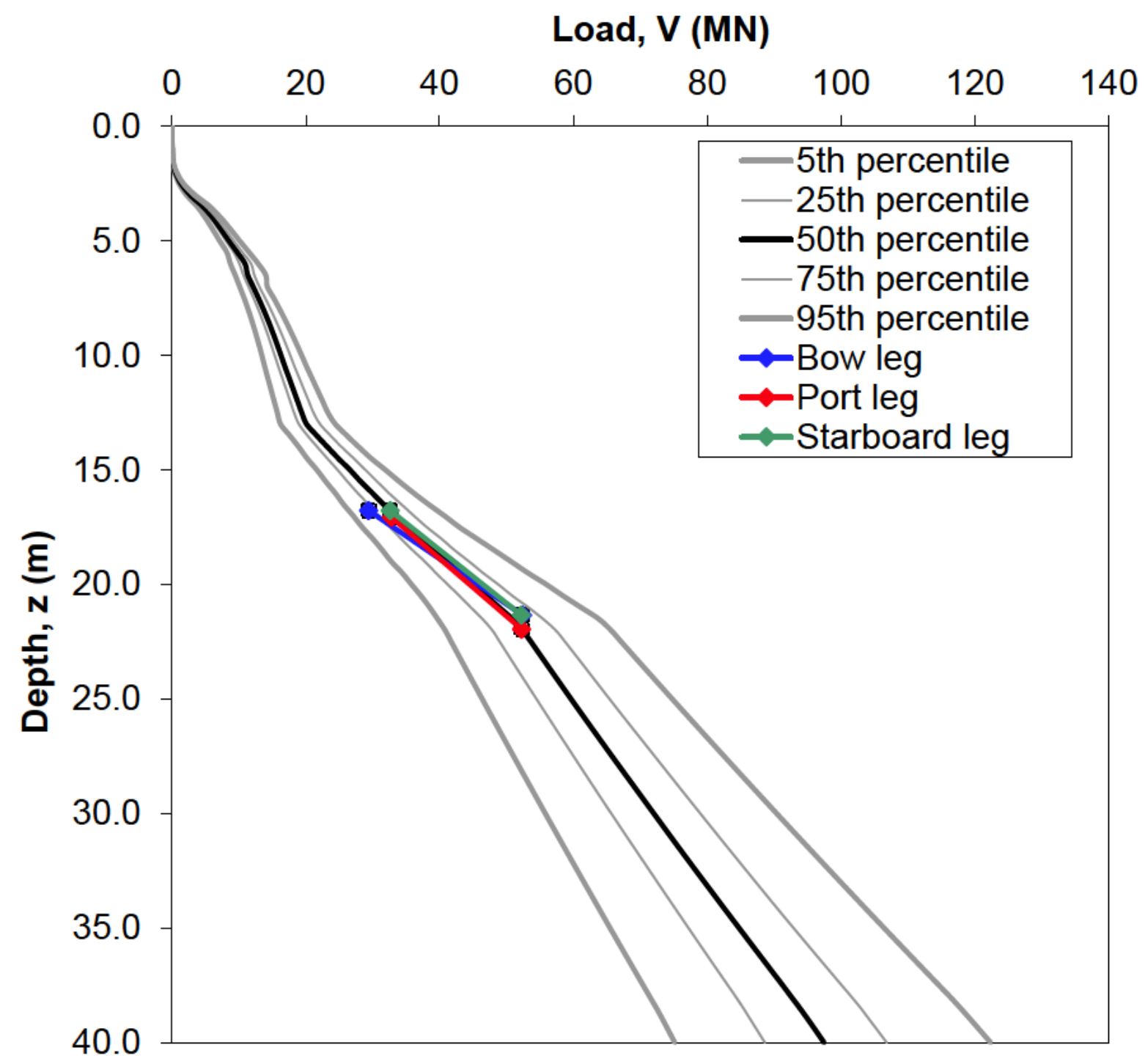

Figure 11: Case record B from the InSafeJIP database 


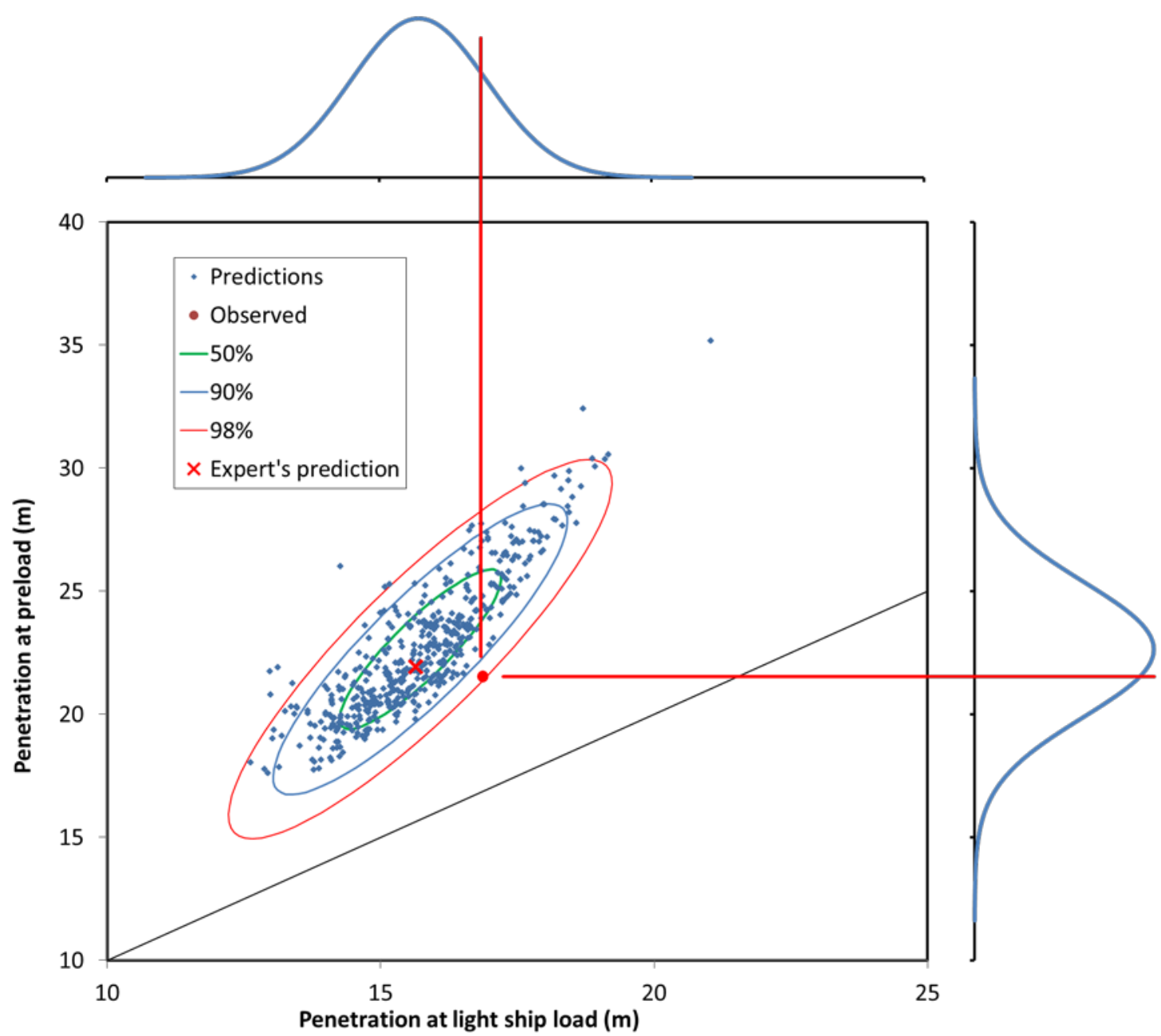

Figure 12: Joint distribution for penetrations at light ship load and preload for InSafeJIP case record B 


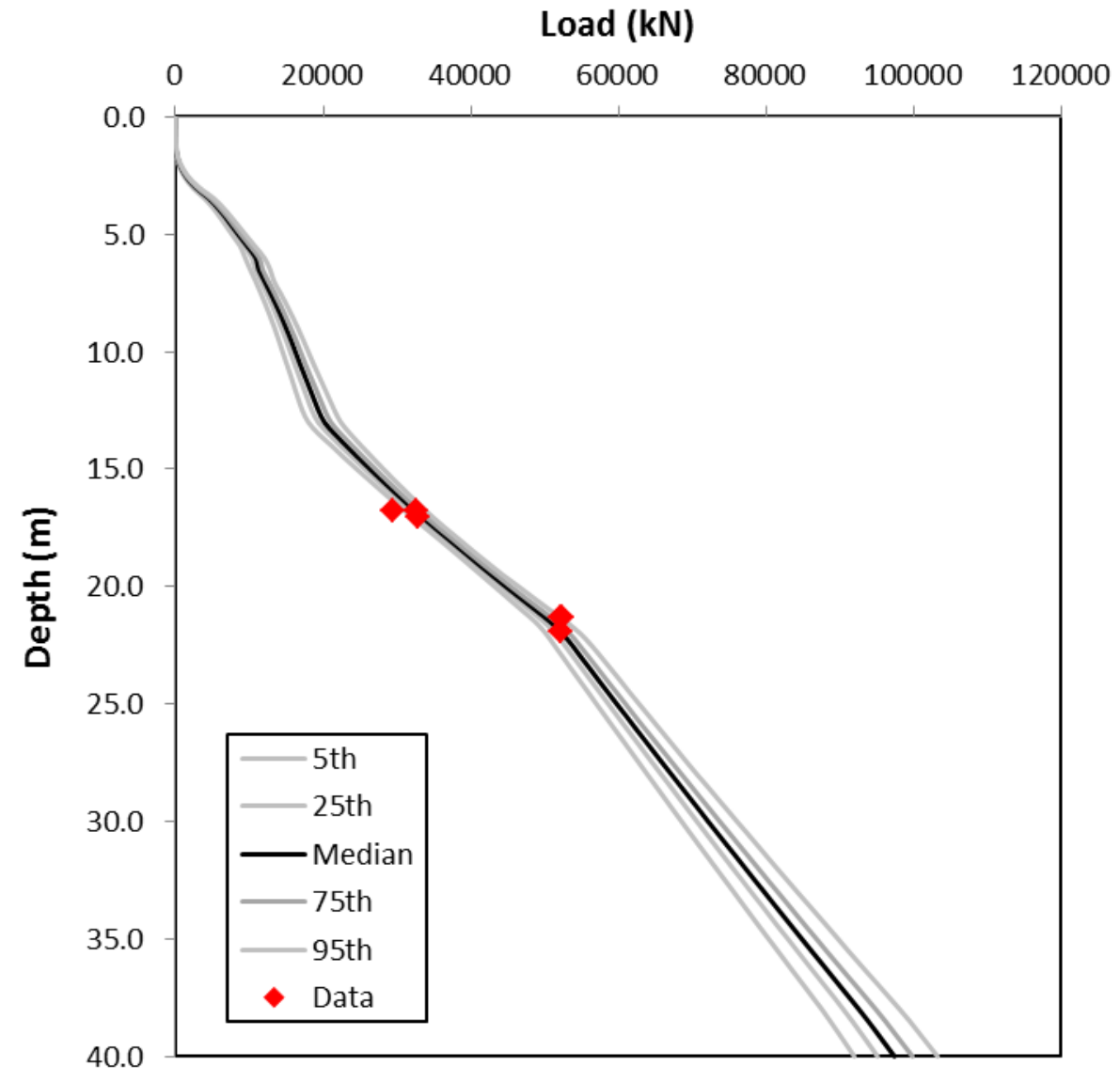

Figure 13: Posterior distribution for load-penetration curves using probabilistic programming approach 


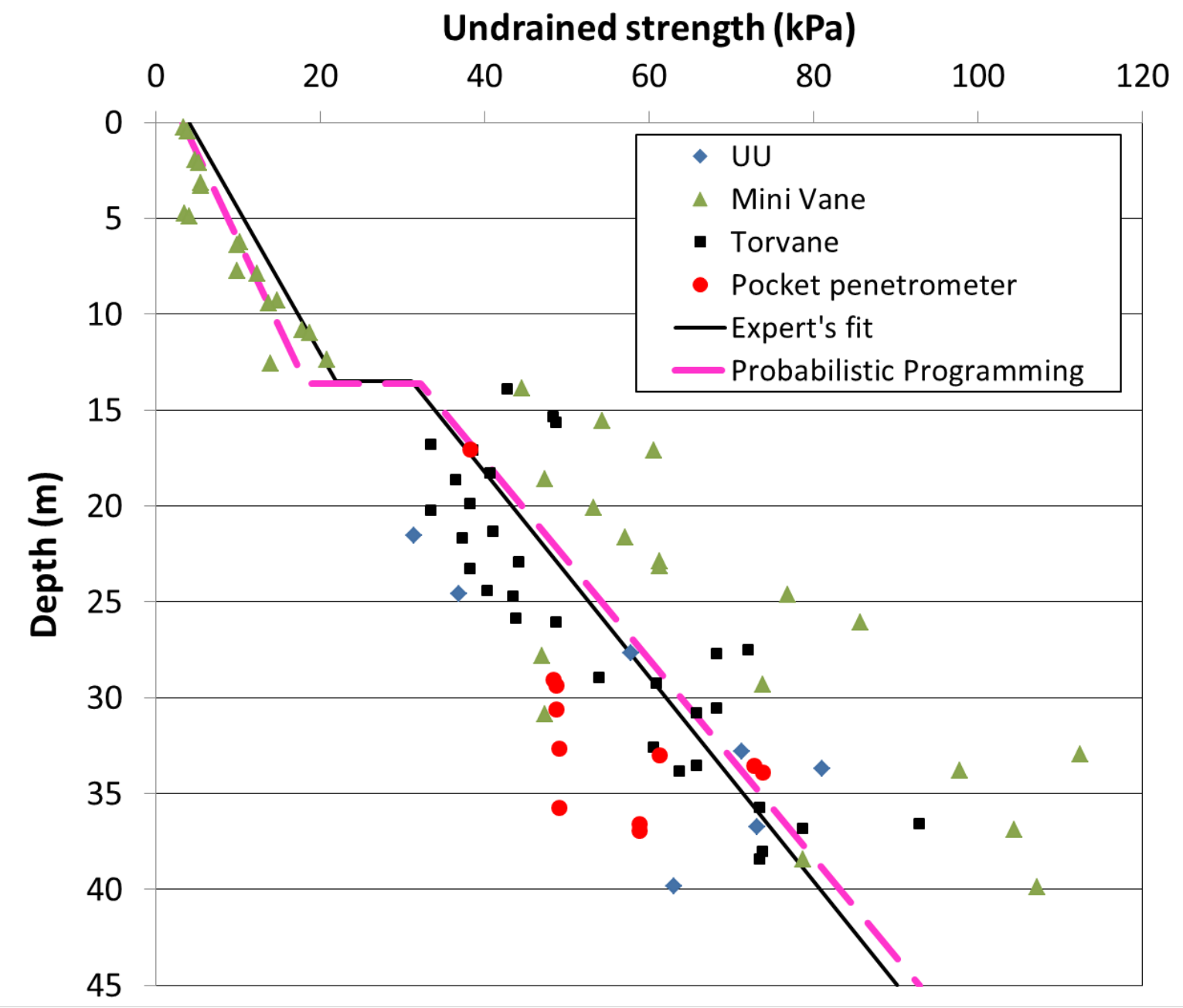

Figure 14: Strength data for InSafeJIP case record B 


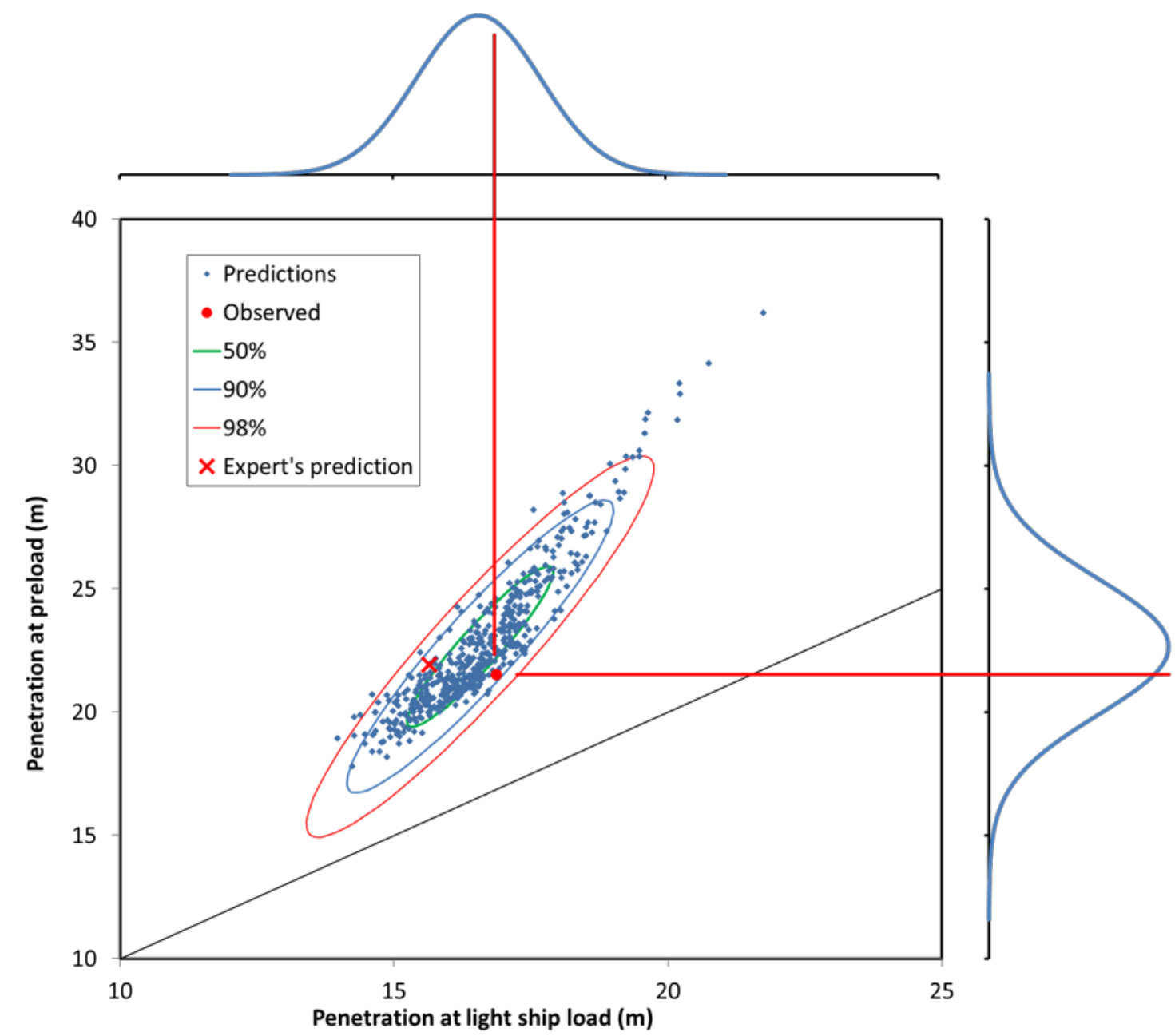

Figure 15: Joint distribution for penetrations at light ship load and preload for InSafeJIP case record B: modified strength profile 


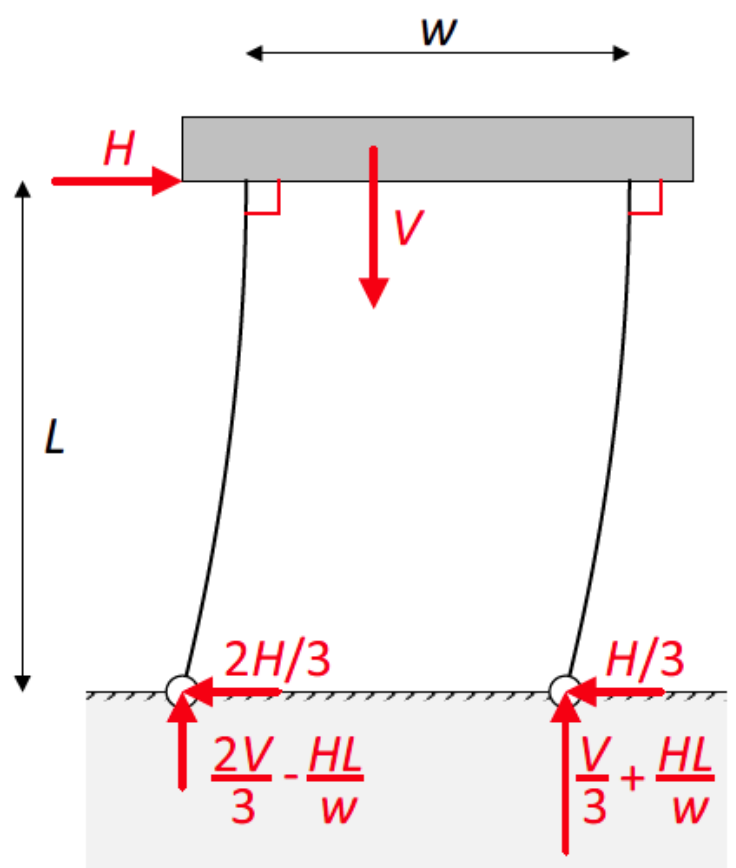

(a)

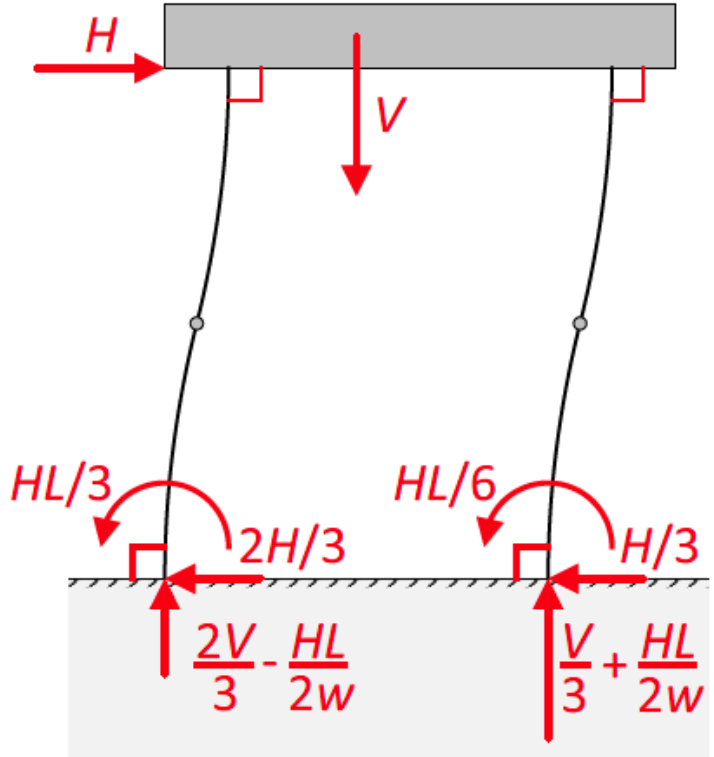

(b)

Figure 16: Simplified view of loads on a jack-up unit (2 legs to windward) with (a) pinned spudcans, (b) fixed spudcans

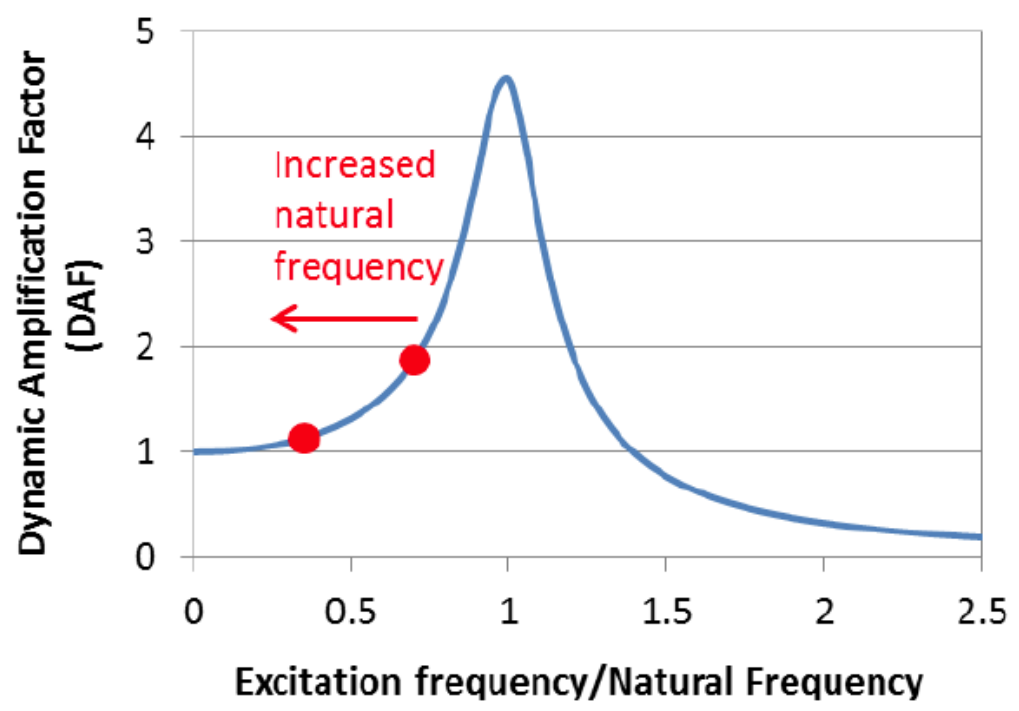

Figure 17: Effect of increased natural frequency on Dynamic Amplification Factor 


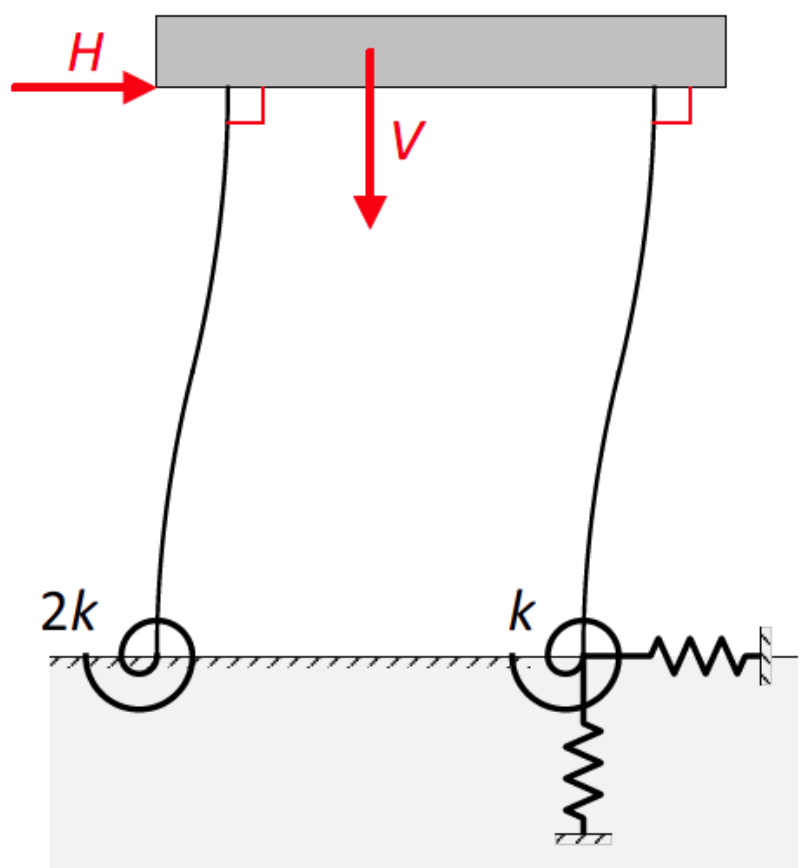

Figure 18: Spudcan foundations modelled as equivalent springs: windward footing shows rotational spring only, leeward footing shows additional vertical and horizontal springs
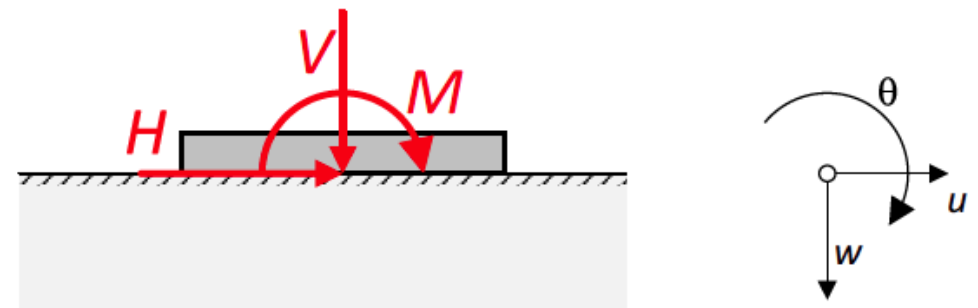

Figure 19: Conventions for load and displacement of foundation

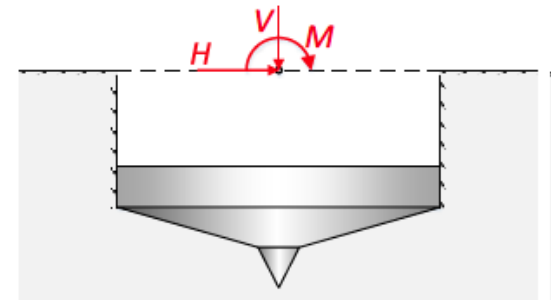

(a)

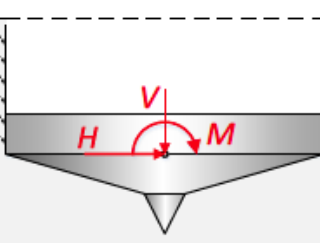

(b)

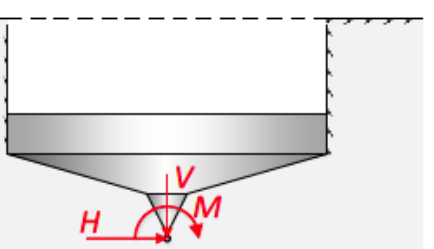

(c)

Figure 20: Possible locations for "load reference point" 


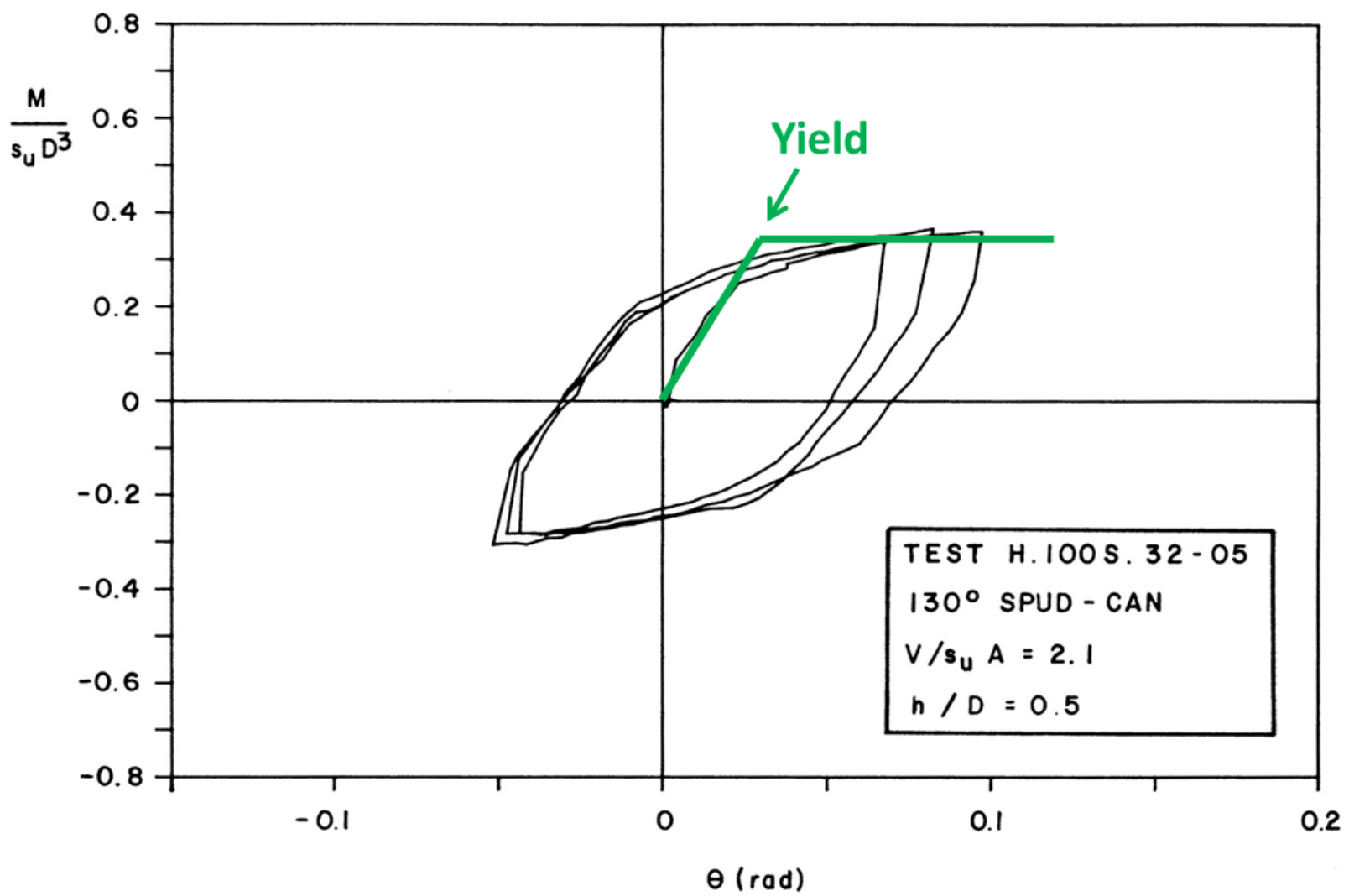

Figure 21: Moment-rotation test on model spudcan (adapted from de Santa Maria, 1988)

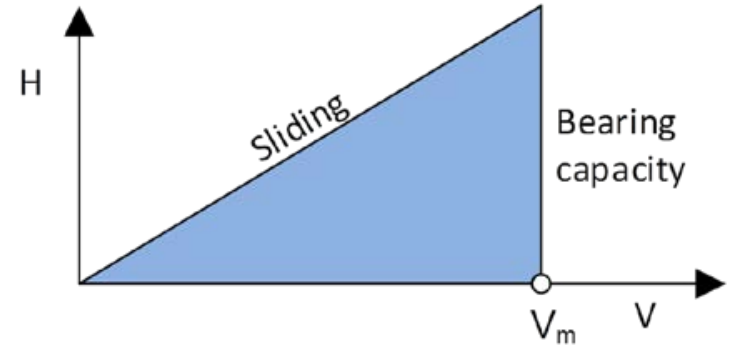

(a)

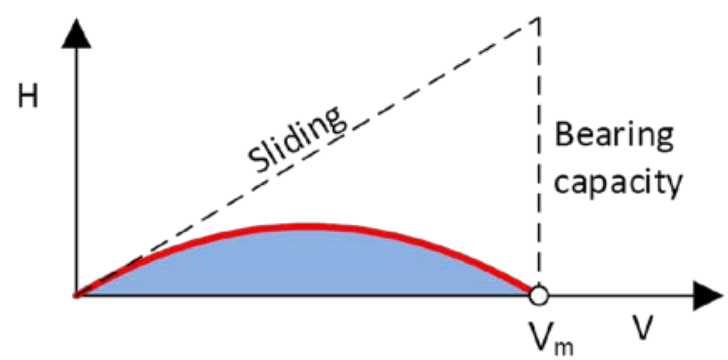

(b)

Figure 22: Hypothetical yield surfaces for vertical and horizontal loading of a flat plate on sand 


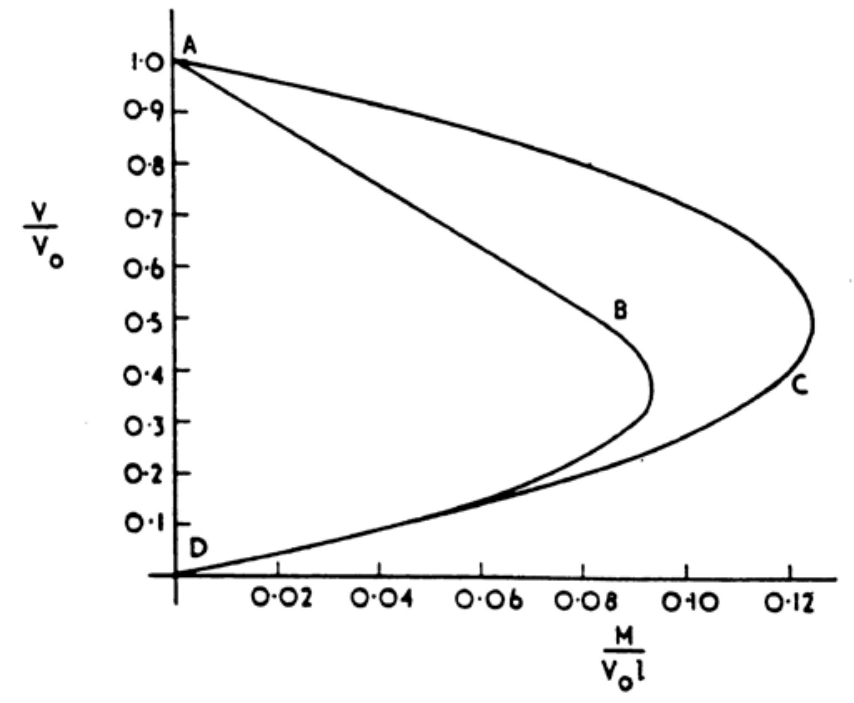

Figure 23: Two dimensional failure surface (from Roscoe and Schofield, 1957)

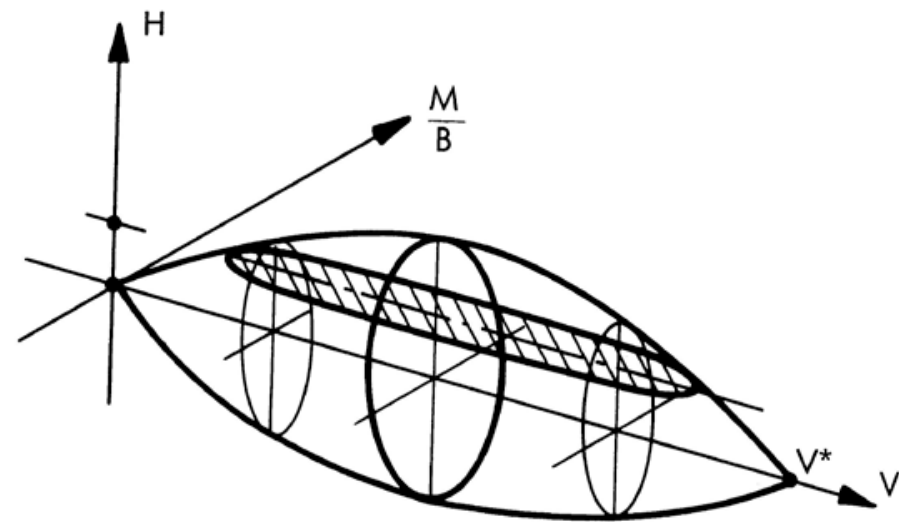

Figure 24: Three dimensional failure surface (from Butterfield and Ticof, 1979) 


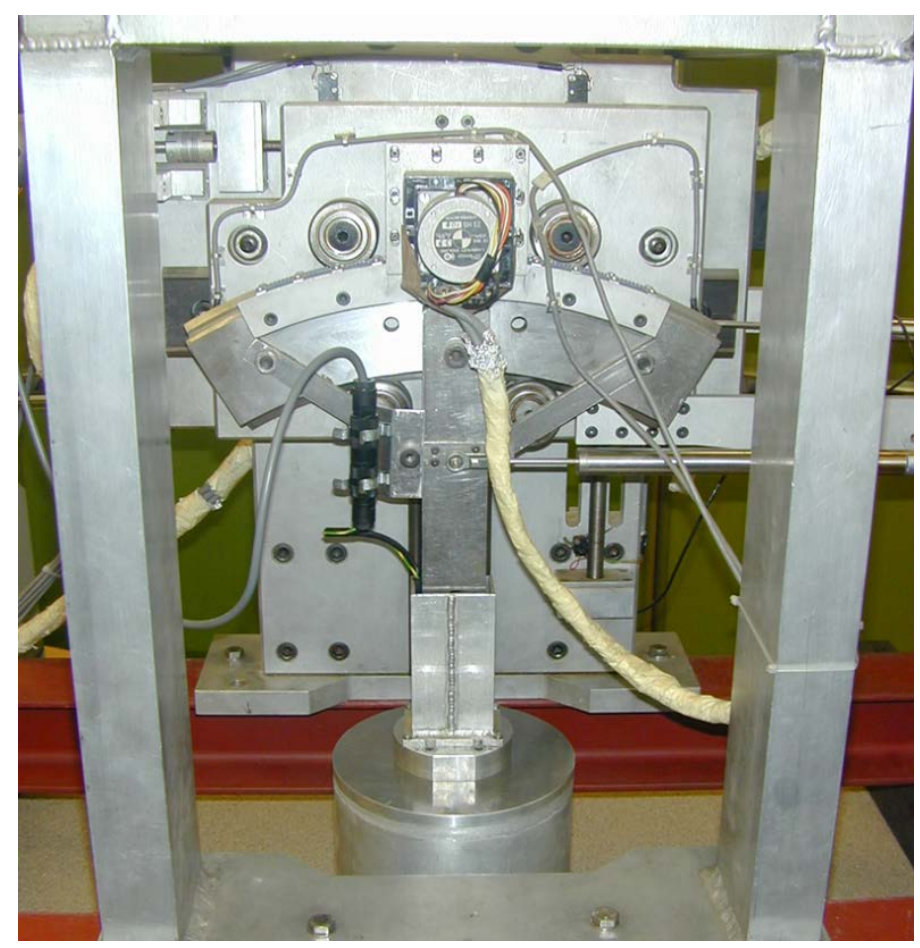

Figure 25: Apparatus for combined loading of model footings

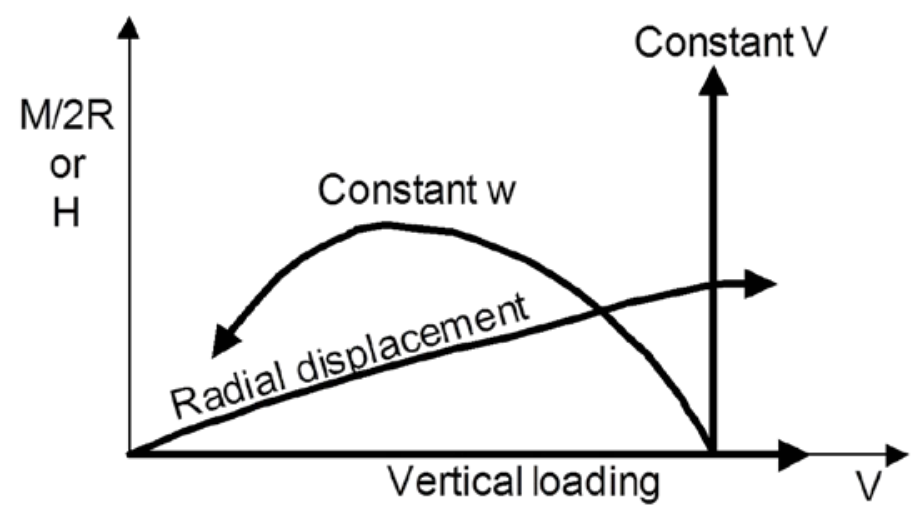

(Figure 3 of Gottardi, Houlsby and Butterfield, 1999)

Figure 26: Load paths attainable with apparatus shown in Figure 25 (from Gottardi et al., 1999) 

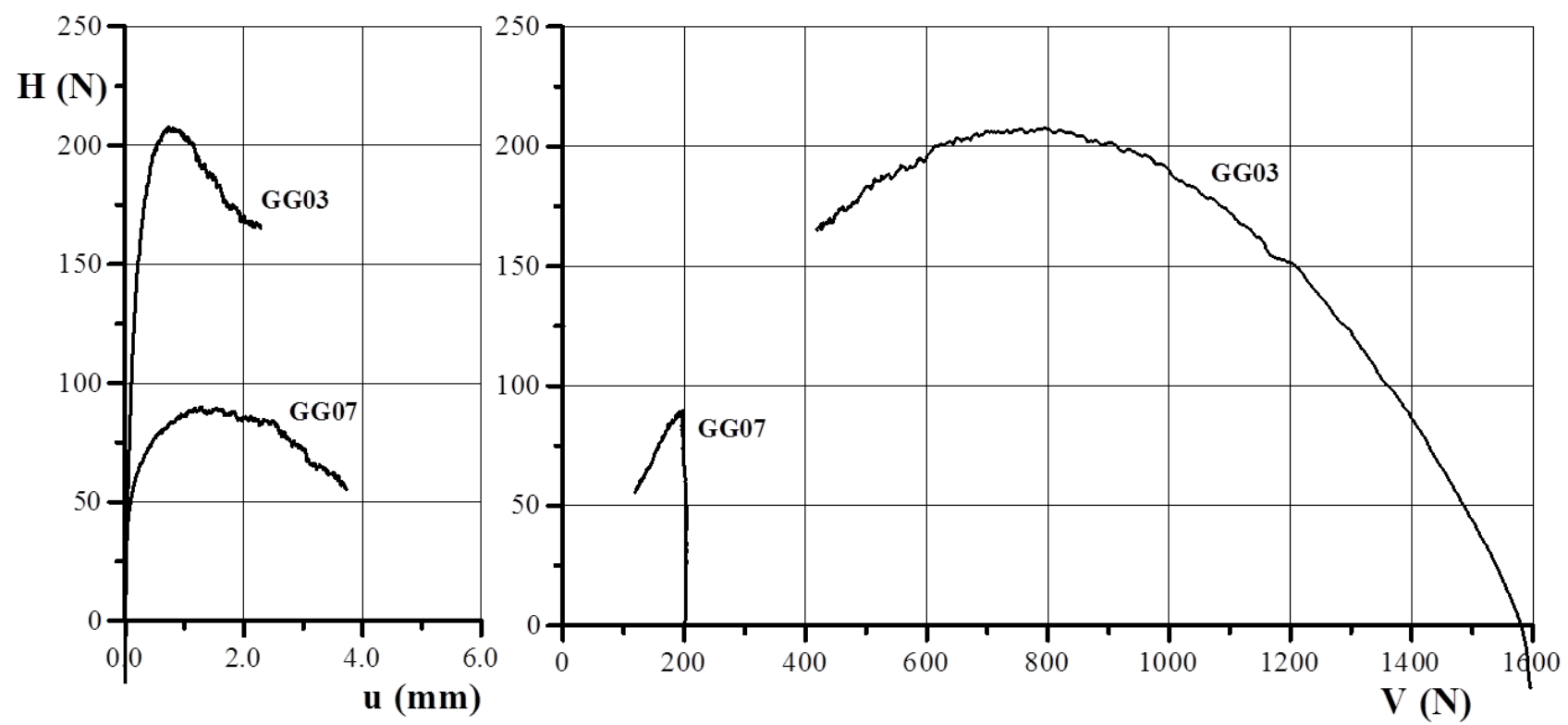

(Figure 6 of Gottardi, Houlsby and Butterfield, 1999)

Figure 27: Horizontal swipe tests on sand (from Gottardi et al., 1999)
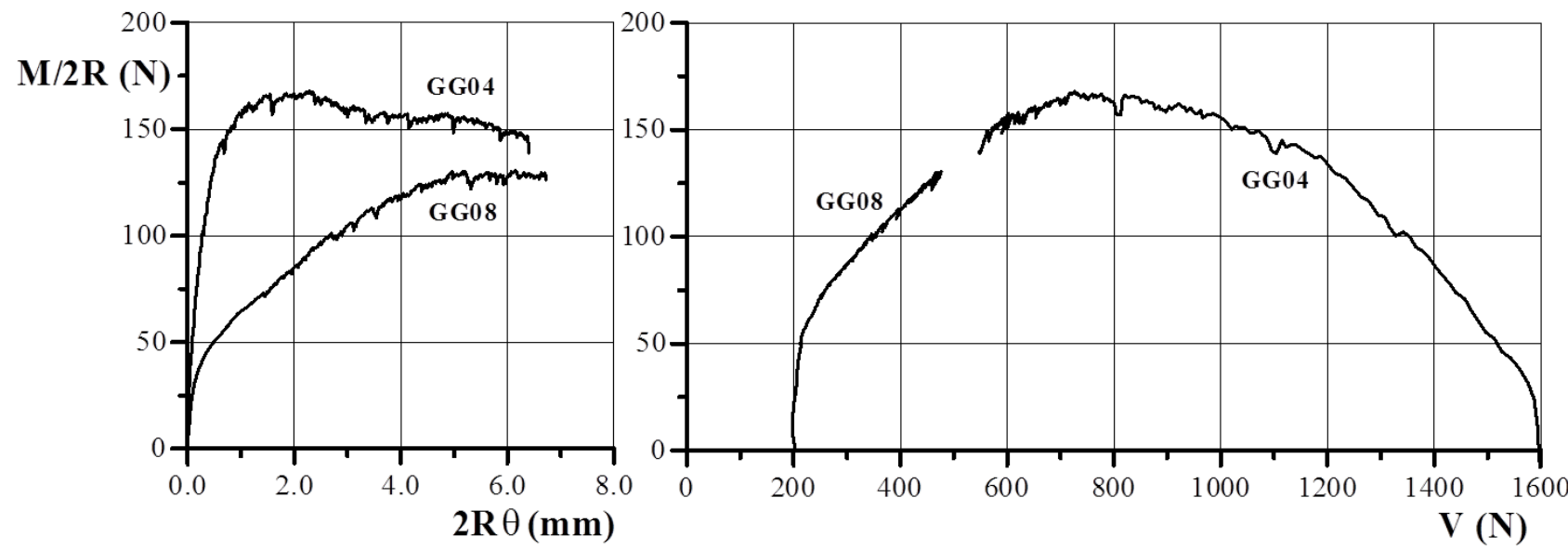

(Figure 7 of Gottardi, Houlsby and Butterfield, 1999)

Figure 28: Moment swipe tests on sand (from Gottardi et al., 1999) 


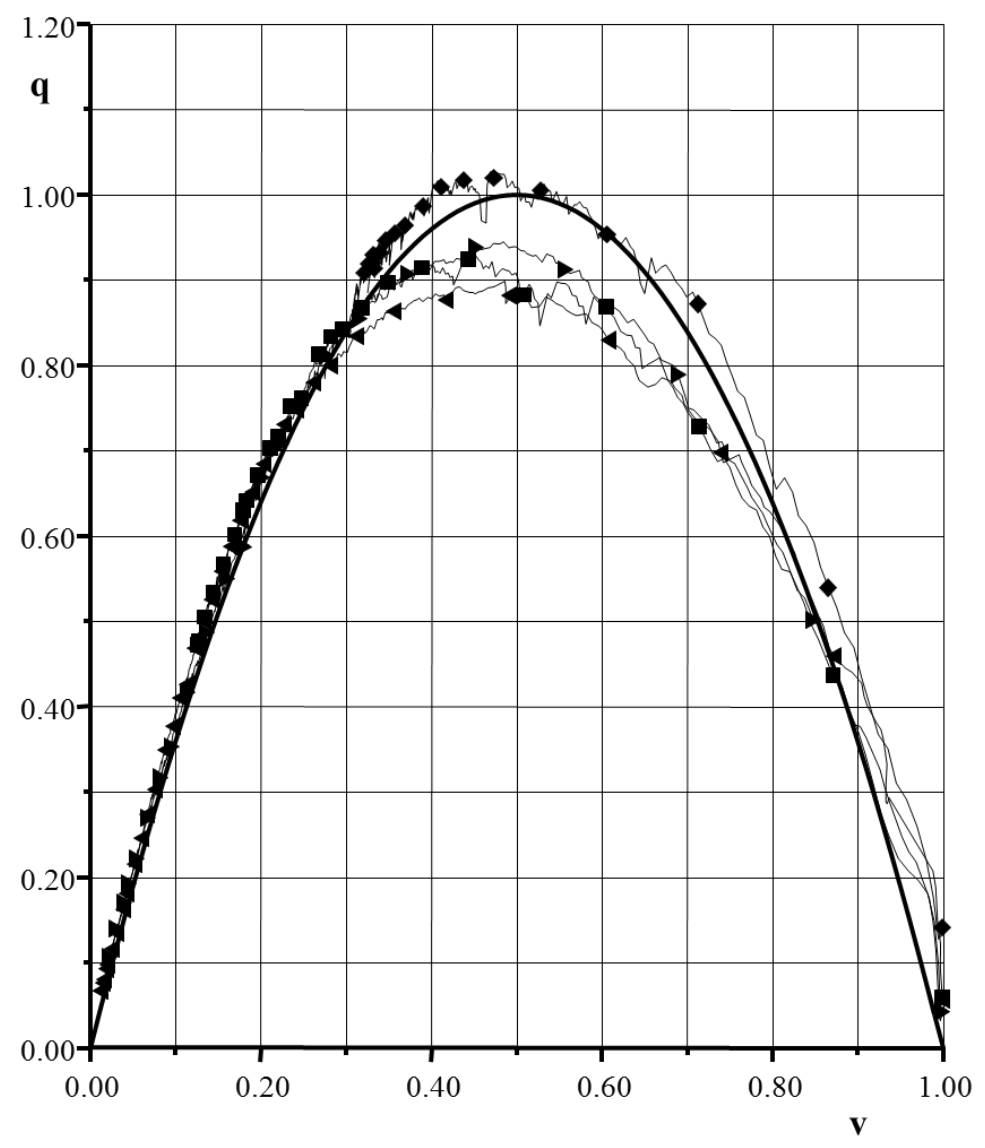

(Figure 12 of Gottardi, Houlsby and Butterfield, 1999)

Figure 29: Unified representation of swipe tests on sand (from Gottardi et al., 1999) 


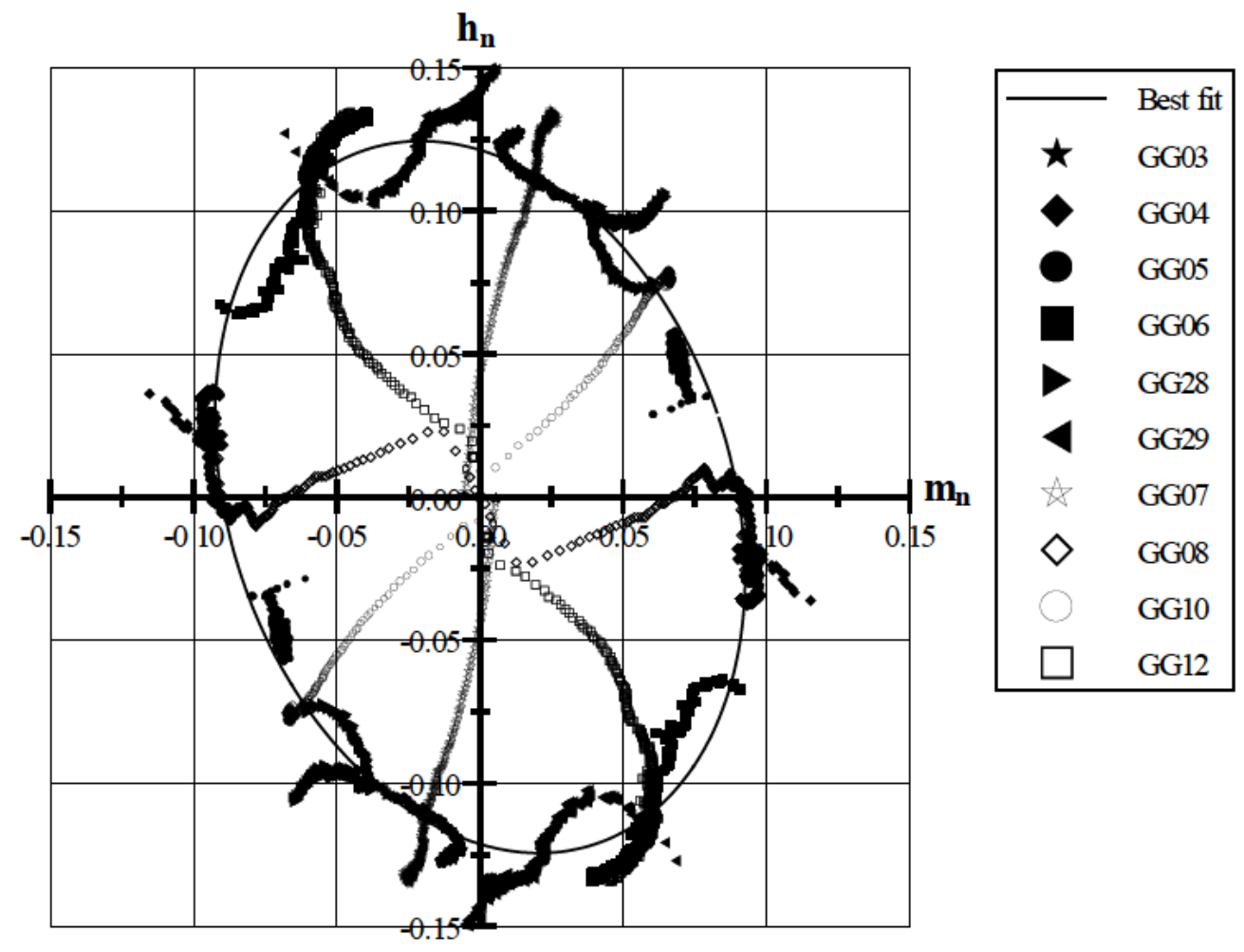

(Figure 11 of Gottardi, Houlsby and Butterfield, 1999)

Figure 30: Representation of section of yield surface perpendicular to vertical load axis (from Gottardi et al., 1999)
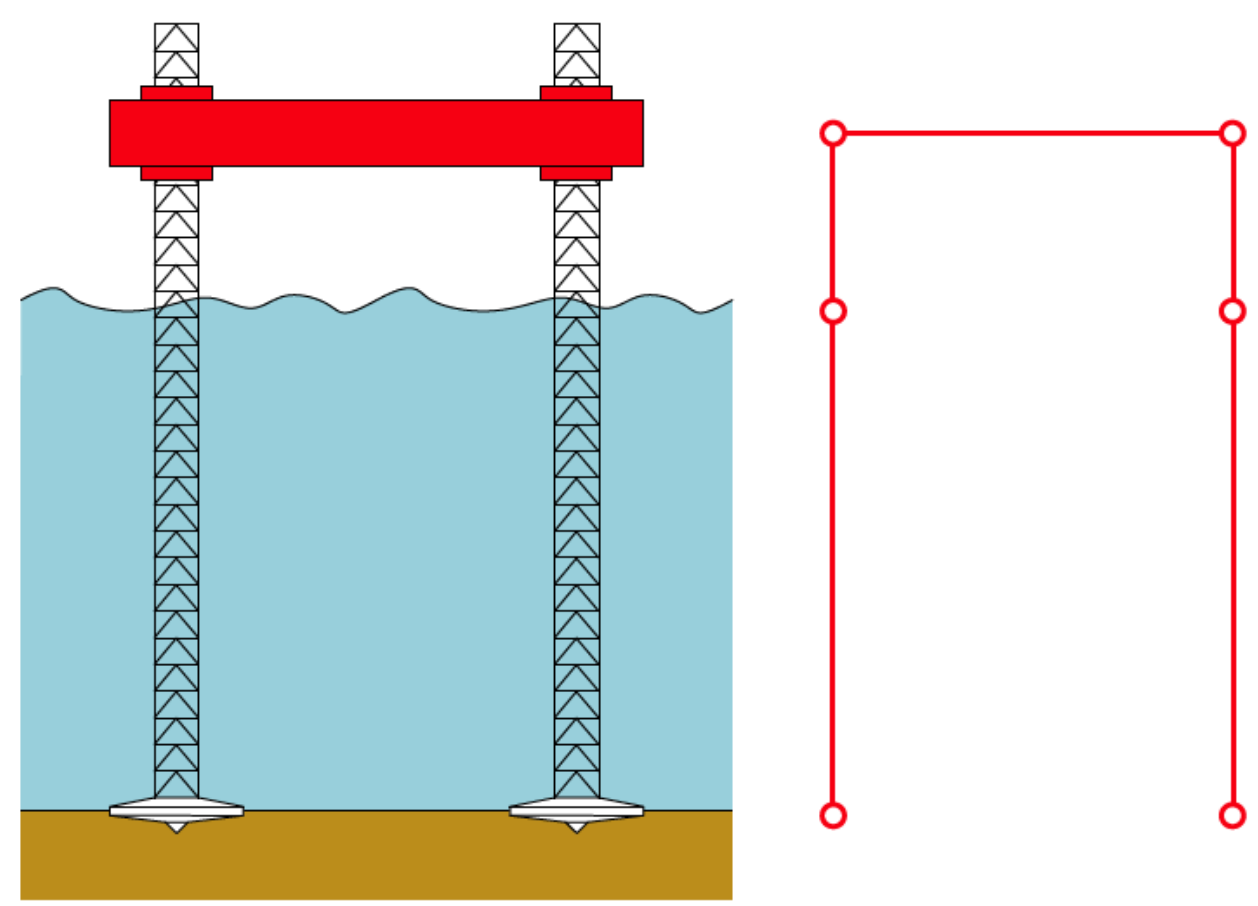

Figure 31: Jack-up unit and its simple idealisation for numerical analysis 


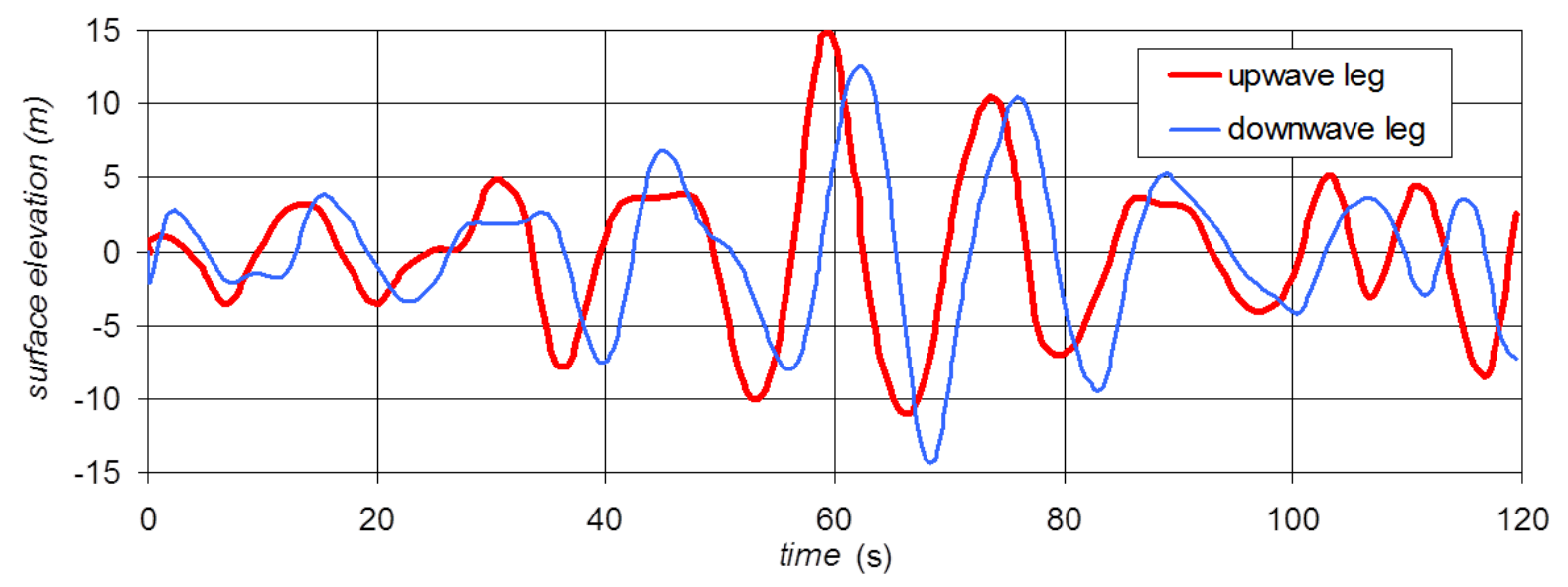

(a)

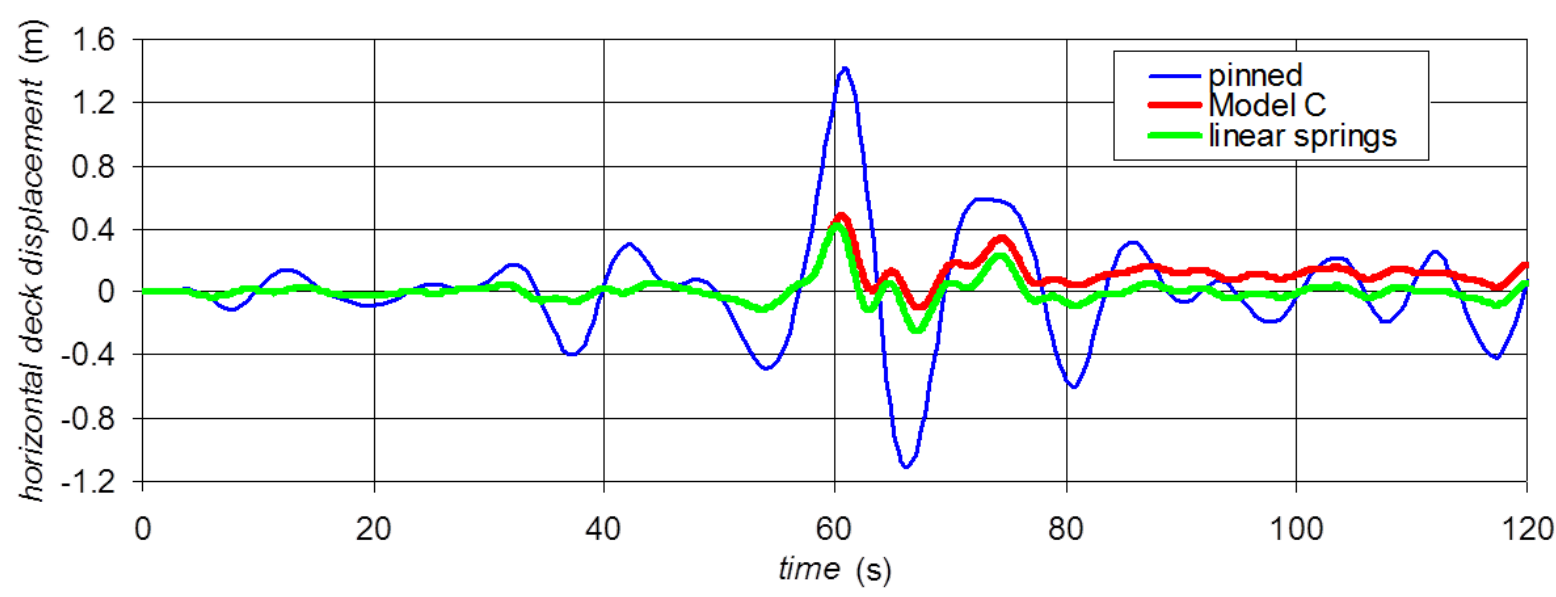

(b)

Figure 32: (a) Constrained New-Wave elevations, (b) Response of jack-up unit to constrained new wave excitation 


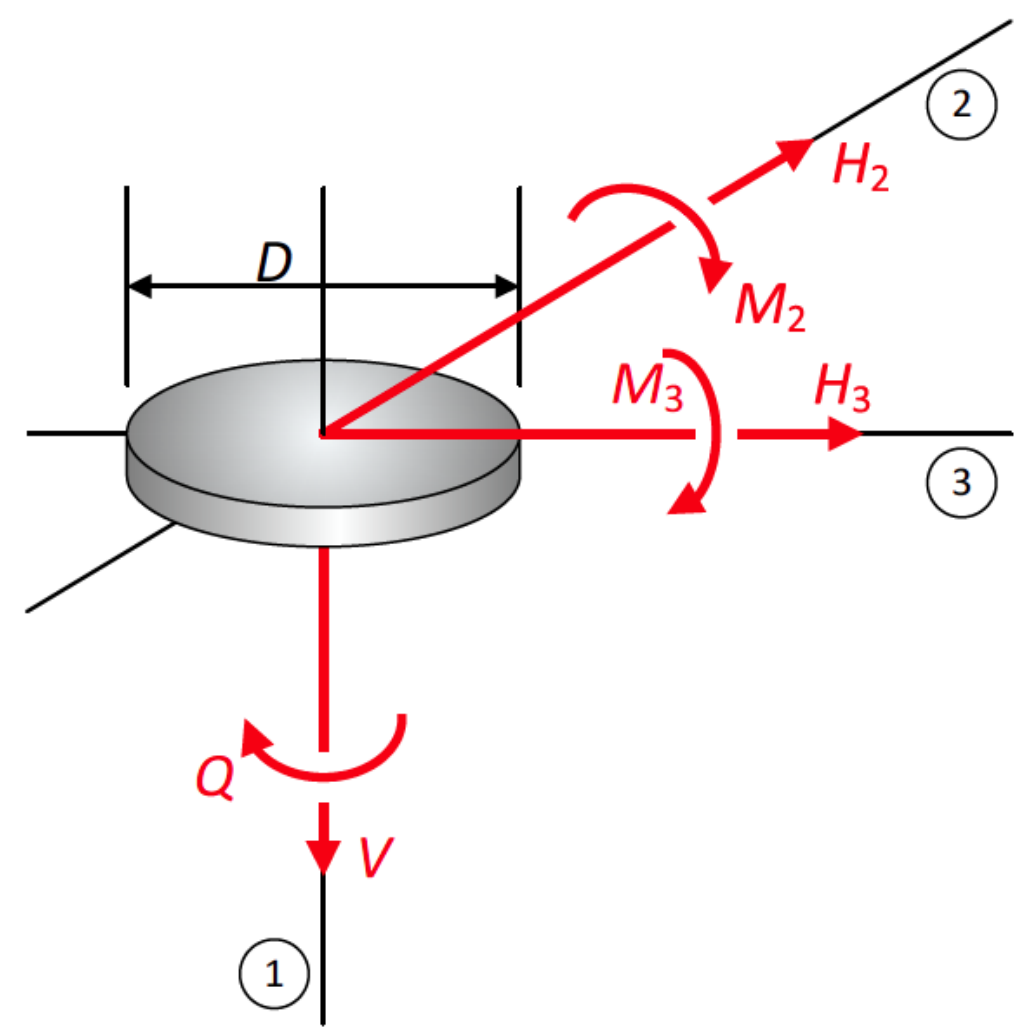

Figure 33: General 3D loading on a foundation

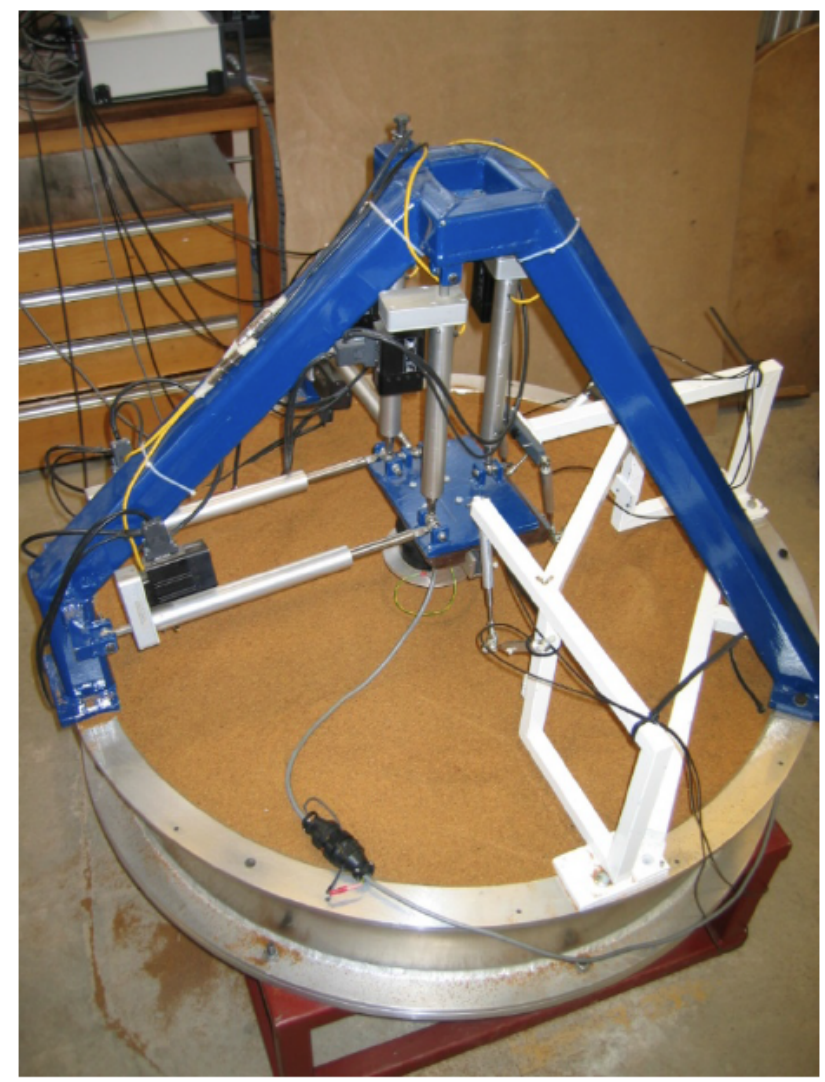

Figure 34: Apparatus for applying general 3D loading to a model foundation 


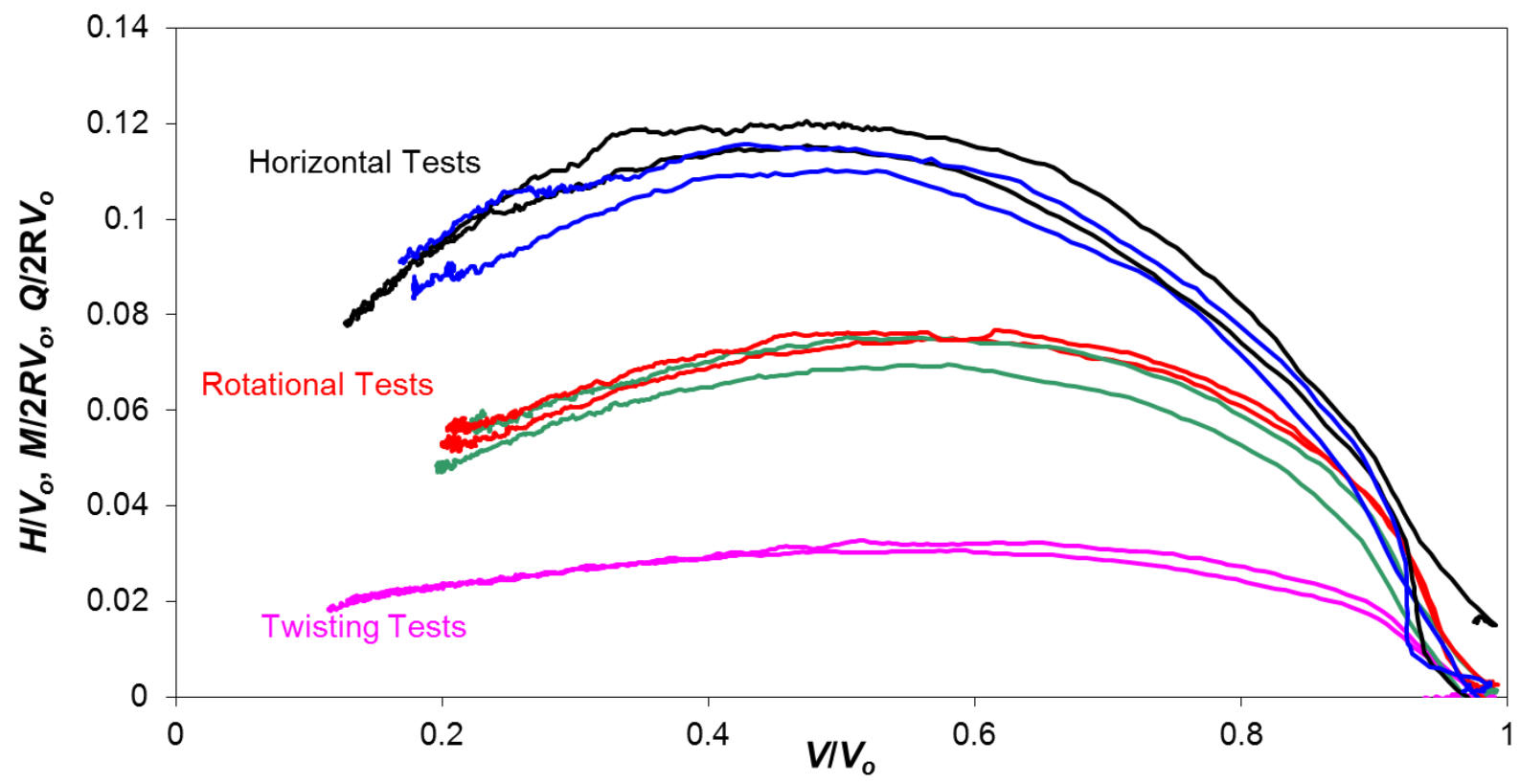

Figure 35: Swipe tests under general loading conditions

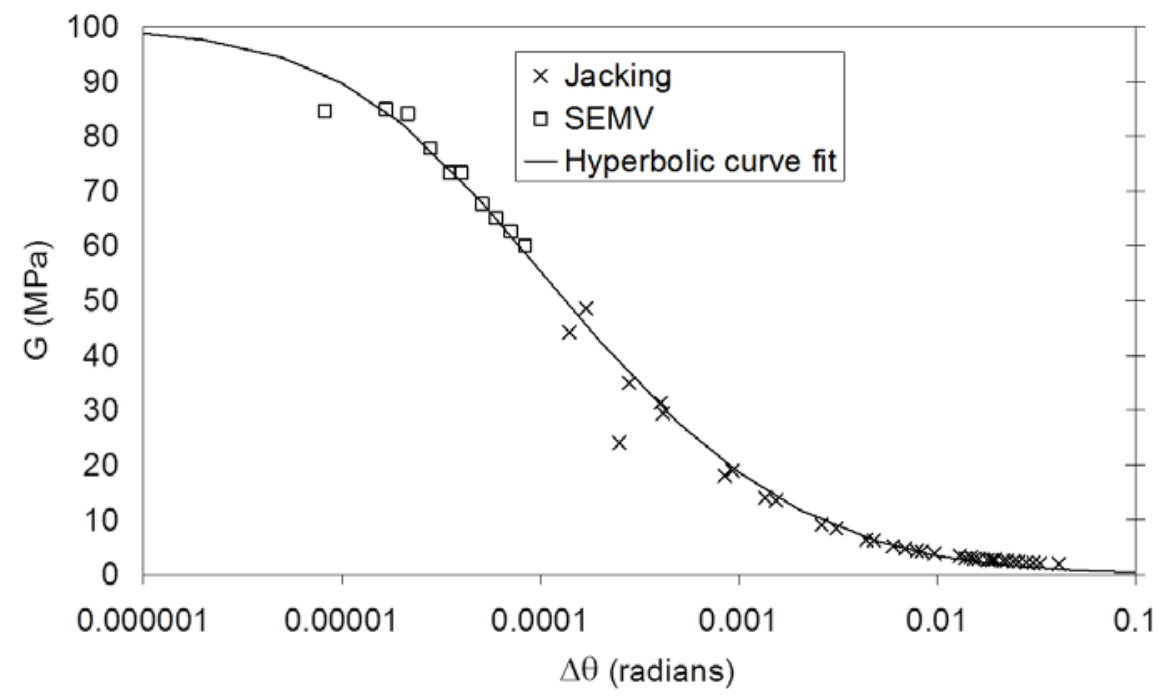

(Figure 14 of Houlsby, Kelly, Huxtable and Byrne, 2006)

Figure 36: Change of rotational stiffness of a foundation as a function of rotation amplitude (from Houlsby et al., 2006) 


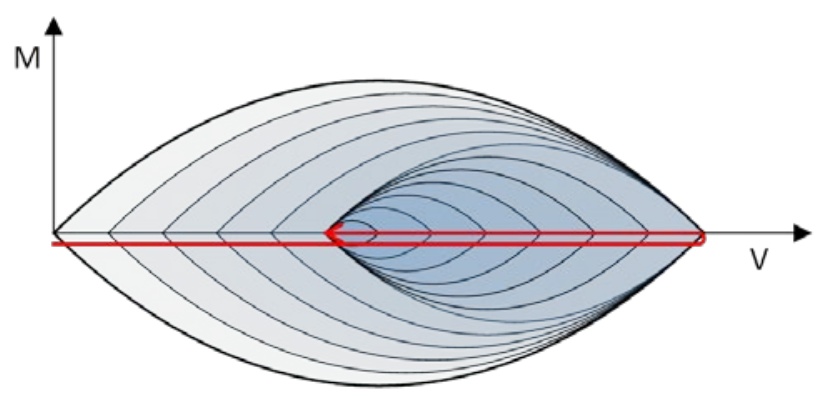

(a)

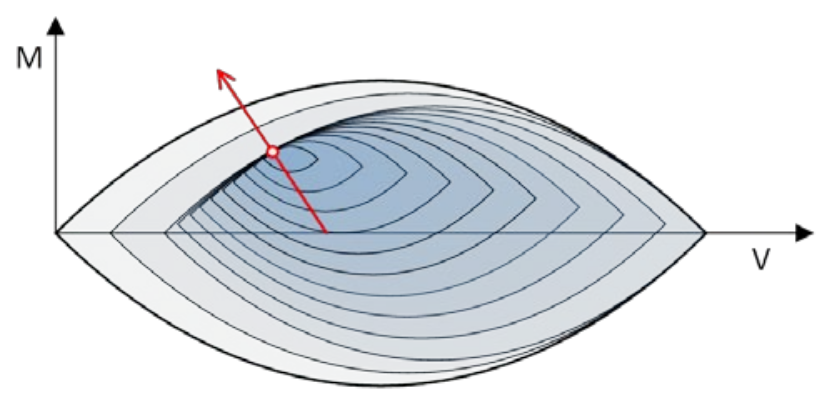

(b)

Figure 37: Yield surfaces in multi-surface model for: (a) preloading and (b) storm loading of windward footing 


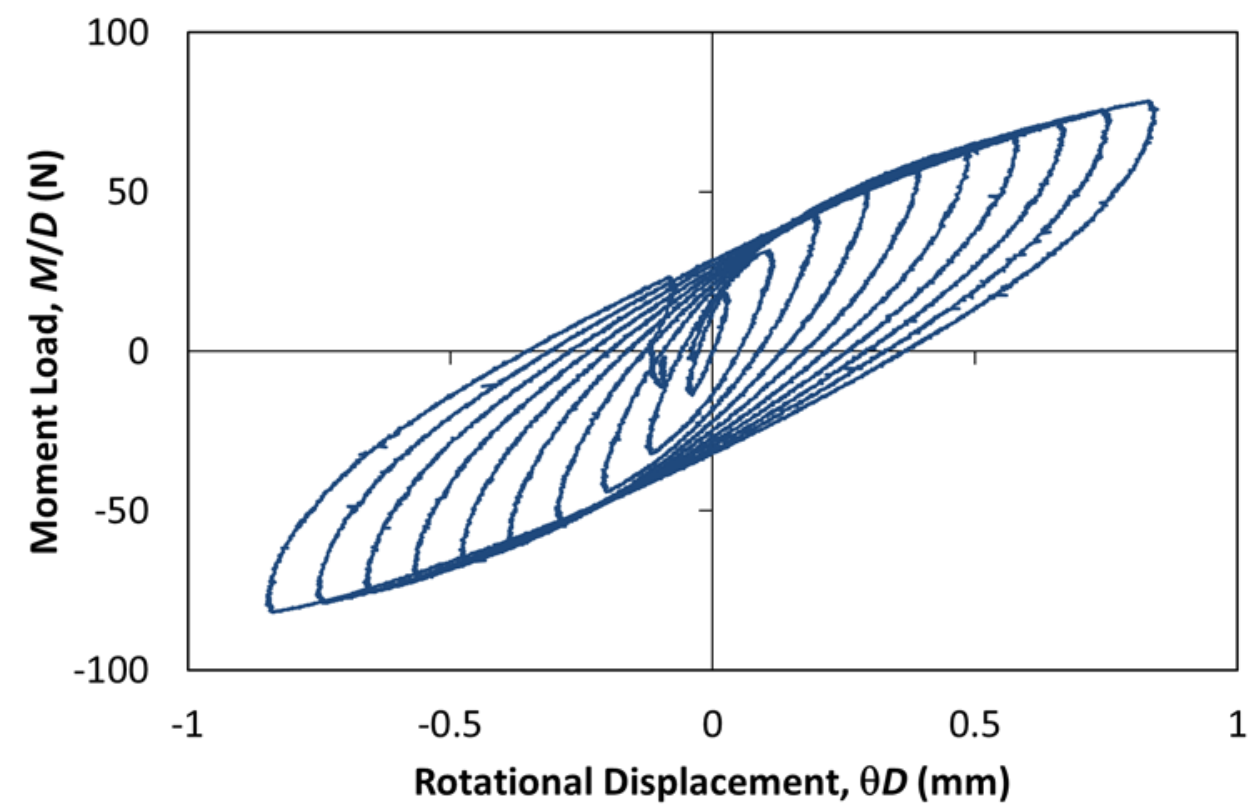

(a)

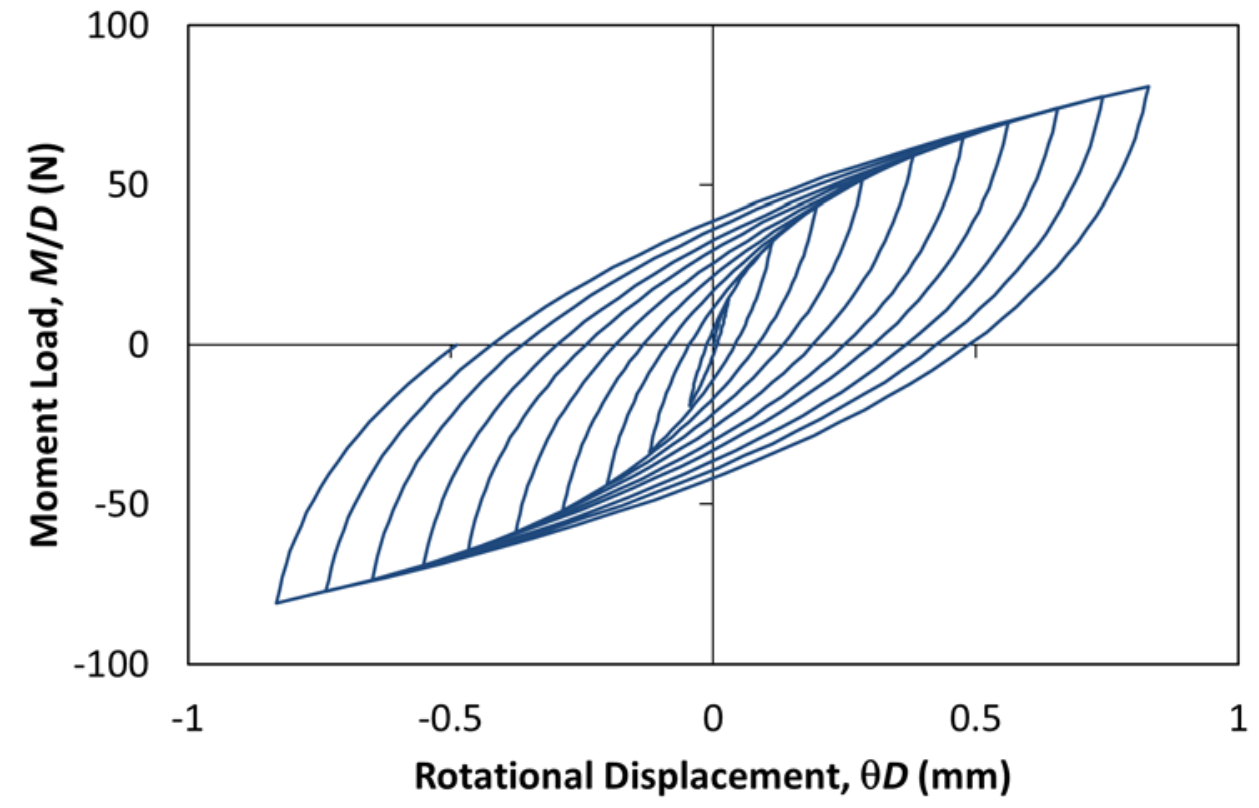

(b)

Figure 38: (a) Experimental measurements of moment-rotation response of footing under increasing amplitude of cycling and (b) modelling using a multi-surface model 


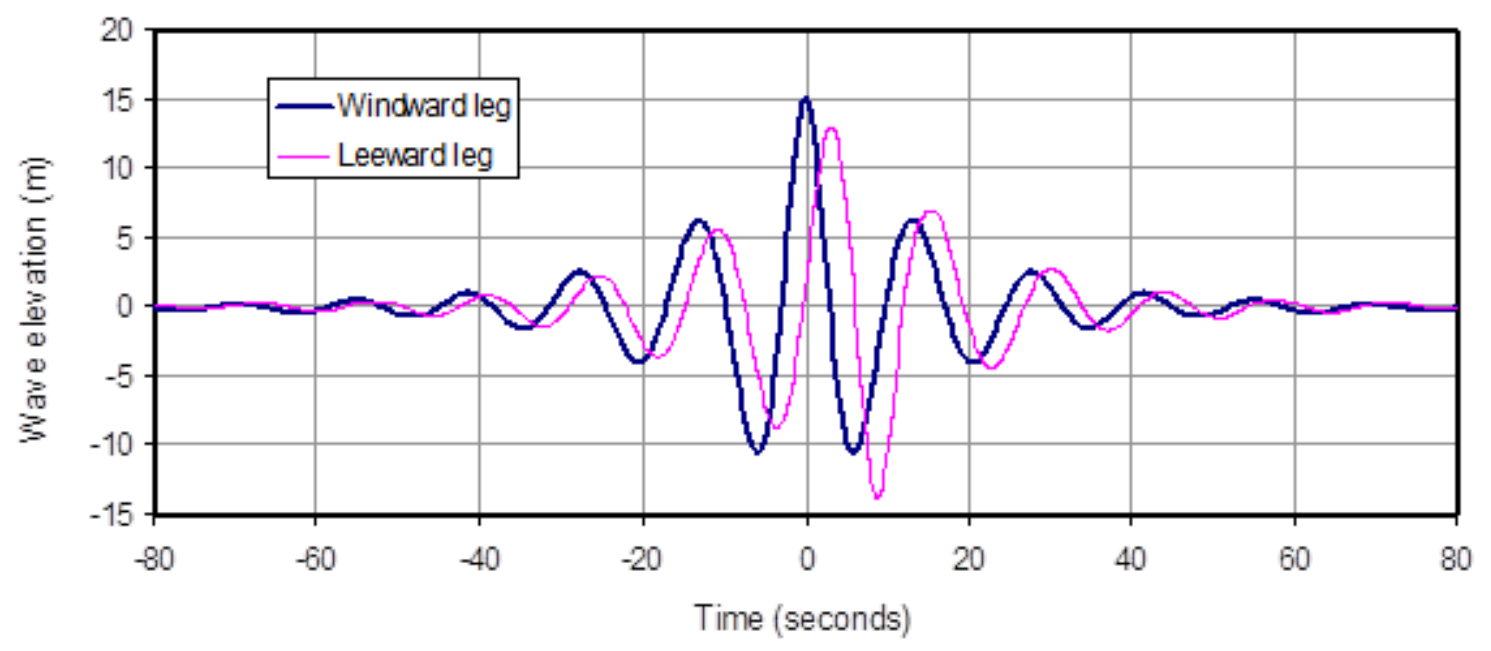

(a)

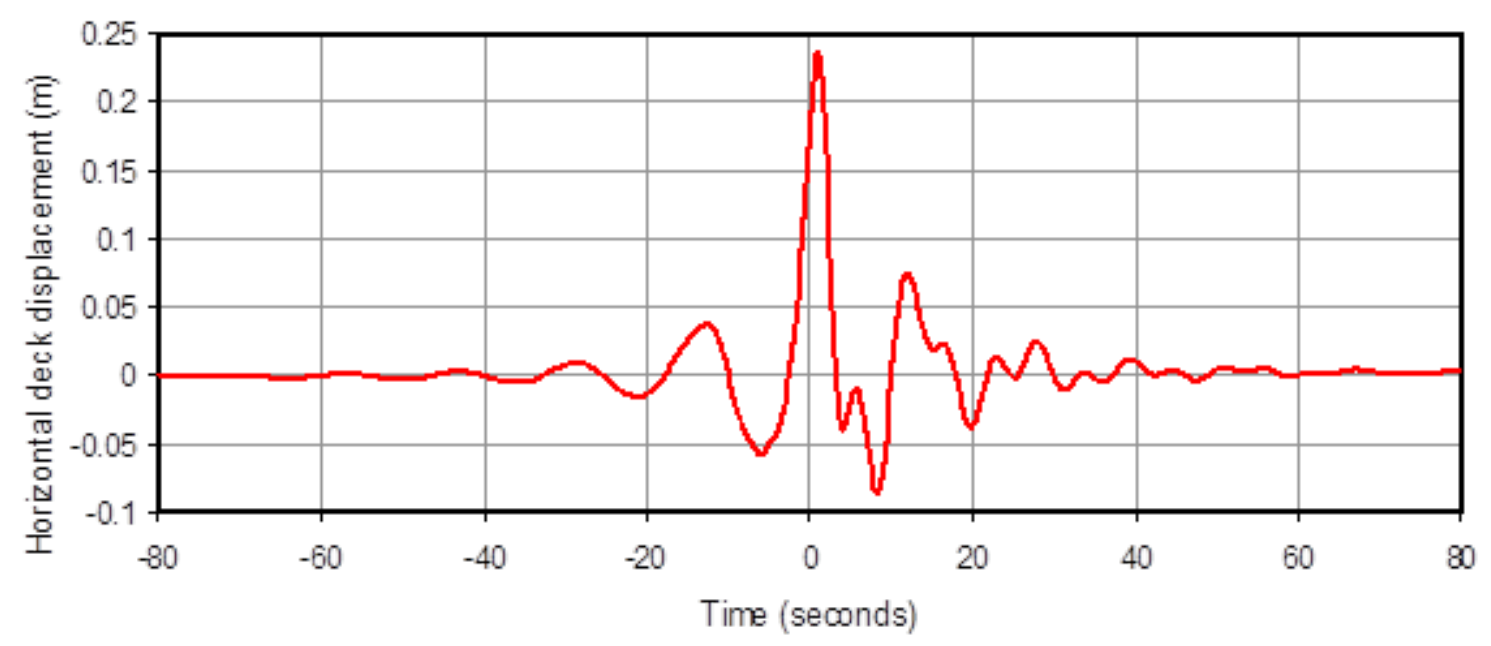

(b)

Figure 39: (a) NewWave surface elevation at windward and leeward legs, (b) horizontal deck movement of jack-up excited by NewWave loading 


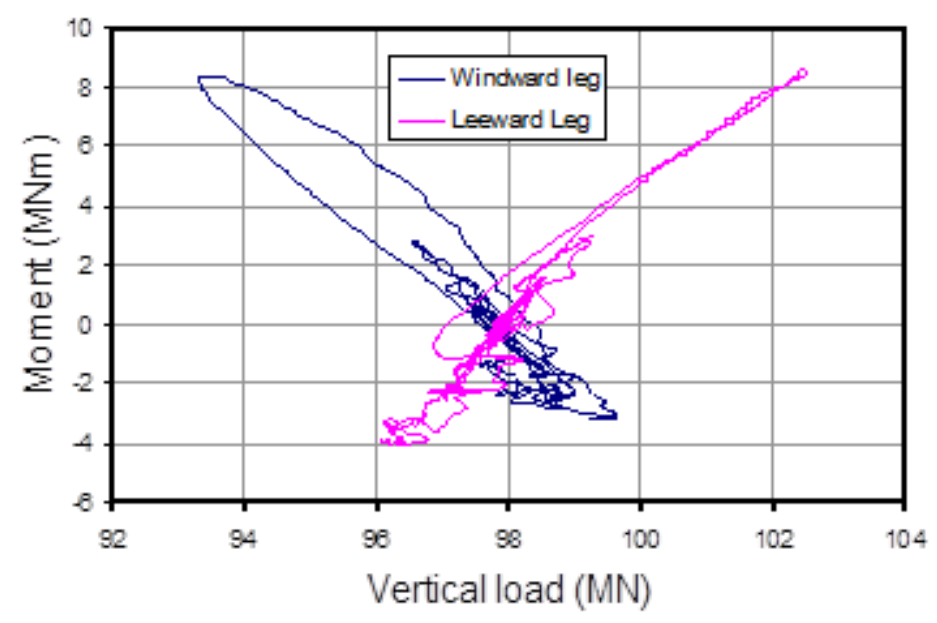

Figure 40: Load paths for windward and leeward legs of jack-up subjected to new wave loading

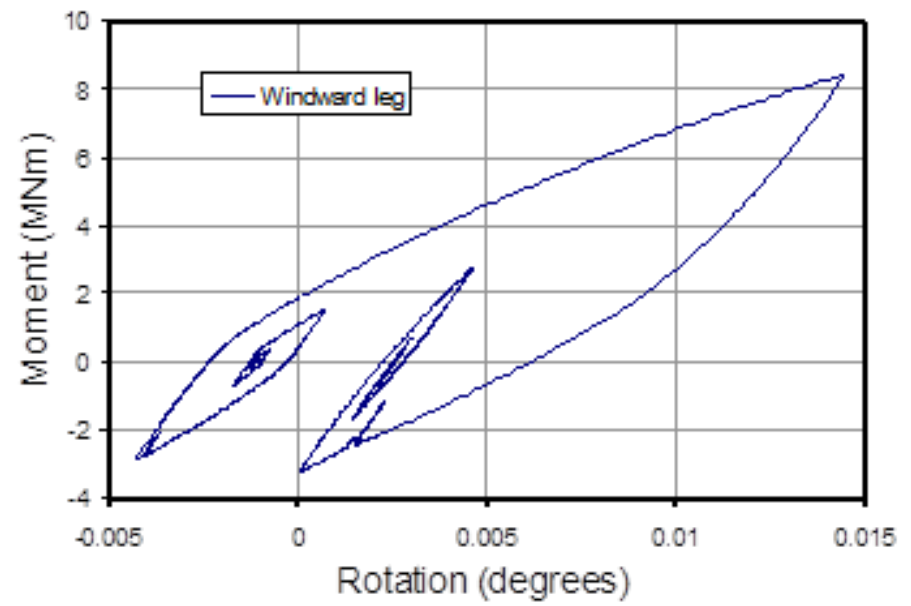

Figure 41: Moment rotation response of windward foundation of jack-up subjected to new wave loading 


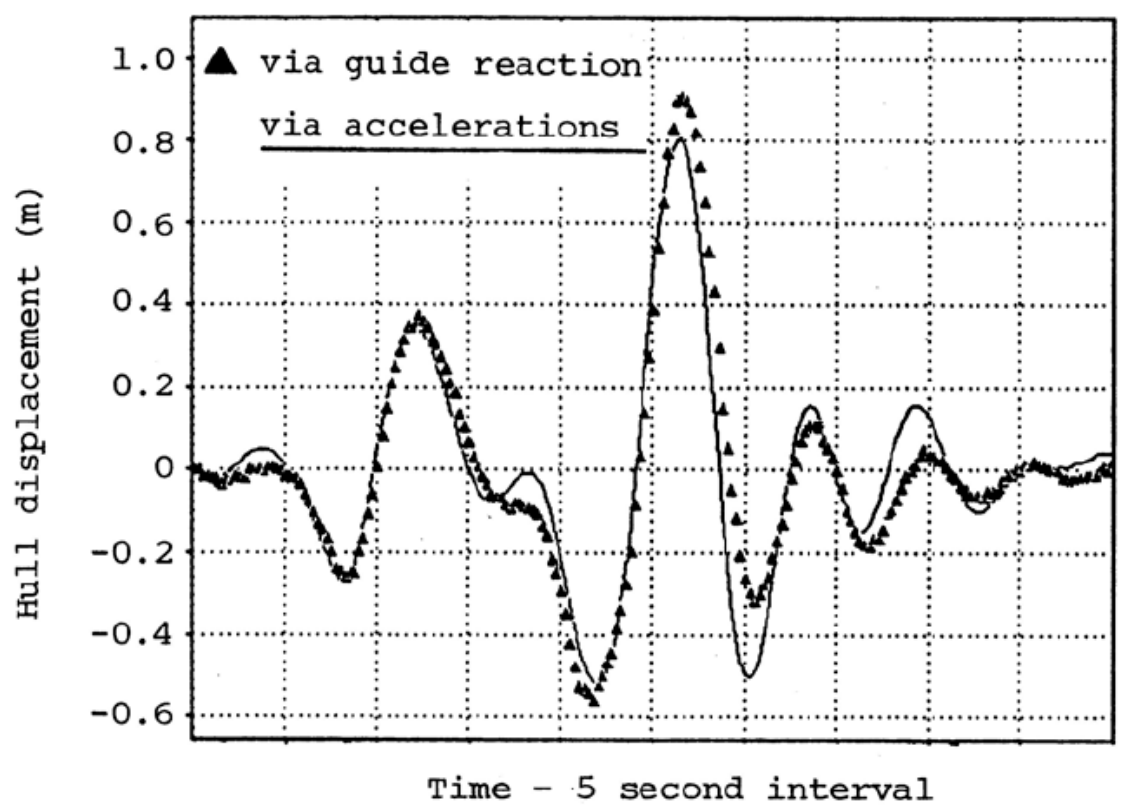

Figure 42: Lateral motion of jack-up hull under extreme load (from McCarron and Broussard, 1992)

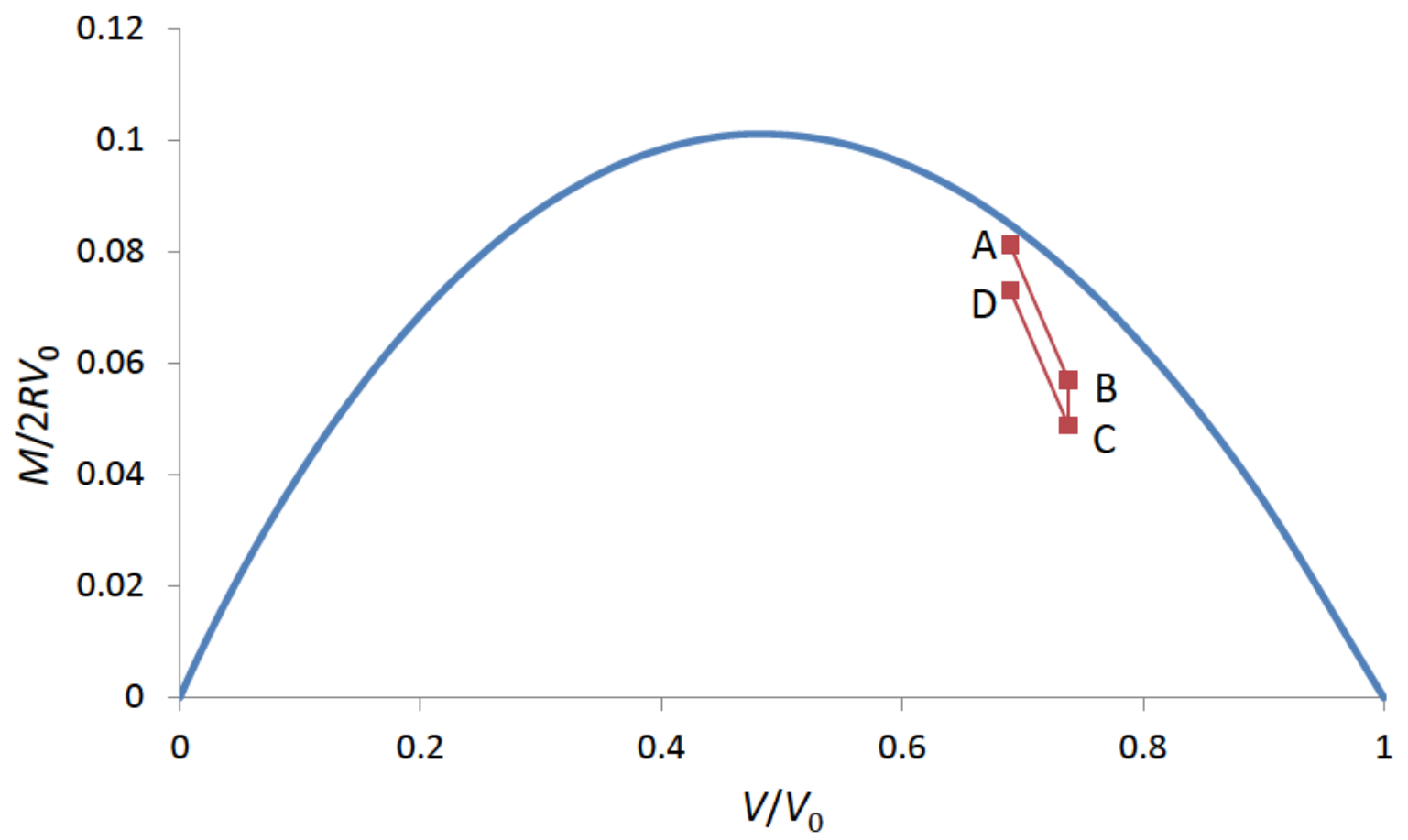

Figure 43: Estimated load path for the Pisa Tower remedial works 


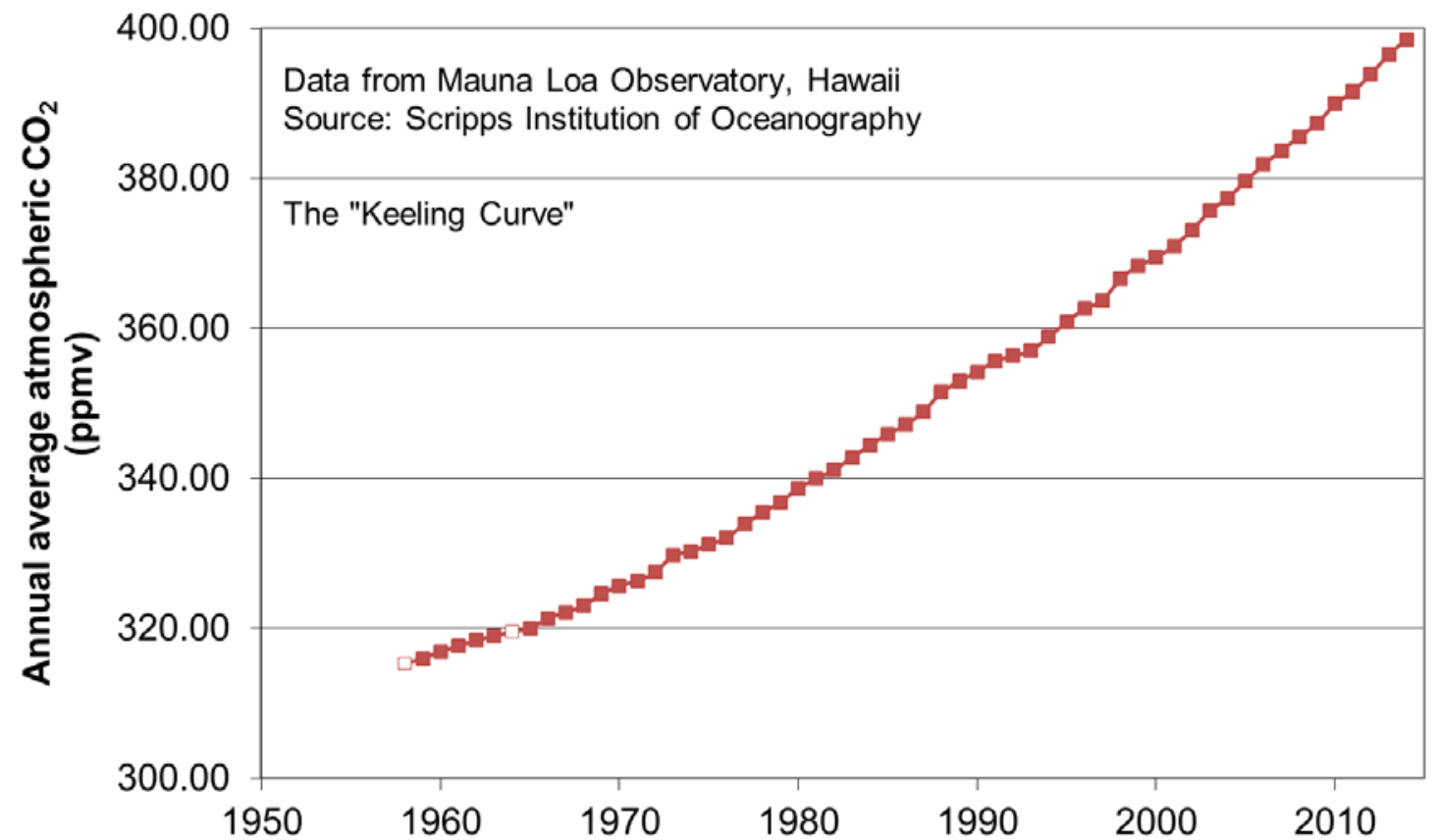

Figure 44: The Keeling Curve: atmospheric $\mathrm{CO}_{2}$ level as a function of time

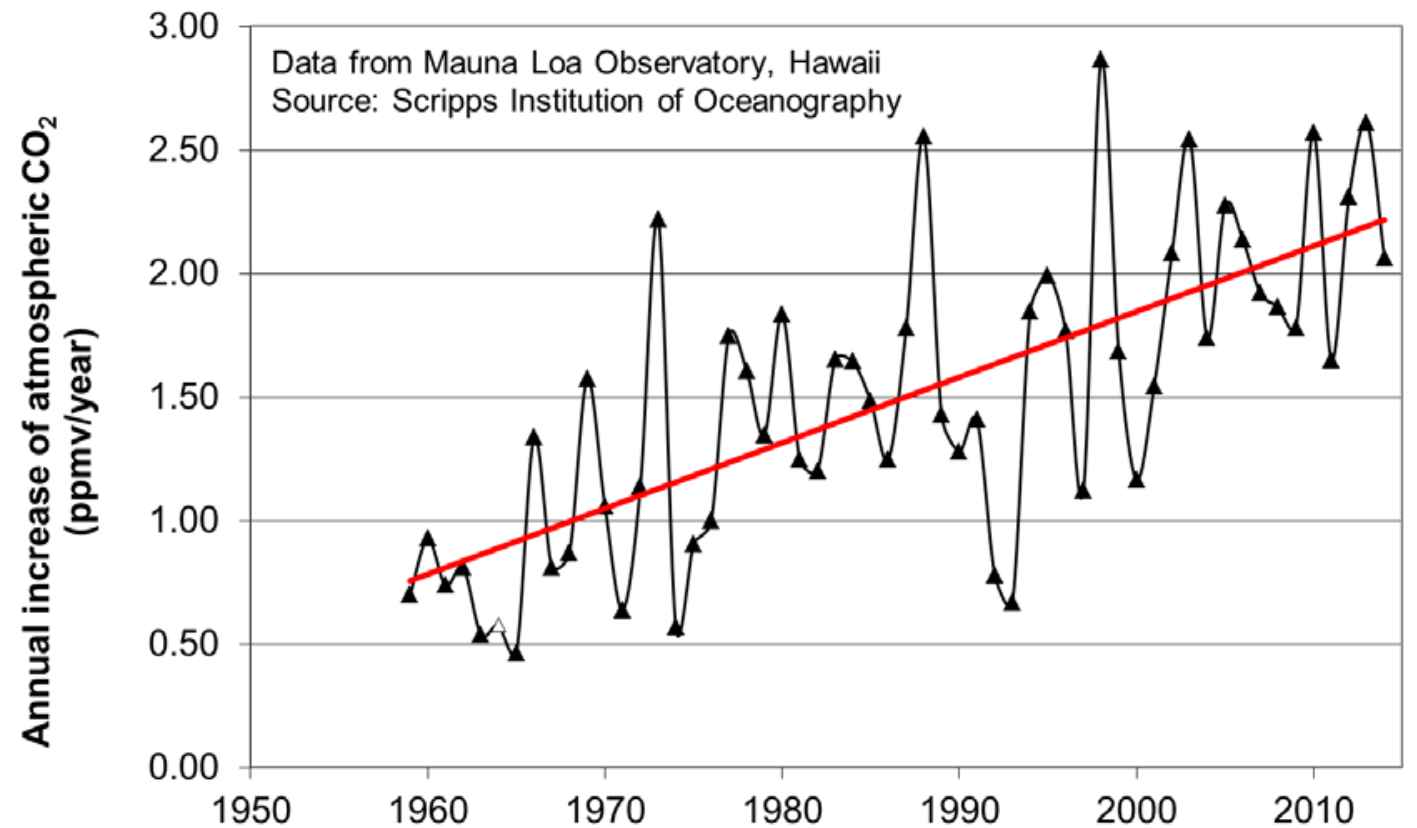

Figure 45: Time differential of the Keeling Curve: rate of increase of atmospheric $\mathrm{CO}_{2}$ level as a function of time 


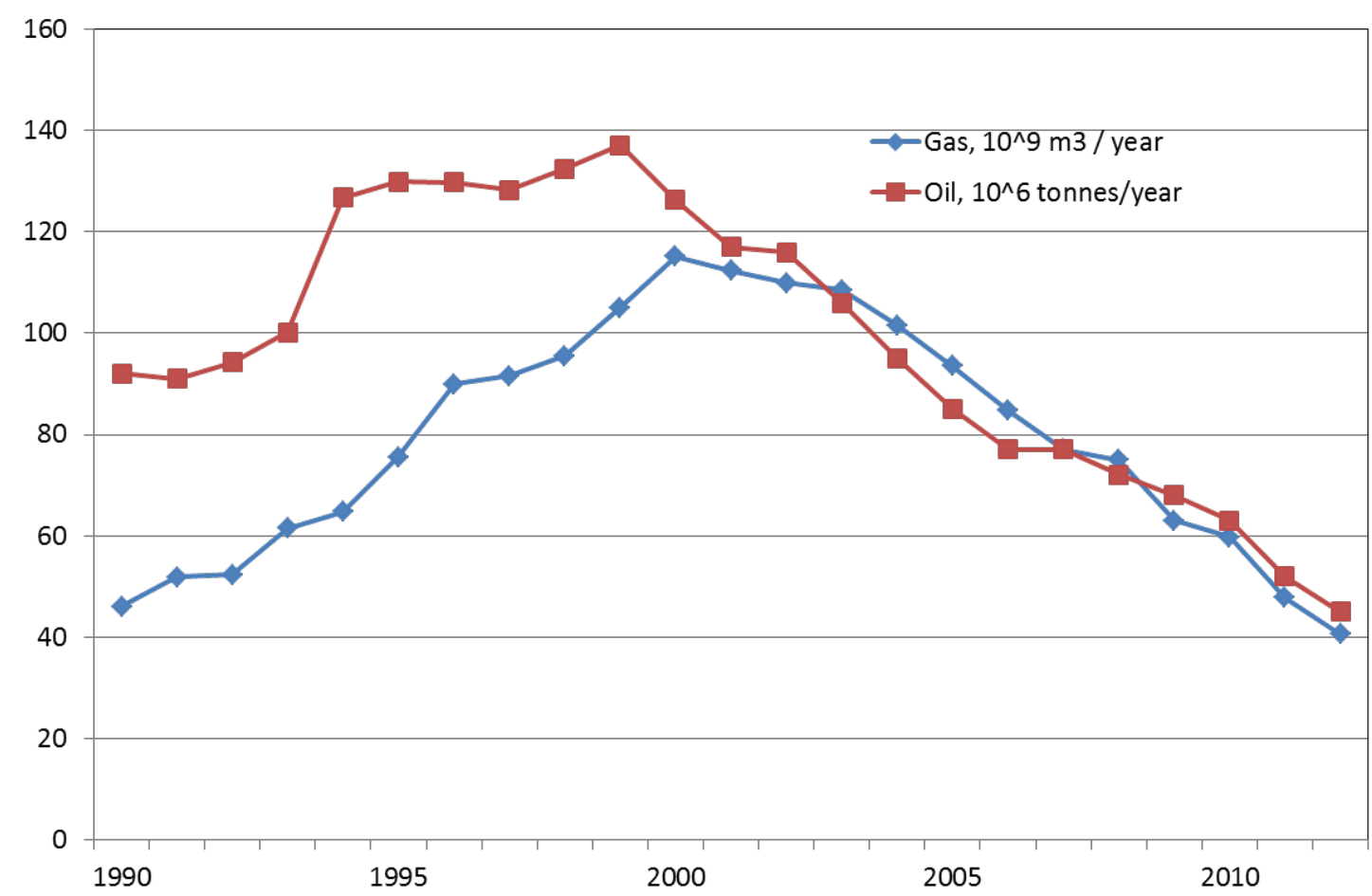

Figure 46: UK oil and gas production as a function of time (source: DECC)

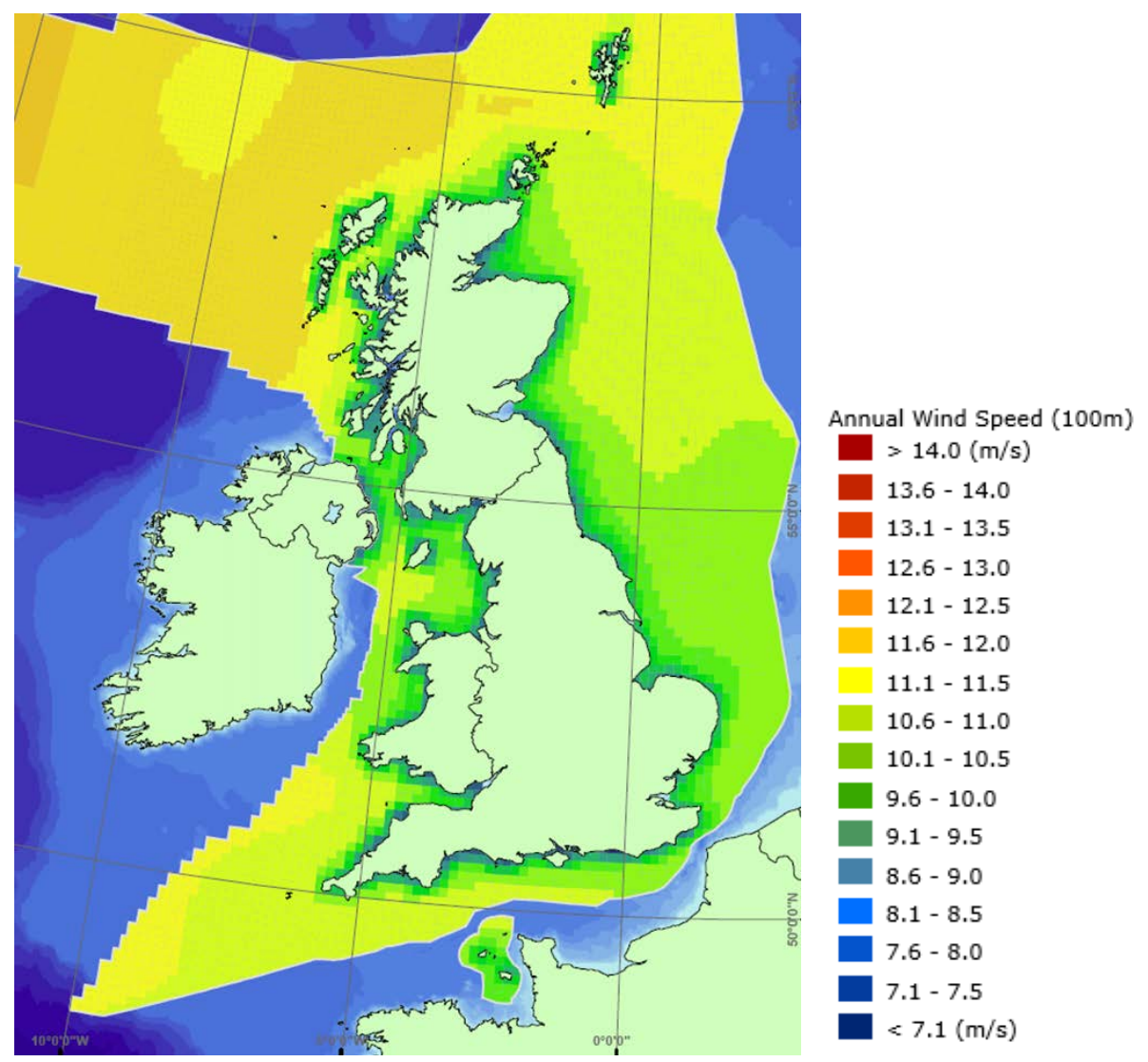

Figure 47: Average wind speed around the UK (from DTI, 2004) 


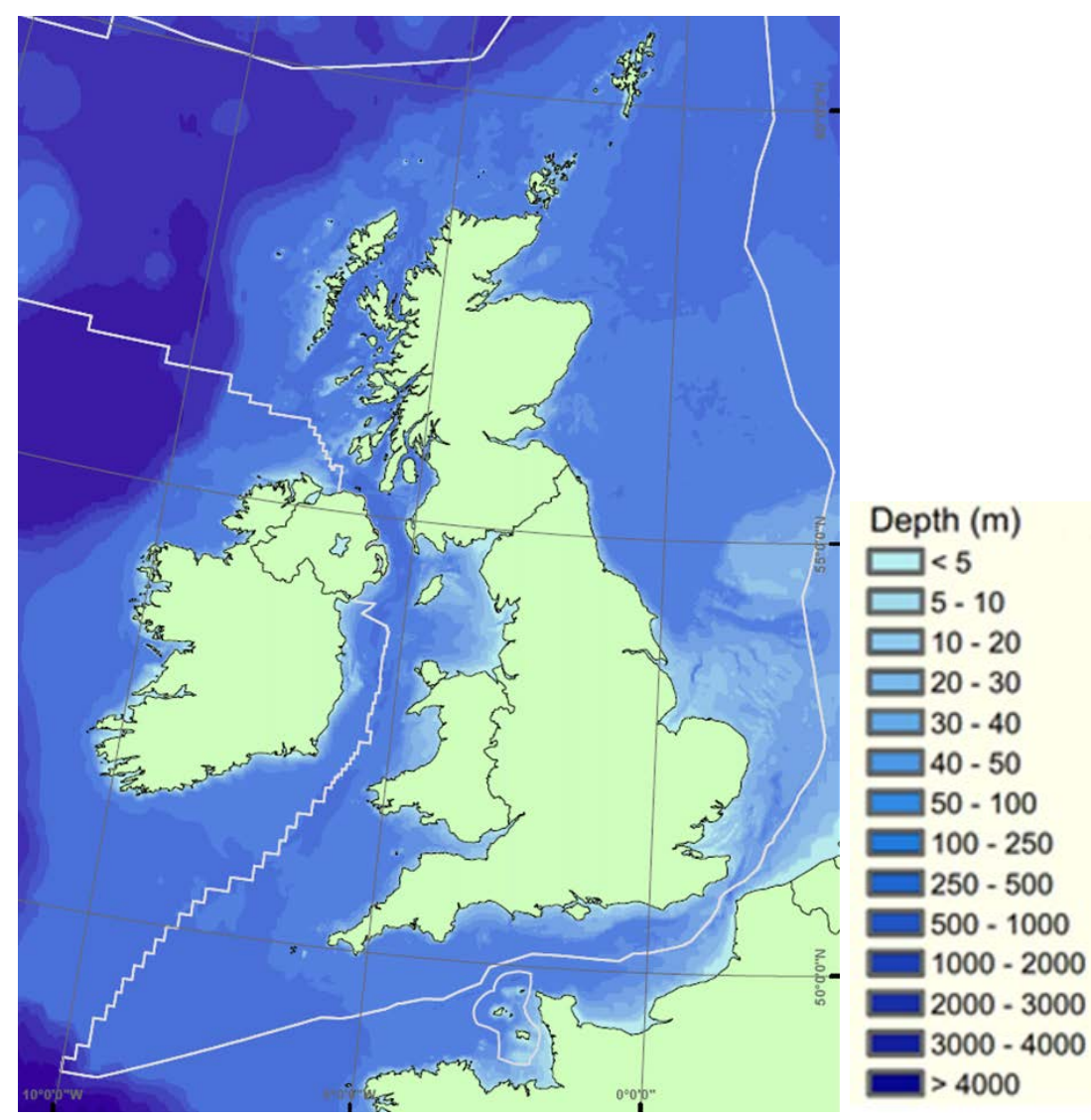

Figure 48: Bathymetry around the UK (from DTI, 2004) 


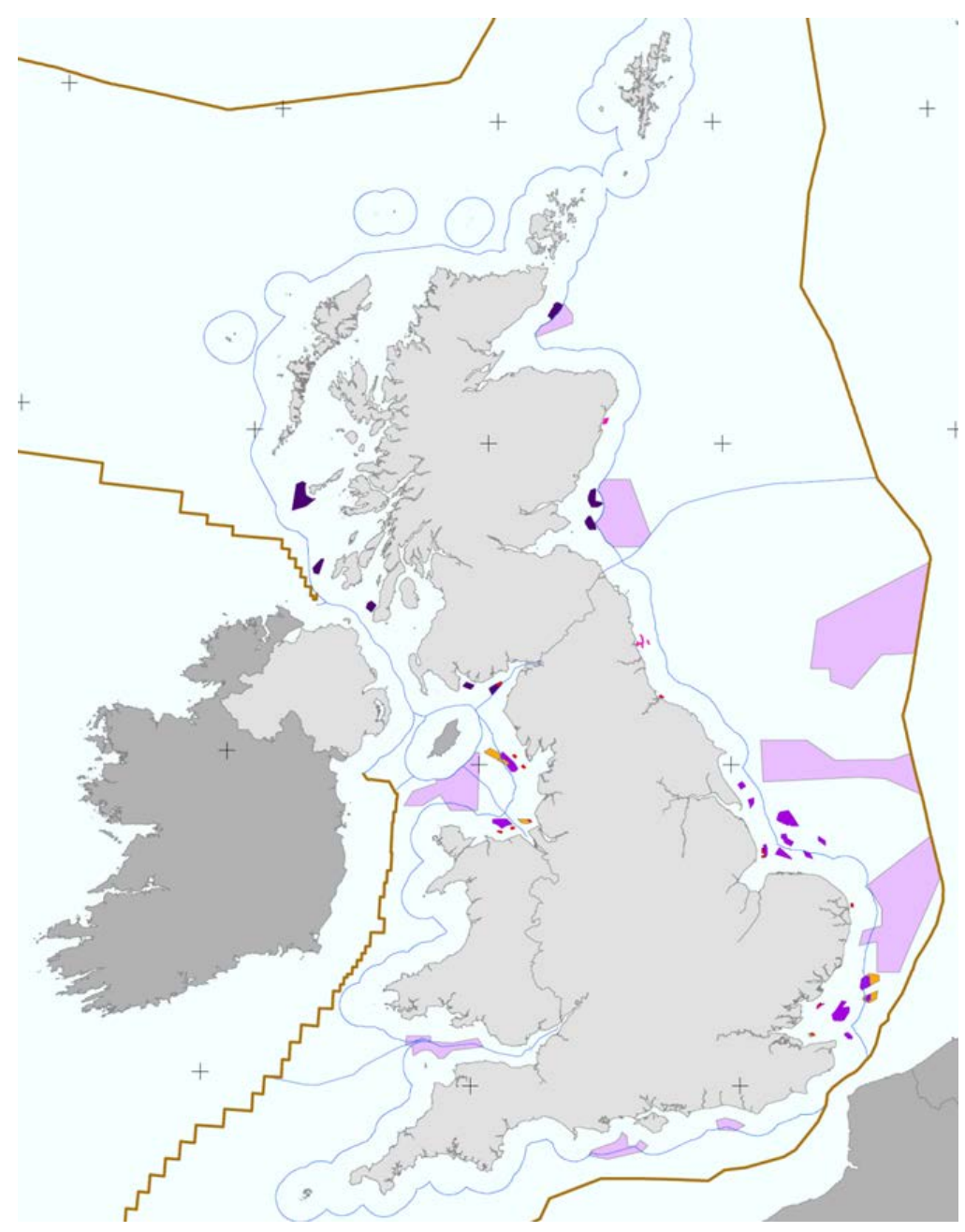

Figure 49: UK $3^{\text {rd }}$ Round Offshore Wind Farm sites (Crown Estate) 


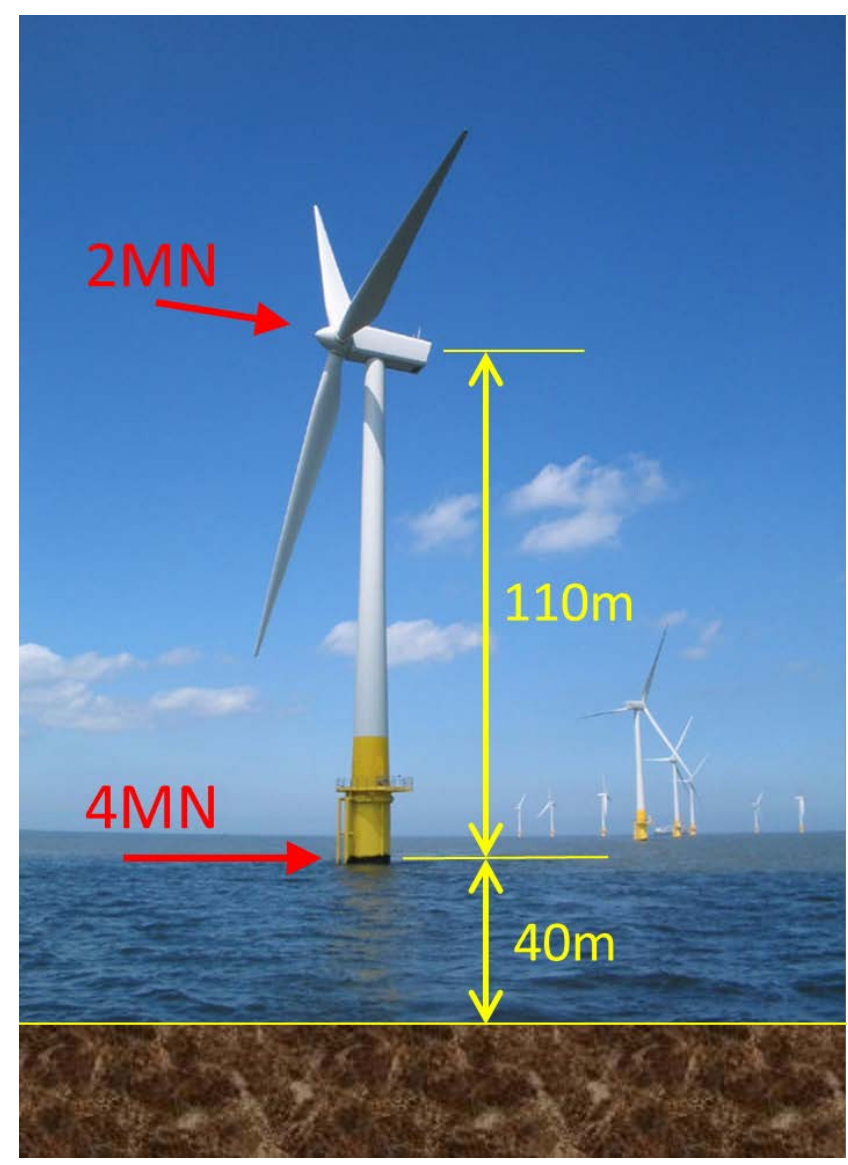

Figure 50: Dimensions and representative loads on a typical offshore wind turbine installation 


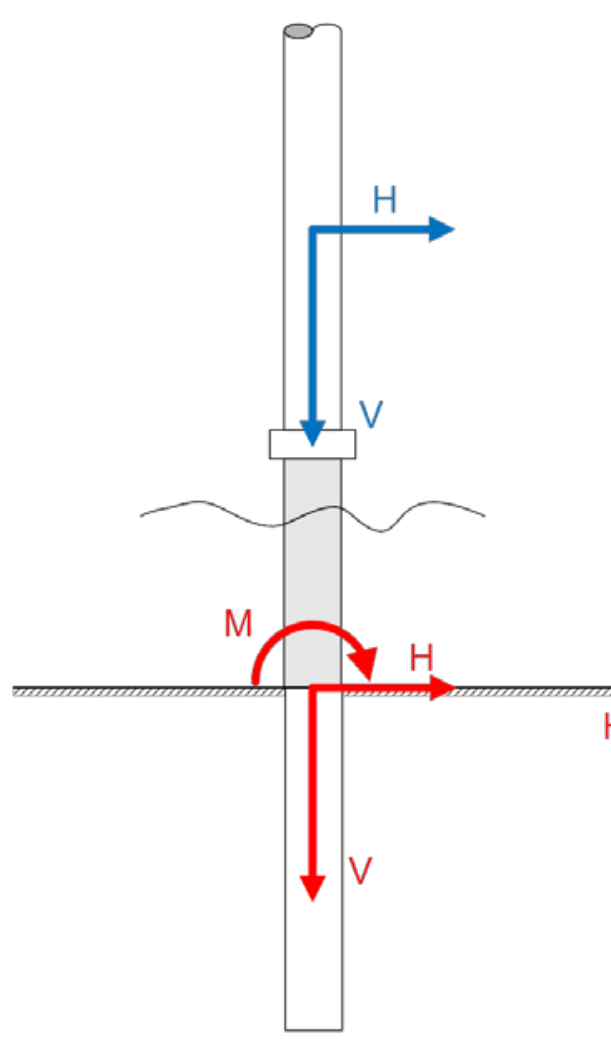

(a)

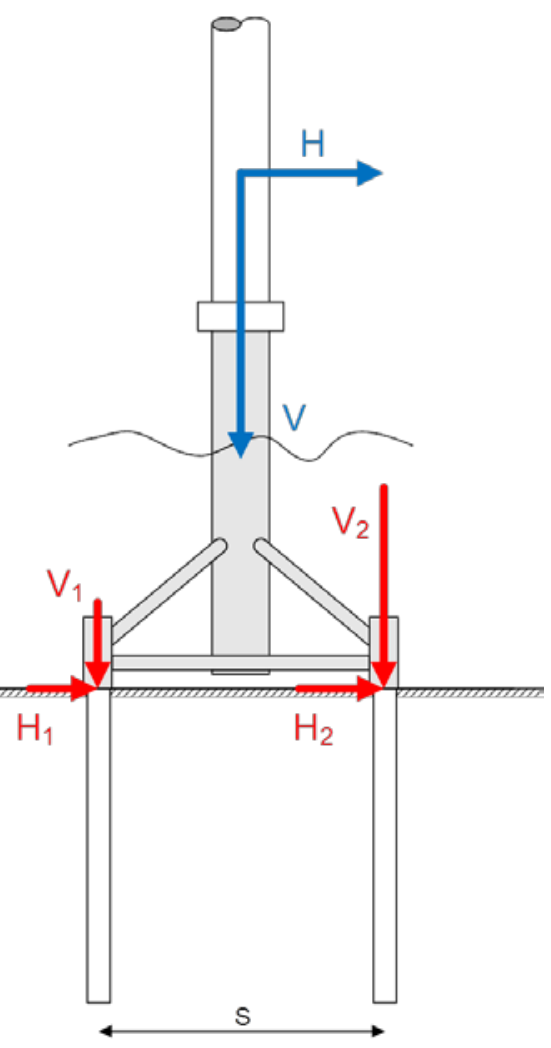

(b)

Figure 51: Load transfer mechanisms for from offshore wind turbine to foundation 


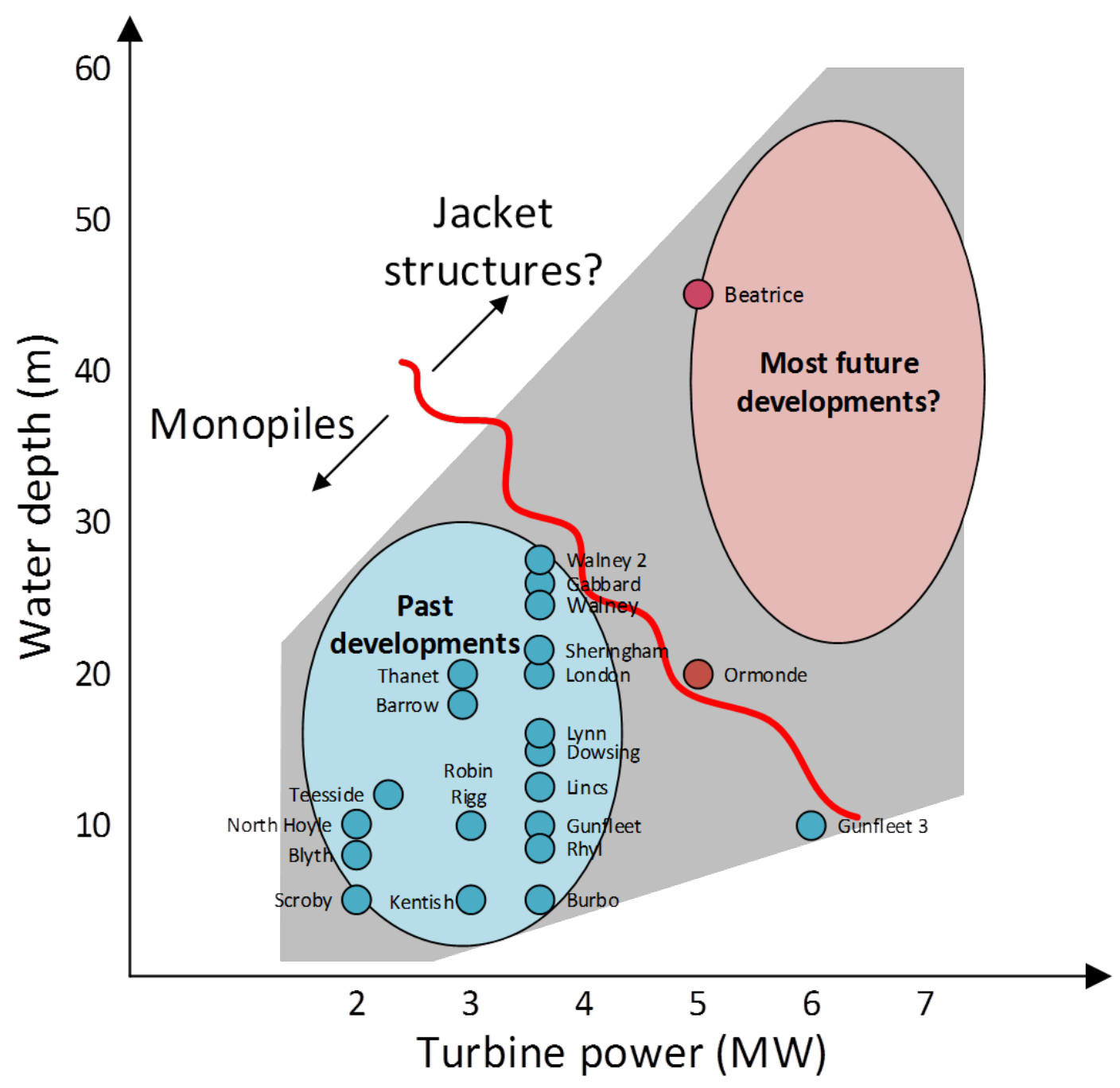

Figure 52: Water depth and sizes of wind farm installations 


\section{Reaction Frame}

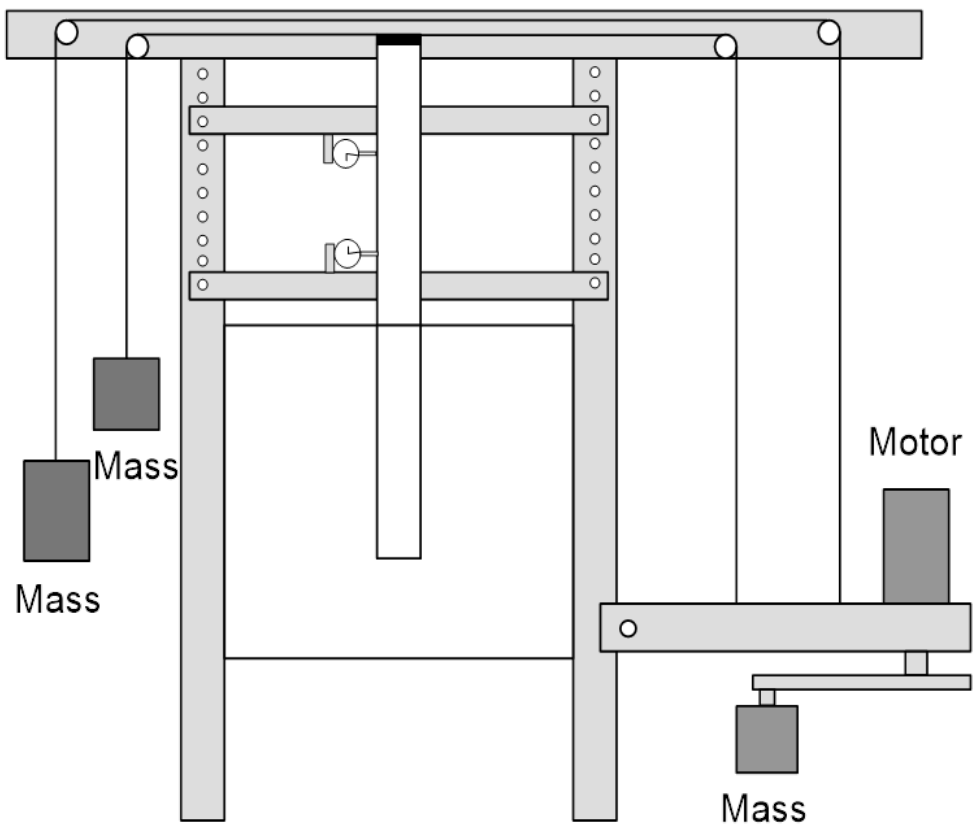

Figure 53: Outline of apparatus for cyclic loading of model monopiles

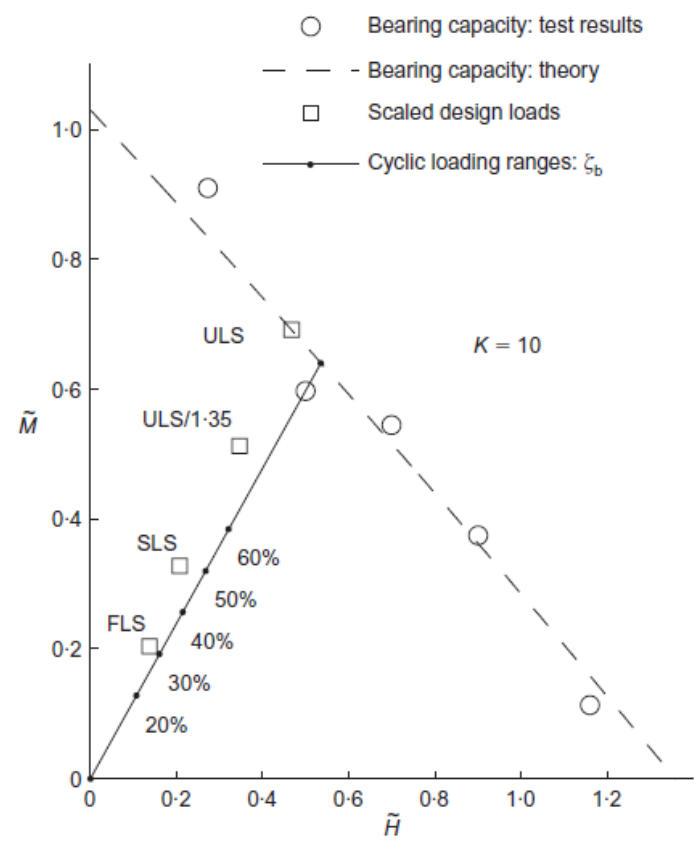

(Figure 8 of LeBlanc et al (2010a))

Figure 54: Estimated failure envelope and loading conditions for cyclic tests (from LeBlanc et al., 2010a) 


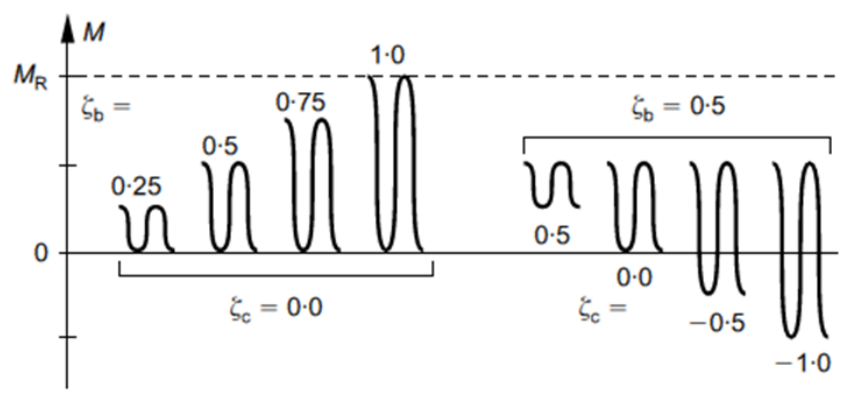

(Figure 6 from LeBlanc et al (2010a))

Figure 55: Variation of amplitude of cyclic loading (left) and form of loading (right) (from LeBlanc et al., 2010a)

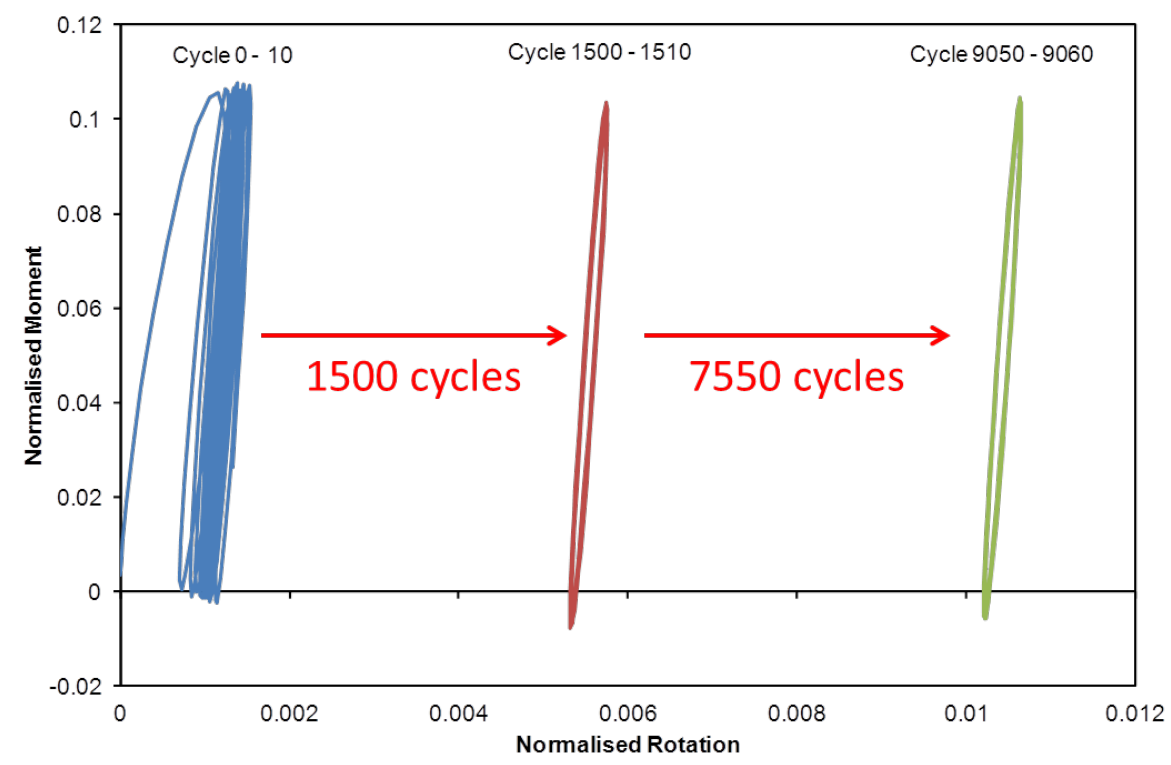

Figure 56: Accumulated displacement during 9000 one-way cycles 


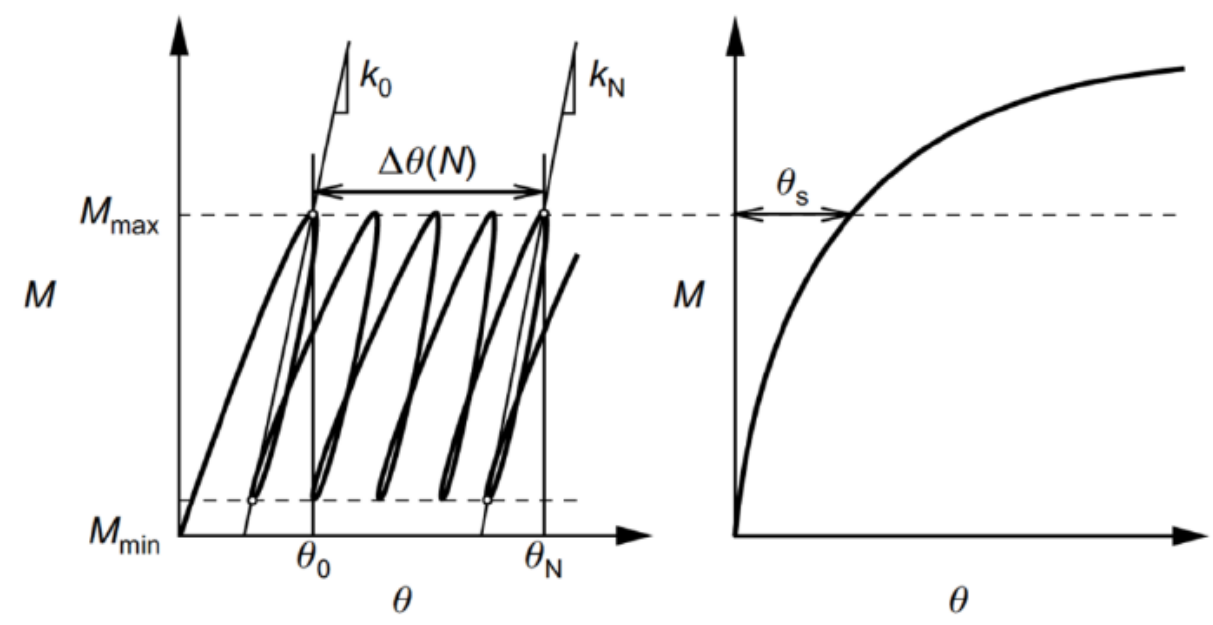

(Figure 9 from LeBlanc et al (2010a)

Figure 57: Definitions of static and accumulated rotation (from LeBlanc et al., 2010a)

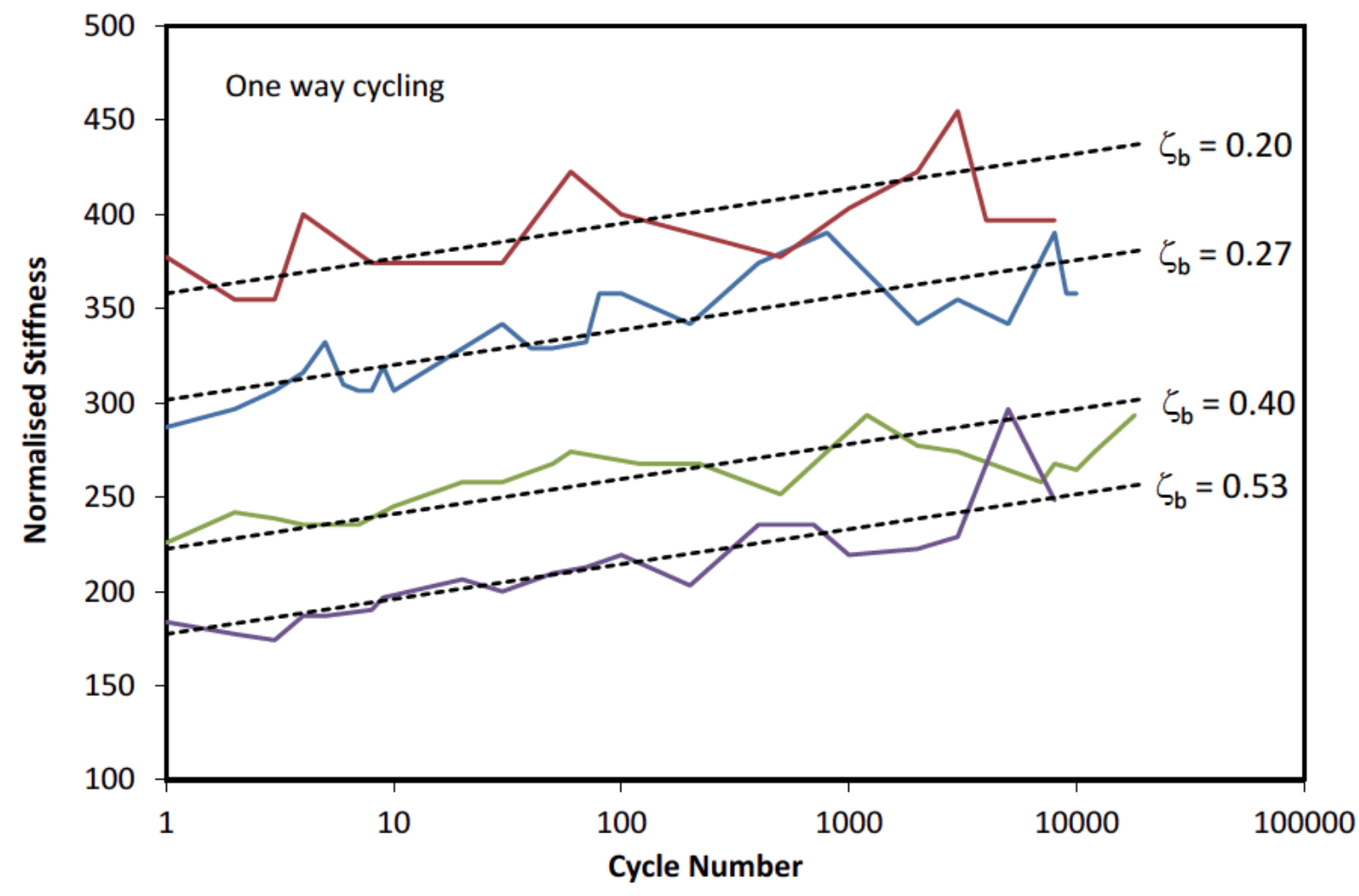

Figure 58: Variation of secant stiffness with load amplitude and cycle number 


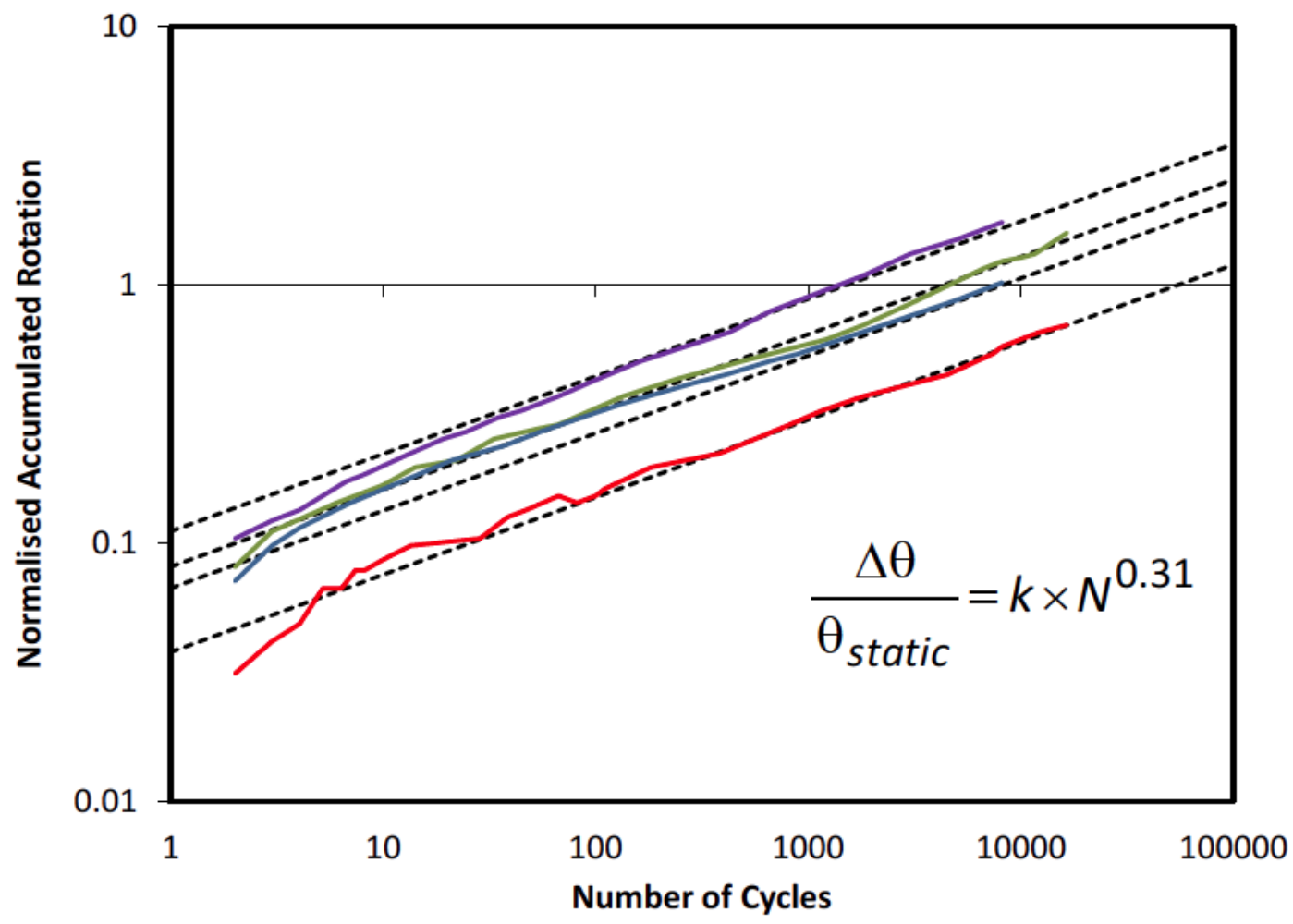

Figure 59: Variation of accumulated rotation with load amplitude and cycle number

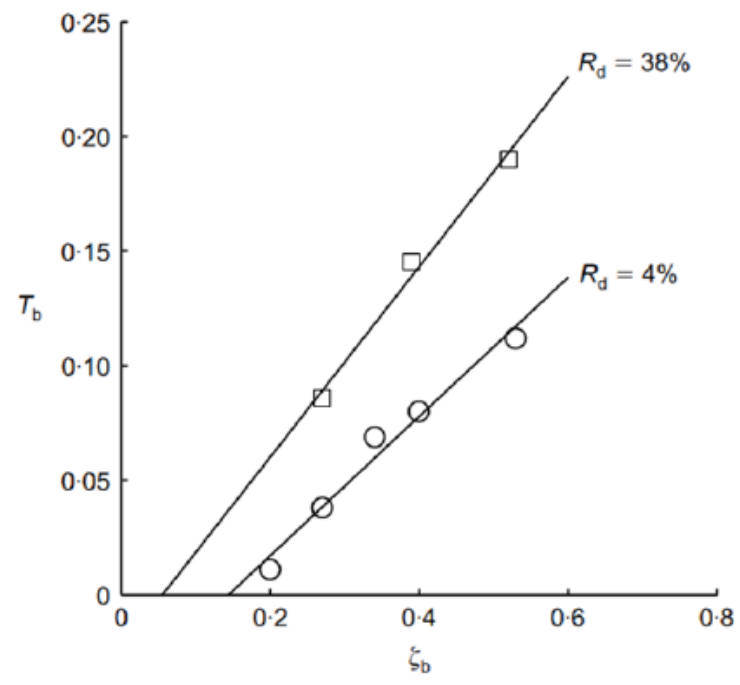

(a)

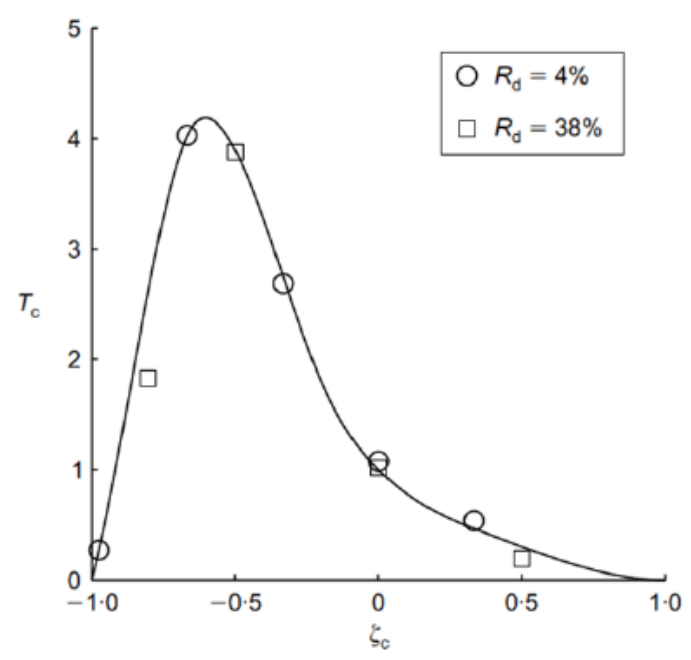

(b)

(Figure 11 from LeBlanc et al, 2010a)

Figure 60: Effects of (a) cyclic load amplitude and (b) cyclic load form on accumulated deformation (from LeBlanc et al., 2010a) 


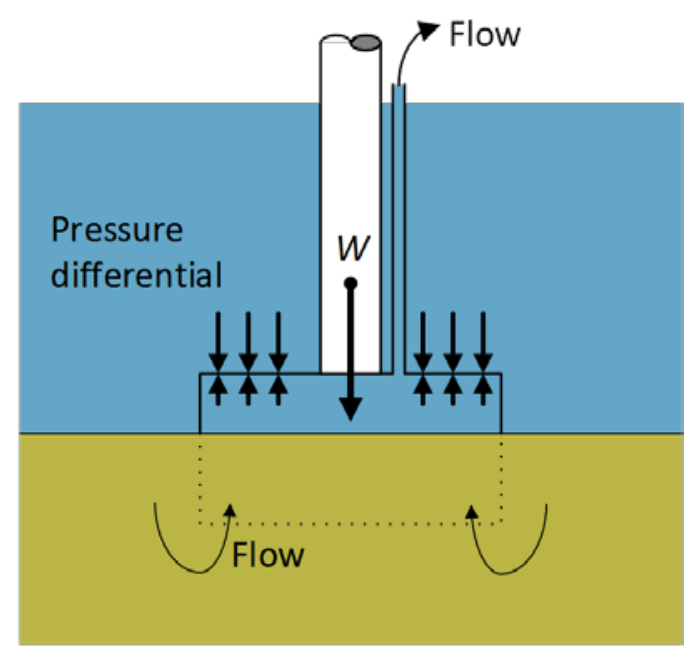

Figure 61: Installation of a suction caisson

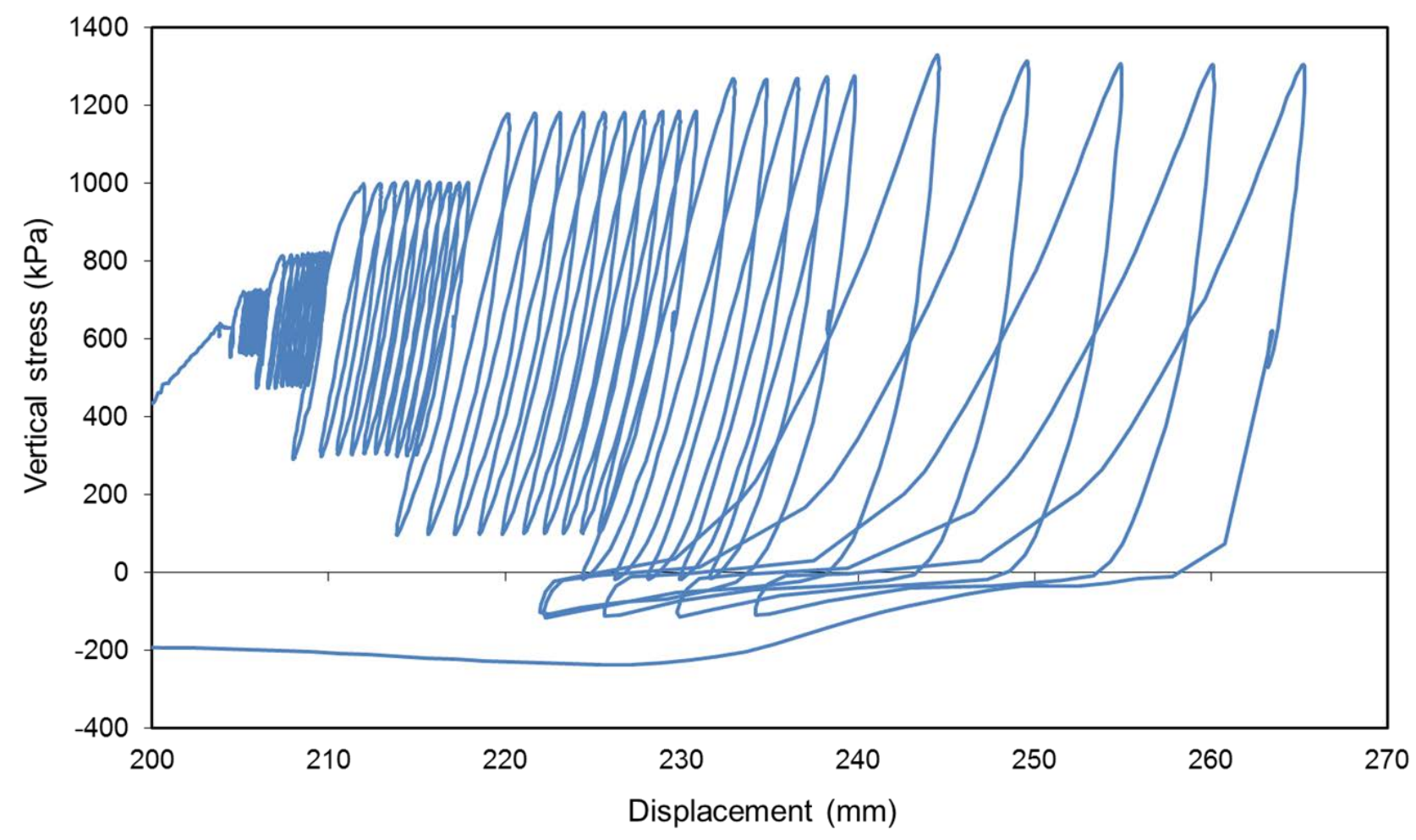

Figure 62: Cyclic loading of a model suction caisson in sand 


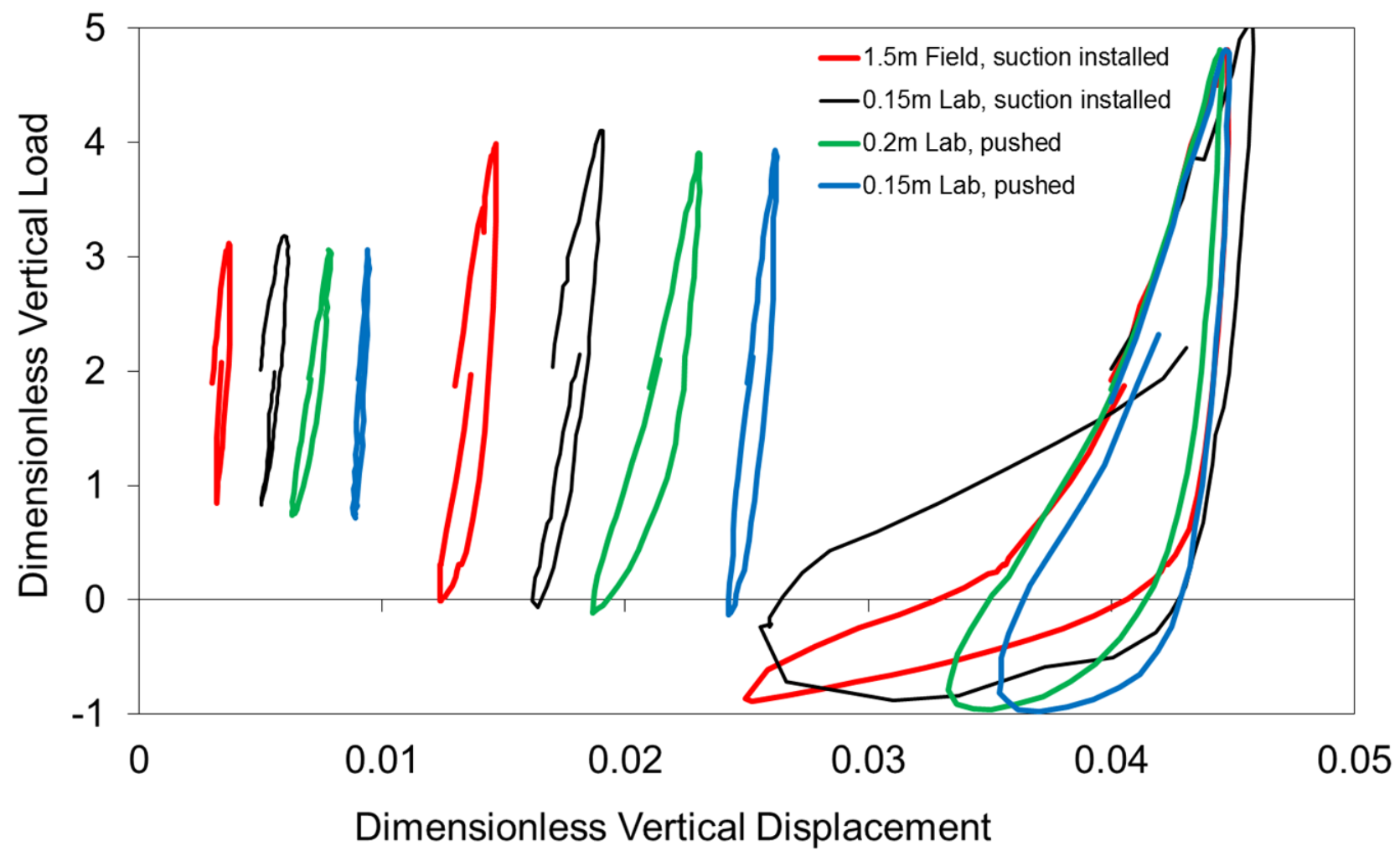

Figure 63: Application of normalisation techniques to load cycles of a suction caisson in sand

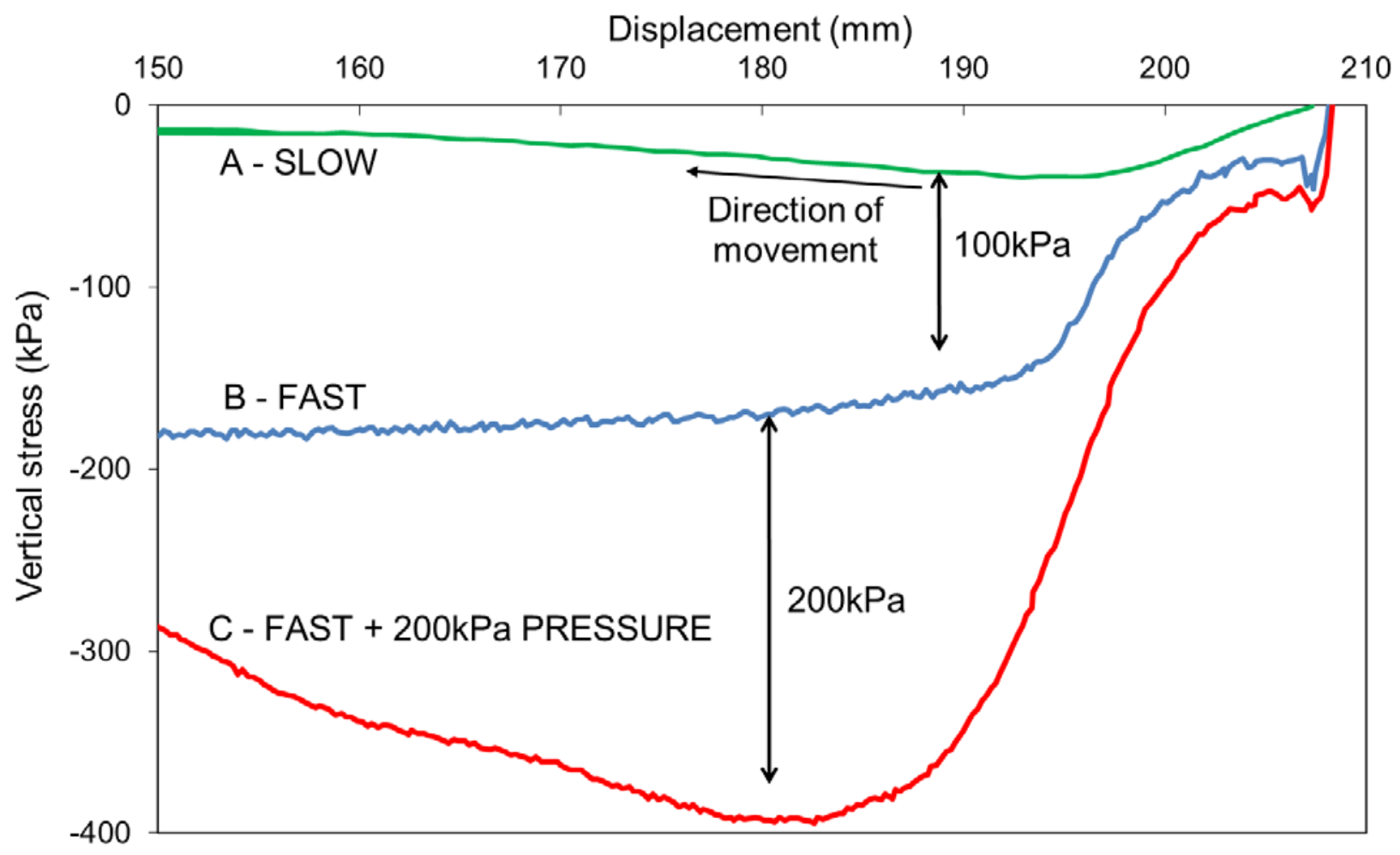

Figure 64: Tensile loading of suction caissons in sand 


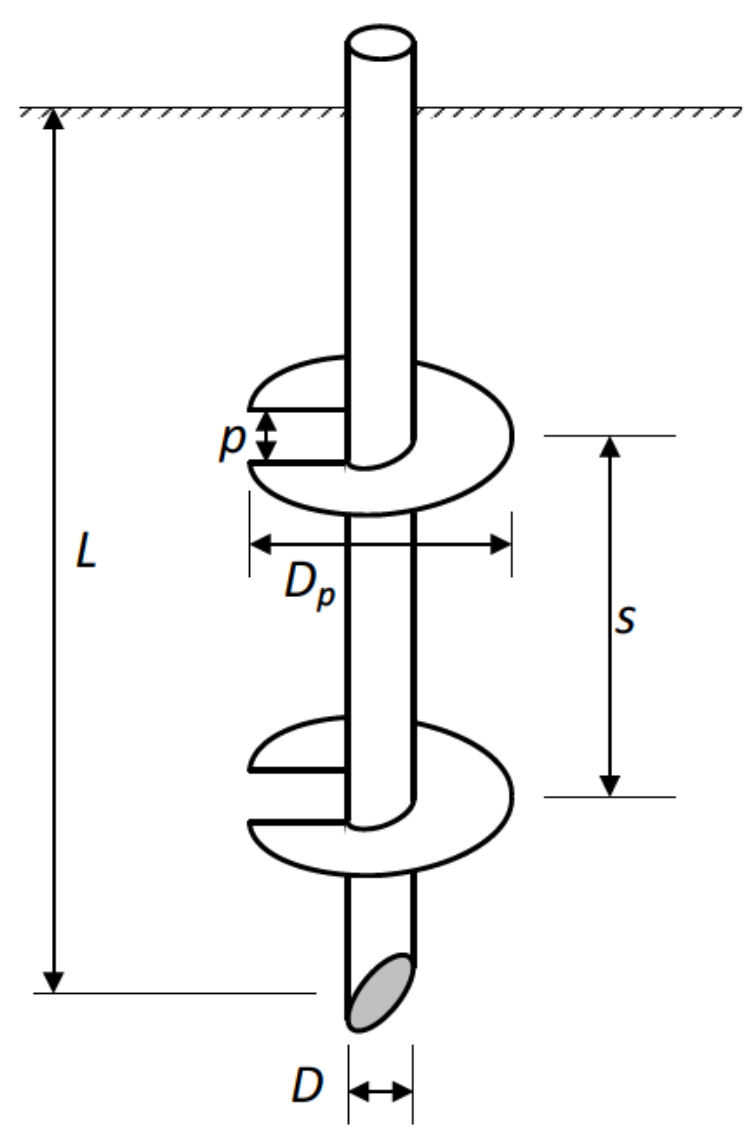

Figure 65: Schematic of screw pile 


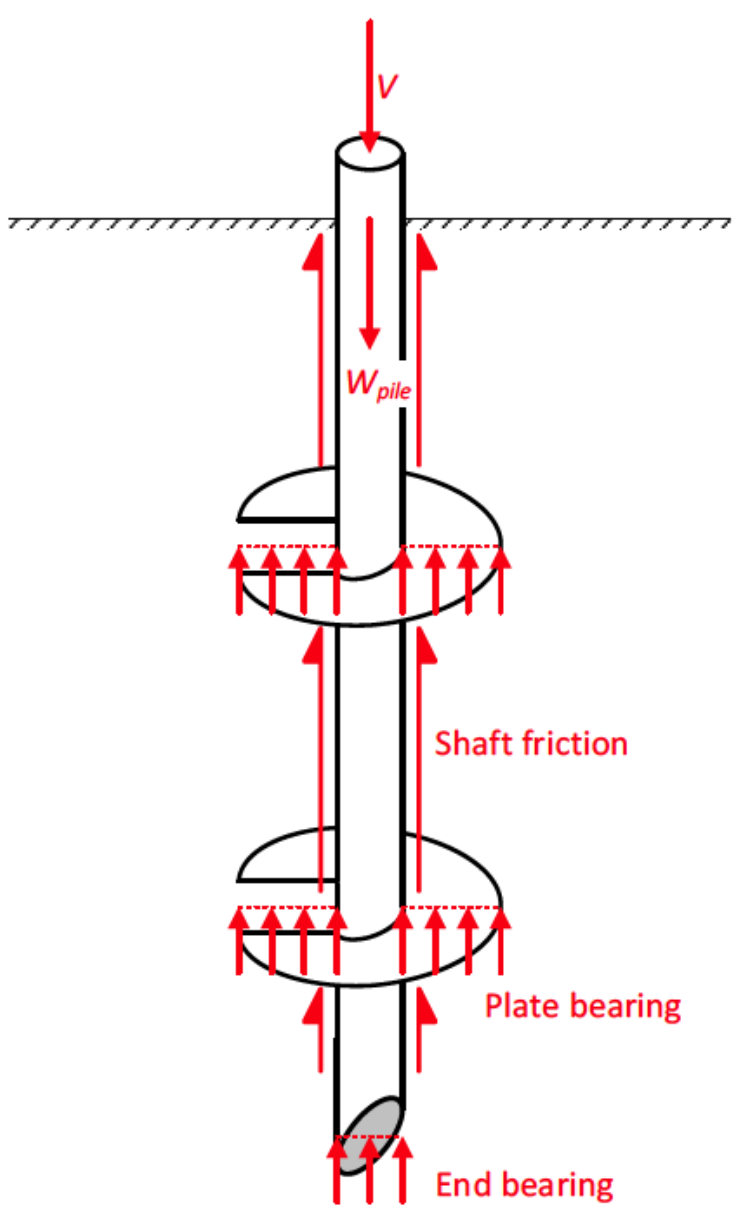

(a)

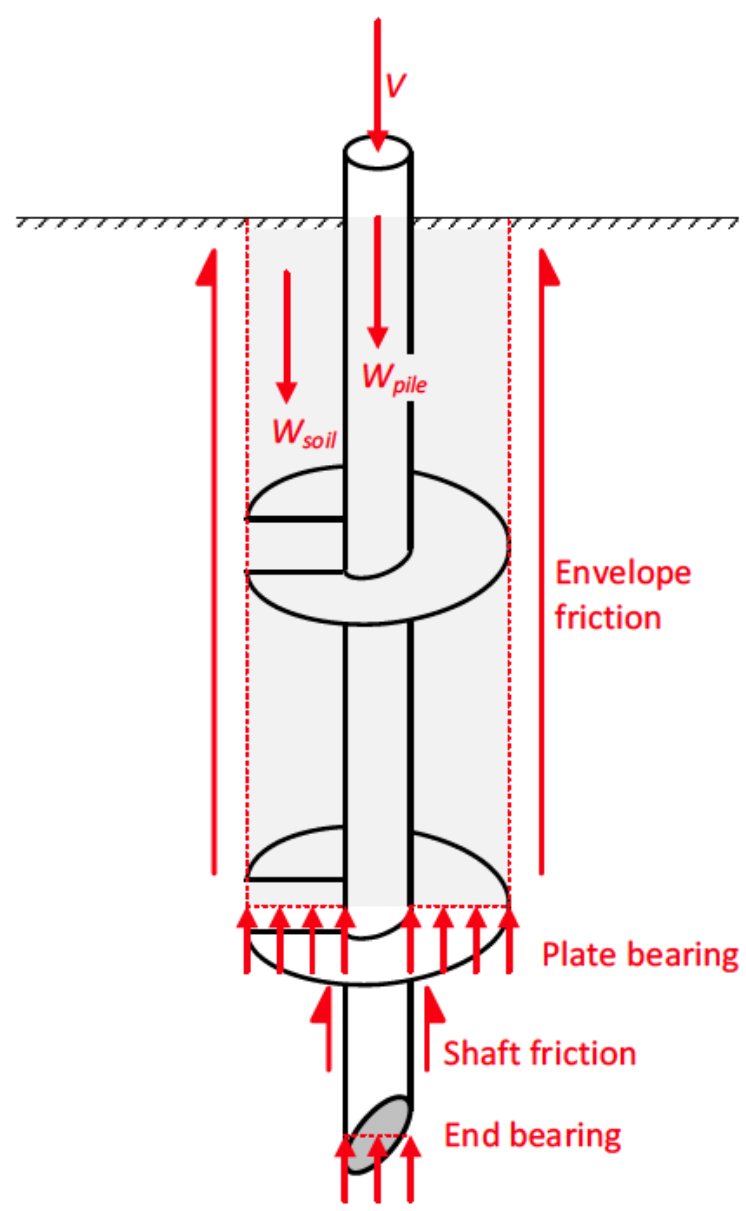

(b)

Figure 66: Compressive loading of a screw pile: (a) individual plate failure, (b) envelope failure 


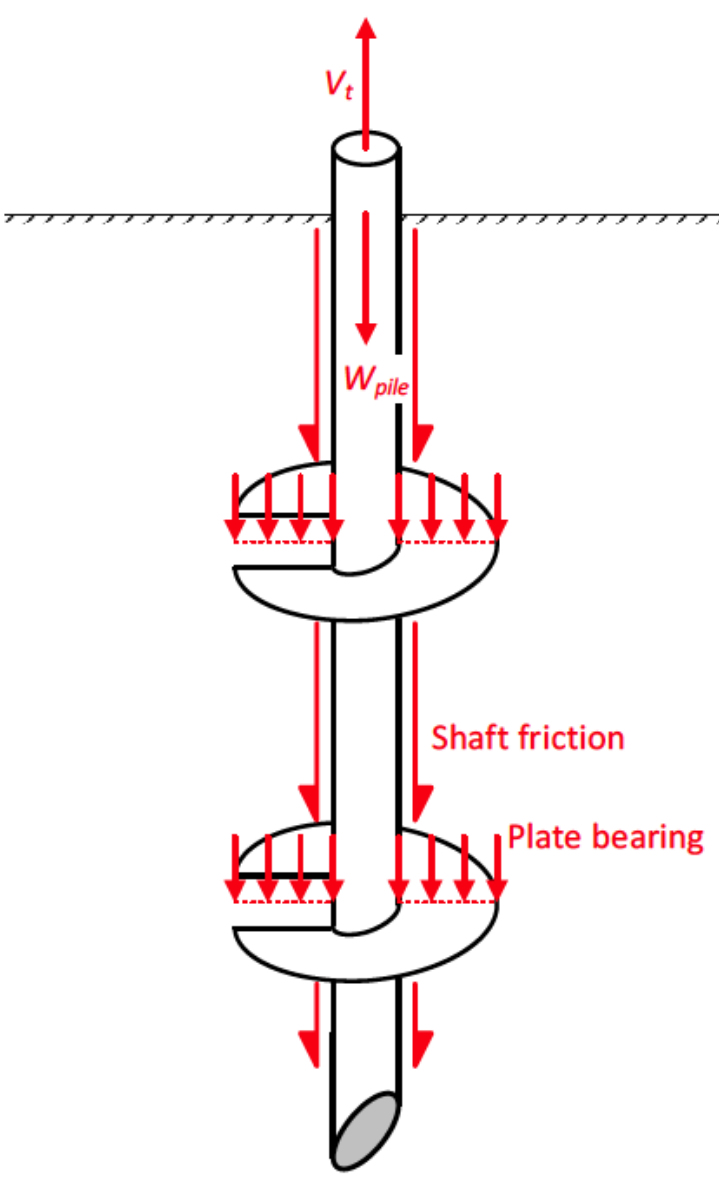

(a)

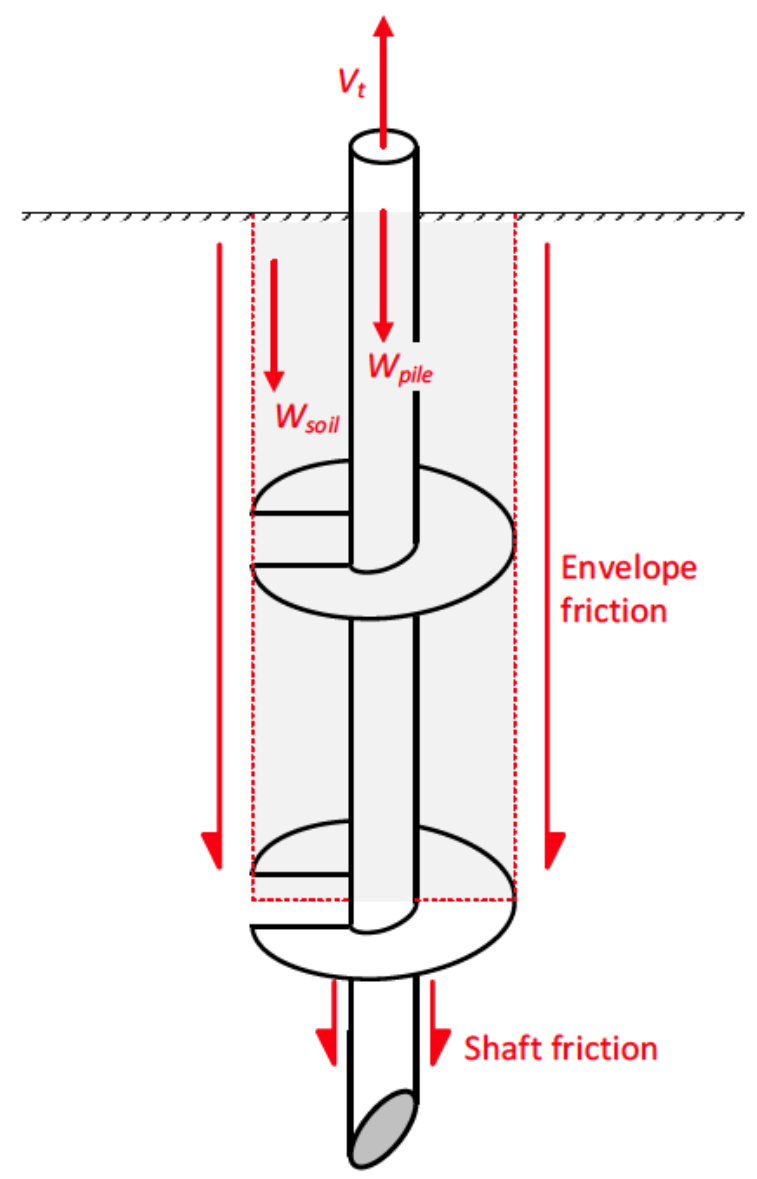

(b)

Figure 67: Tensile loading of a screw pile: (a) individual plate failure, (b) envelope failure 


\section{Total Bearing Load, kN}

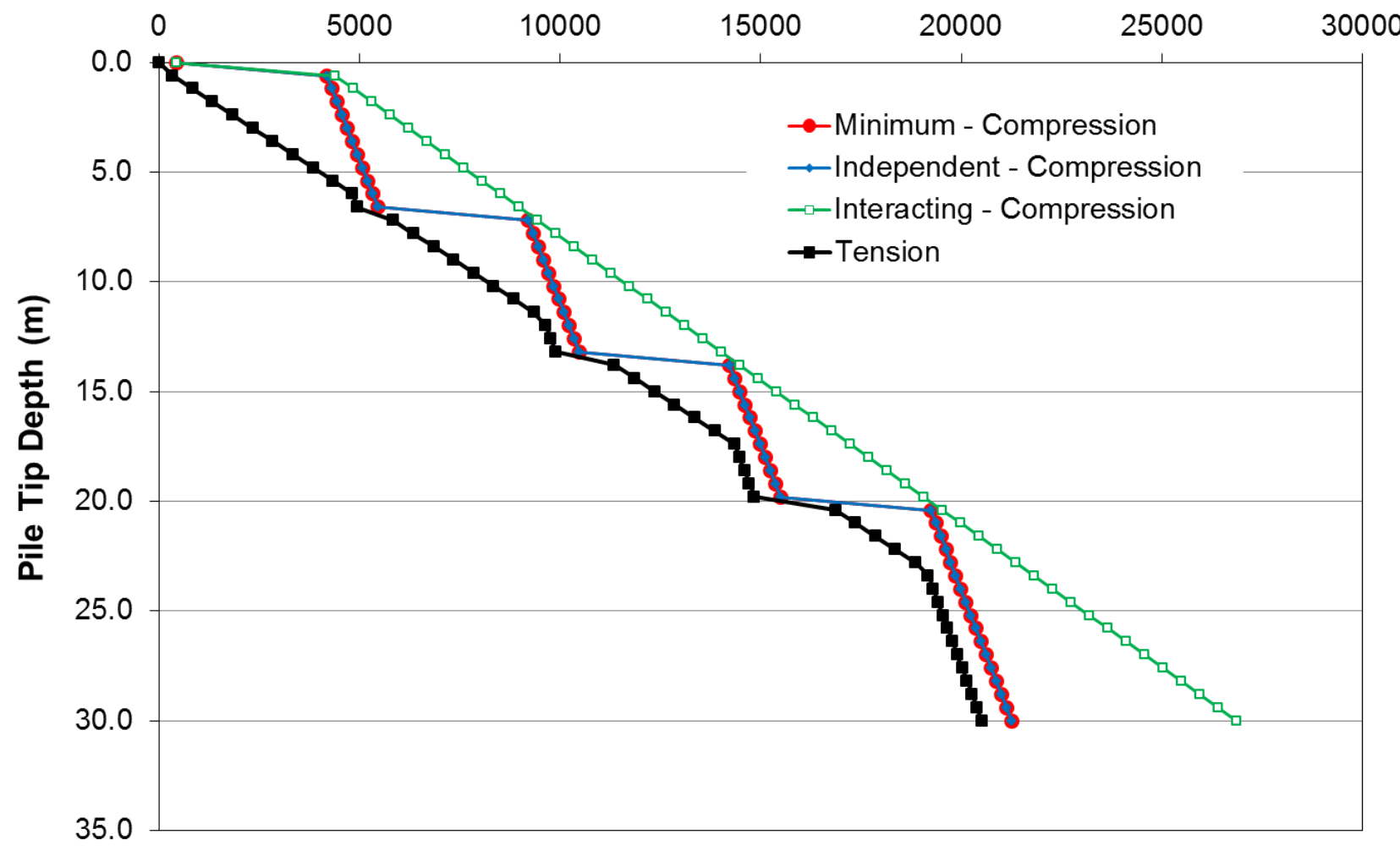

Figure 68: Predictions of ultimate loading on a screw pile for a realistic deep water North Sea site

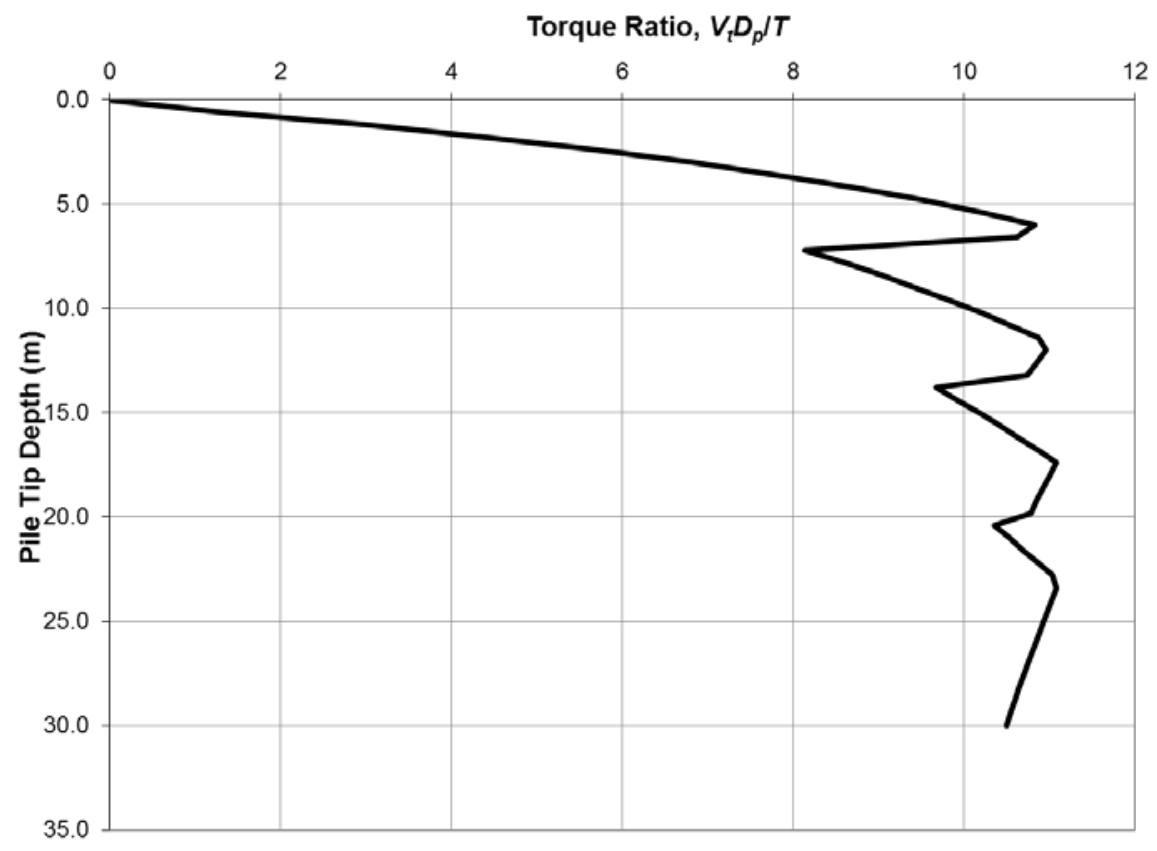

Figure 69: Normalised torque ratio for a screw pile 
Tension/Compression capacity ratio, $V_{T} J V$

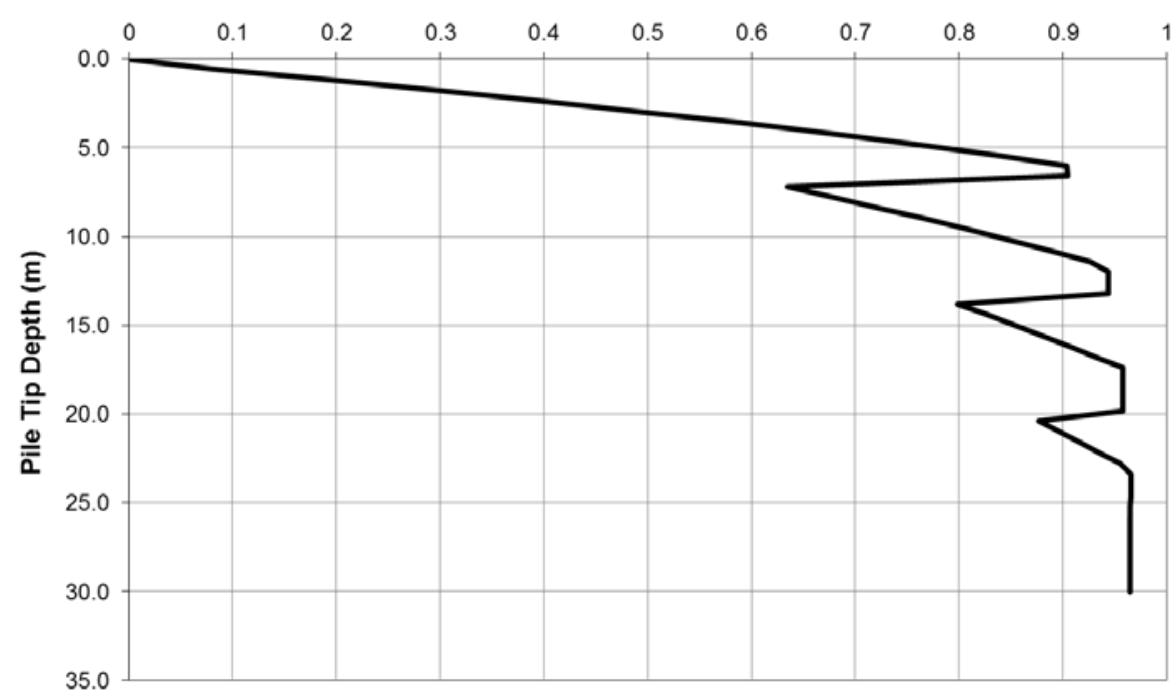

Figure 70: Tensile to compressive capacity ratio for a screw pile 


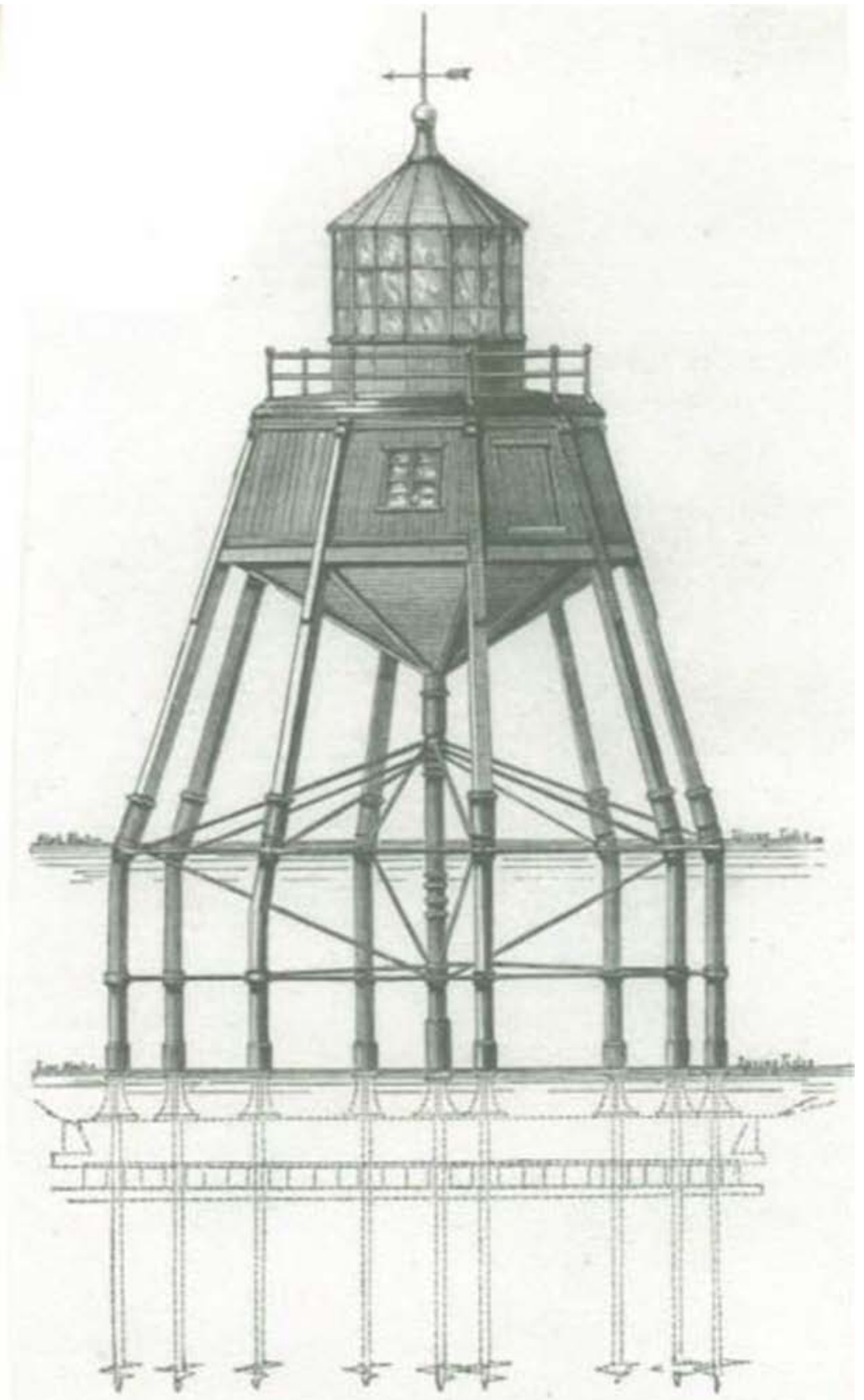

Figure 71: Maplin Sands Lighthouse (from Mitchell, 1848) 